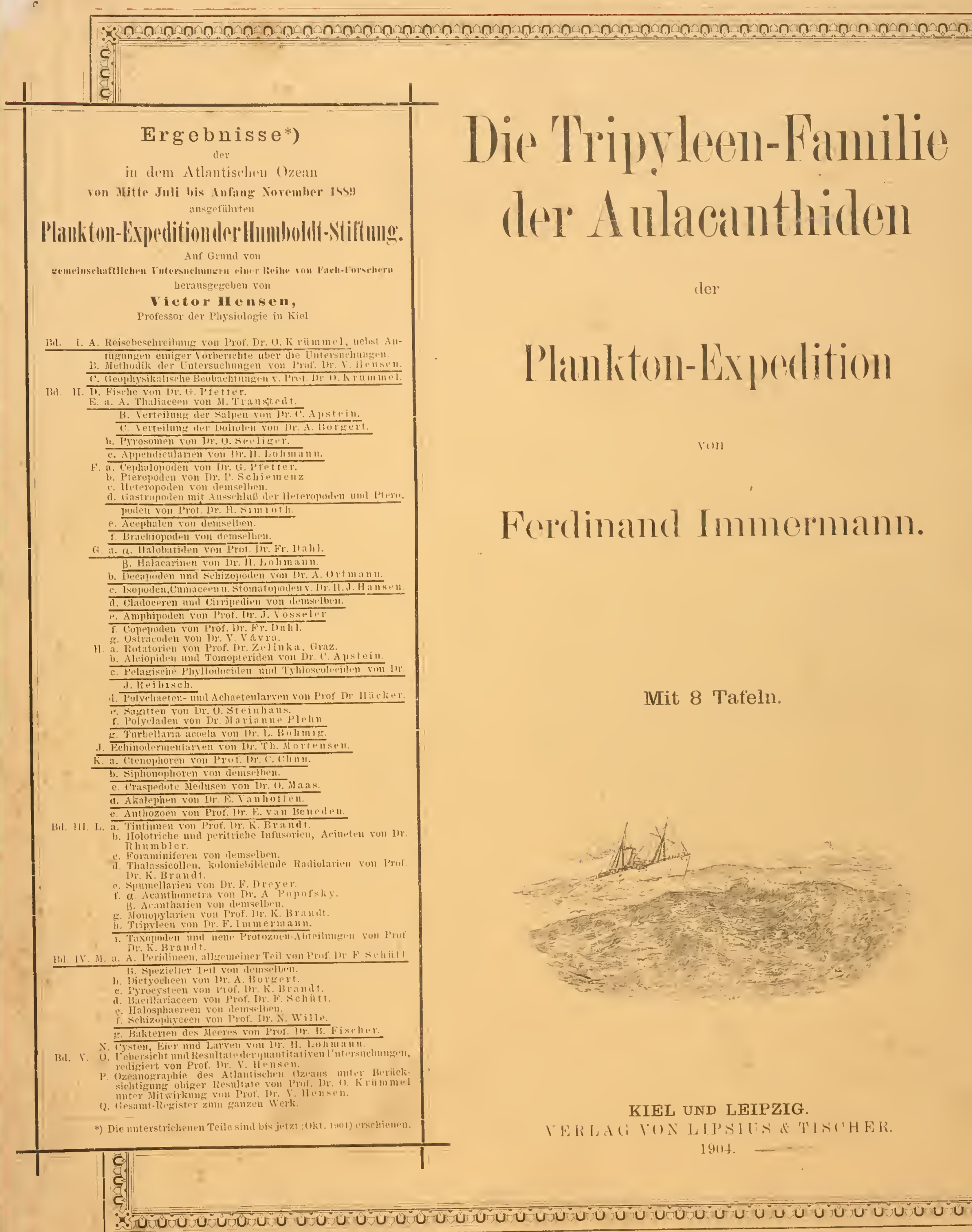





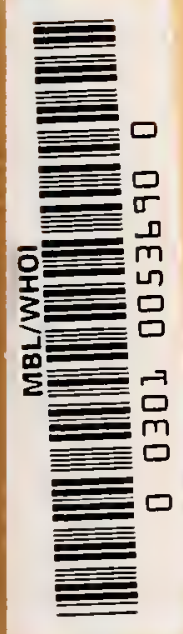



Ergebnisse der Plankton-Expedition der Humboldt-Stiftung. Bd. III. L. h.

\title{
Die
}

Tripyleen-Familie der Anlacanthiden

\section{Ferdinand Immermann.}

\author{
Mit 8 Tafeln.
}

Kiel und Leipzig.

Verlag von Lipsius \& Tischer. 

$\mathrm{D}$ urch Vermittelung von Herrn Professor Dr. K. Brandt wurde mir seitens des Herm Geheimrat Dr. V. Hensen der ehrenvolle Auftrag, die Familie der Aulacanthiden fiir das Werk der Plankton-Expedition zu bearbeiten. Beiden Herren sage ich hiermit für das mir geschenkte Vertrauen meinen besten Dank. Namentlich bin ich Herrn Professor Dr. K. Brandt verpflichtet für die freundliche Unterstützung, die er mir durch Überlassung der Fangprotokolle und Bordnotizen, ferner durch seine geschätzten Ratschläge zu Teil werden ließ, und für das Interesse, welches er jederzeit meinen Untersuchungen bekundete. Herrn Privatdozenten Dr. C. Apstein, der die Liebenswïrdigkeit hatte, mir Kopien aus dem Werke Peragallos und anderer Diatomeenforscher zeitweise behufs Artbestimmung zur Verfügung zu stellen, spreche ich an dieser Stelle in gleicher Weise meinen Dank aus.

Fiir die Anordnung des Stoffes habe ich mich im großen und gamzen an die Vorbilder in oben genanntem Sammelwerke bereits erschienener Bearbeitungen gehalten. Nach einigen kurzen Bemerkungen über das mir zur Untersuchung übergebene Material sei in einem ersten Abschnitt das Allgemeine ïber den Ban und die physiologischen Verhältnisse des Anlacanthidenkörpers erledigt. Eine historische Übersicht der Entwickhnng unserer Kenntnisse betreffs dieser Lebewesen wirl den Anfang bilden. Daran schlielit sich eine Darlegung der durch bisherige Untersuchungen gewomenen Resultate und zwar zunächst in anatomischer, sodann in physiologischer Hinsicht. An diese Erörterungen werde ich das anknüpfen, was ich als spezielles Ergebnis der Plankton-Expedition in dieser Hinsicht betrachten darf. Auf diesen allgemein gehaltenen Abschnitt wird ein zweiter folgen, welchen ich als speziell zoologischen bezeichne. Er enthält die Systematik der Aulacanthiden und im Anschluß hieran eine eingehende Beschreibung der auf der Plankton-Expedition crbenteten Gattungen und Arten. Der dritte und letzte Abschnitt wird der Faunistik gewidmet sein. Durch Beigabe eines möglichst vollständigen tabellarischen Verzeichnisses mag aus diesem Teil ein Überblick gewonnen werden ïber die horizontale und vertikale Verbreitung der Aulacanthiden-Familie im nördlichen und tropischen Atlantik.

Bemerkungen über Material und Methoden.

Das mir durch Herrı Professor Dr. K. Brandt zur Untersuchung übergebene Material bestand einerseits in einer Kollektion Alkoholpräparate, welche in einzehnen Glassöhrchen mit beigefïgter Journalnummer untergebracht, zu größerer Anzahl in verschiedenen Sammelgläsern vereinigt waren, andererseits in zwischen zwei Glimmerplatten eingeschlossenen mikroskopischen Präparaten, sogenannten Schleimpräparaten, bei welchen eine Auswahl nach Tierformen nicht getroffen war, sondern jedes Präparat Portionen des Fangs als solchen enthielt. Das zuerst genannte Material war nach beigegebenen Bemerkungen teils in Sublimat, teils in Jodalkohol, Osmium- oder Pikrinsäure fixiert worden und befand sich seither in $70^{\circ} \%$ Weingeist 
aufbewahrt. Jahrelanges Stehen hatte natürlich bei einzelnen Gläschen zur Folge gehabt, daß der Inhalt etwas eingetrocknet an den Wänden klebte. In solchen Fällen erwies sich ein Gemisch von Wasser mol Glycerin mit etwas Thymolzusatz als erfolgreiches Mittel zum Erweichen. Die Körperchen nahmen durch Quellung wieder eine einigermaßen natürliche Gestalt an. Da bereits mehrere anderweitige Untersuchungen der meinigen vorangegangen waren, so befand sich tas Material nicht meln in dem ursprünglich geordneten Zustand. Bei Vergleichnng mit dem mir gütigst überlassenen Protokoll der Expedition stellte sich heraus, daß die früher herausgesuchten Anlacanthiden mehrerer Fänge, hanptsächlich von Schliehnetz-Nummern, zur Zeit nicht aufzufinden waren. In solchen Fällen mußte ich mich an die in den Listen enthaltenen sclniftlichen Angaben, die mir wertvolle Dienste leisteten, halten und durch Vergleichung mit entsprechenden Vertikalfingen eine Ergänzung suchen. Eine von Herrn Professor Dr. K. Brandt gleich nach Beendigung der Fahrt gelegentlich der ersten Materialverteilung angelegte allgemeine Übersicht der Schließnetzfänge machte es glücklicherweise möglich, wenigstens die Gattungen der fehlenden Exemplare fostznstellen. Da jedoch, wie sich im folgenden ergeben wirl, eine Revision der Genera notwendig wurde, so war es in verschiedenen Fällen zweifellaft, was unter dem in der Notiz enthaltenen Gattungsbegriff zu verstehen war. Hier mulite die Vermutung Platz greifen orler das ursprünglich vorhanden gewesene mit einem Fragezeichen behaftet werden. 'Teilweise befanden sich, soweit dies möglich war, die Anlacanthiden infolge bereits friiher vorgenommener Verteilungen heransgesucht und abgesondert, teilweise hingen sie mit len übrigen Fangresten so innig zusammen, dal. eine Isolierung ohne Verletzung des Tierkörper's nicht anging mnd daB sie mit diesem anderweitigen Gemenge anfbewalurt wuden. Anch die vereinzelten Aulacanthiden waren meist auf ihrer Oberfläche mit Schlamm bedeckt. Ein Entfernen desselben behufs Freilegung der Stachelenden war mit grol’en Schwierigkeiten verknüpft, indem selı' leicht bein Lösen des Belags nit der Präjariernadel zugleich die Radialstacheln, die fest darin verankert waren, mit heransgezogen wurden. Infolgedessen erwies es sich als vorteilhaft, die Tierkörper in ihrem vorgefundenen Zustand zu belassen und so in Nelkenöl überzufülıren. Hierdurch erfolgte eine genügende Auflellıng, um die Endbildnngen der Radialstacheln beobachten zu können. Zeigte ein l'räparat benerkenswertes, so wurde es zum Zweck weiterer Beobachtung und Vergleichung in Kanalabalsam eingeschlossen, wobei zwischen Deckglas und Objektträger zwei schmale Kartonstreifen von entsprechender Dicke eingeschoben wurden, um jede Qnetschung zn vermeiden. Auf diese Weise war im Laufe der Untersuchming jede Spezies in mindestens einem Exemplar, sowie etwaige kleine Abweichungen von derselben jederzeit einer V'ergleichming zugänghich. Besonders gut erhaltene Individuen wurden zur Anfertigung von Abbildungen benutzt, wobei das Leitzache Zeichenprisma Verwendung fand. Von den einzelnen Gattungen wurden Vertreterimen derselben in Paraffin eingebettet und in Serienschitte zerlegt, wobei auch ich die Erfahrmng machte, daß die Kieselbildungen dem Messer keinerlei Hindernisse bieten. Über die angewandten Fürbemethoden, sowie die damit erzielten Resultate wird an späterer Stelle eine Mitteilung erfolgen. 


\section{.I. Allgemeiner 'Teil.}

\section{Historisches.}

Die erste Aulacanthide, ron welcher wir Kenntnis haben, wurte im Jahre 1859 von E. Häickel im Mittellïndischen Meere anfgefunden. Der Forscher beschriel) dieselbe als Aulacantha scolymantha und ordnete diese Spezies in seinem ersten Raliolarienwerke (1) (heraungegeben im Jahre 1862) zunächst der Familie der Colliden unter. Seine späteren Untersuchnngen veranlabten ihn, fün die eben erwïhnte Art eine selbständige lamilie, die der Anlacanthiden anfznstellen, wetche in cler Orhnngy der Pansolenia ilnen Platz fand (2). Schon ein Jahn nach der Veröffentlichung dieser Ergebnisse wah sich der Furncher zn einer abermaligen Änderung grenötigt nud die Legion der Phaeodarien (nach dem Vorkonmen einer später noch genaner zu behandelnden Pigmentmasse. dem l'haeodium, benannt) mmfalite fortan anch die Fanilie der Aulacanthilen. Eine weitere Bezeichumg, dir derelbe Gelehrte fïr die gleichen Formen schuf, war diejenige der Cannopylea. Sie beruht auf der Gestaltung der Öfönungen der Zentralkapsel. Letztere waren es. welche R. Hortwig (3) im Jahre 1879 einer nüheren Untersuchung nnterzog und die er als in der Dreizahl bei bestimnten Formen vorhanden feststellte: eine Hanptöffnung, ror wehcher das Häckel'sche l'haeodium lagerte, nucl zwei Nebenöfnnngen anf der entgegengesetrten Seite. Auf dieses regelmäbige Verhalten grïndute R. Hertwig seine Bezcichnug Tripyleen, welche anch von den späteren Bearbeitem wieder aufgenommen wurde, wähnend ti. Häckel neben derselben an seinen bisherigen Benennungen festhielt. Bis zum Jahre 1881 waren unsere Kenntnisse von den Anlacanthiden anf diese eine Art beschränkt. Da veröffentlichte li. Häckel einen lintwurf zn einem Radiolariensystem (5) auf Grund der Funde der Crathexcitr-Expedition. Diesem Vorlänfer folgte im Jahre 1887 das bedentende Rardiolarienwerk (9) als bigelmis diever englischen Forschungsreise, durch welches eine Unmenge Formen im allgemeinen unt anch eine grobe Zahl von Tripyleen, resp. Anlacanthiden im speziellen bekannt wurde. E. Hïckel hatte sich der Aufgabe muter\%ogen, das llaterial zu sichten und sytematisch zu ordnen (9). Was die Anlacanthiden anbelangt, so zerlegte er diese Fanilie in sechs (iattungen:

1. Aulactinium, 2. Aulucuntur. 3. Aulograplis. 4. Auloceros, 5. Aulospathis, 6. Aulodtendron. Da im folgenden noch relegenheit sein wird, sich mit den einzelnen Arten näher zu beschäftigen.

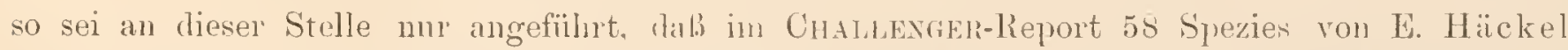
beschrieben sind, von welchen 3 der Gattung Aulactinium, 6 der Gattung Aulacantha, ㄴ6 der. 
Gattung Aulographis, 8 der Gattung Auloceros, 10 der Gattung Aulospathis und 5 der Gattung Aulodendron zufallen. Im gleichen Jahre fand K. Brandt im Mittelmeer eine neue Form, die er als Aulacantha nov. spec. bezeichnete (8). Nach A. Borgert (32) dürfte dieselbe mit Aulographis pandora Häckel identisch sein. Auch K. Möbius und T. Hensen erwähnen in dem V. Bericht der Kommission zur wissenschaftlichen Untersuchung der deutschen Meere (10, 11) eine Aulacanthide, für welche jedoch eine Beschreibung fehlt und von der nur der Name Aulacantha tenuis Häckel angeführt ist. (Ich konnte diese Form sonst nirgends ausfindig machen. Auch von A. Borgert wird sie nur zitiert.) E. Vanlöffen (25) und P. T. Cleve (27) trugen mit bei zur Kenntnis der Verbreitung dieser Lebewesen. Im Jahre 1898 wurde durch G. H. F ow le r (26) eine nene Form im Gebiet des nördlichen Golfstron-Astes beim Faroe-Kanal anfgefunden und mit dem Namen Aulocoryne eine nene Gattung dafiir aufgestellt, welche durch diese einzige Art, Aulocoryne zetesios Fowler, seither vertreten war. Diese und die übrigen von Fowler beschriebenen Arten werden im systematischen 'T'eil dieser Arbeit noch Erwähnung finden. In den Veröffentlichungen des englischen Gelehrten finden sich anch nähere Angaben über die vertikale Verbreitung der gefangenen Organismen. A. Borgert (33), dem wir in nenester Zeit die eingehendsten Untersuchungen über T'r i p y le e n verdanken, fügte im Jahre 1901 eine neue Art von Aulographis aut. den bekannten hinzu, welche er als Aulographis mediterramea Borgert beschreibt und abbildet. Er $(\mathbf{2 0 , 2 2 , 2 9 )}$ sowohl, wie W. Karawaiew $(\mathbf{1 9}, \mathbf{2 3})(1896$ 11. 1900) zogen auch die Fortpflanzungsfrage in den Kreis ihrer Betrachtungen, und im folgenden wird noch auf die Ergebnisse ihrer Forschungen näher eingegangen werden. In seiner Abhandlung »über die nordischen 'Tripyleenarten« hat A. Borgert (32) sodann alles zusammengestellt, was an Aulacanthiden für die höheren Breiten bekannt war. Es sind dies 5 Gattungen mit zusammen 10 Arten. Hierbei wurde anch das neve Genus Aulocoryne kassiert und die betreffende, sie repüäsentierende Spezies, der Gattung Aulographis Häckel, Borgert einverleibt. A ußjer geringfügigen Abweichungen hat sich A. B or g e r't sonst an den Vorgang E. Hïckels gehalten, und es hat seit der Veröffentlichung der Lrgebnisse der ChaldExGERExpedition der ganze ïbrige, von E. Häckel beschriebene Teil der Familie keine Revision erfahren. Außer dieser größeren Zusammenstellung ist aus den letzten Jálıren noch die Veröffentlichung von H. N. Wolfenden anzufïhren, welche das Plankton des Faroe-Kanals behandelt und nnter bekamnten A ulacanthiden anch eine neue Form Aulographis furcellata anfiiht (34).

Nachdem hiermit angeführt ist, in welcher Weise sich der Entwicklungsgang unserer Kenntnisse von den Aulacanthiden im allgemeinen gestaltet hat, möge nun in nachstehendem erwähnt sein, wie es mit unserem bisherigen Wissen ïber den anatomischen Bau und die physiologischen Verhältnisse dieser Tiere bestellt ist. E. Häckel (1, 2, 9, 12), R. Hertwig (3), A. Borgert (29) und W. Karawaiew $(\mathbf{1 9}, \mathbf{2 3})$ sind die Namen, an welche sich hauptsächlich das Verdienst, hier Anfklïrung geschaffen zu haben, knïpft.

\section{Anatomischer Bau.}

Suchen wir ums nun zunächst darïber klar zu werden, was für ein Bild wir durch die soeben aufgezähiten wissenschaftlichen Errungenschaften von dem anatomischen Ban des Aula- 
canthidenkörpers gewonnen haben, un im nächsten Abschnitt das gleiche in bezug auf seine physiologischen Leistungen zu tun. Nur was sich im allgemeinen hierïber sagen läßt, sei jetzt angefïhrt. Modifizierungen, soweit solche vorkommen, werden bei der Abhandlung der Systematik ihre Besprechung finden.

A ulacanthiden sind Radiolarien, d, h. einzellige Lebewesen, welche sich durch das Vorhandensein einer Zentralkapsel vor anderen Protisten auszeichnen. Dieselbe bildet einen 'T'eil des Weichkörpers, des Malakoms, welcher wieder seine Stütze findet in einem Skelet, das aus kieselsänrehaltiger Substanz besteht.

Wenden wir uns zunächst der Betrachtung des Weichkörpers zu. An demselben, der in grol̉en und ganzen eine kugelförmige Gestalt besitzt, können wir mehrere konzentrisch angeordnete Regionen unterscheiden. Peripher beginnend, treffen wir auf eine solche, welche beim lebenden T'ier durch die ausgesandten Pseudopodien eingenommen wird. Von feinsten Endstrahlen aus bisweilen beginnend, sammeln sich dieselben zu grölỉeren Strängen, mehrfach untereinander anastomosierend, anch mitunter Vakuolen bildend an. Diese Stränge gelangen in eine schaumig zusammenhängende protoplasmatische Schicht, von Hä ckel als Sa r codictyum bezeiclnet, welche einer gallertartigen Masse, dem Calymma, aufgelagert ist. Letztere beansprucht so ziemliclı den größten Teil des Raumes, den der gesante Weichkörper einnimnt. Sie besitzt trotz ihrer Weichheit eine ziemliche Resistenz gegen Druck und ist vollkommen farblos und durchsichtig, zahlreiche Takuolen enthaltend. Bei toten und, wie berichtet wird, anch bei lebenden Exemplaren ist die Oberfläche gewöhnlich mit Staub und anderen Fremdkörpern bedeckt, welche durch die klebrige Konsistenz des Protoplasmas dort festgehalten werden. Hierdurch werden erst die Umrisse des Weichkörpers deutlich sichtbar, zumal wenn das Tier in Wasser beobachtet wird, mit welchem das Calymma gleiches Lichtbrechungsvermögen besitzt. Nicht nur von den Skeletnadeln wird dieser Gallertmantel durchsetzt, sondern auch das Protoplasma des S a r codict y u ms durchdringt dasselbe in netzartig verwobenen (nach der Auffassung Dreyers (16) wabenförmig) Strängen (von Häckel intercalymmare Pseudopodien oder Sarcoplegma genant, im Gegensatz zu den extracalymmaren, oder Astropodien, welche frei in das Wasser ausstrahlen), die größere und kleinere Vakuolen anf ihrem Wege bilden. Dieselben sind oft so zahlreich, daB ihre ursprüngliche Kngelgestalt durch gegenseitigen Druck verändert wird. Nach R. He r't wig besitzen sie keine abschließende Membran, sondern die Sarcode bildet einen äußerst zarten umgrenzenden Mantel. E. Häckel beobachtete an zwei Stellen des Körpers stärkere Protoplasmastränge, welche von ihm Collopodien genannt werden und deren Verlauf ungefähr mit der Hanptaxe (siehe weiter unten bei Beschreibung ler Zentralkalsel) des Körpers zusammenfällt. Ich habe dieselben sonst nirgends erwähnt finden können. Auch ist in der Häckel'schen Arbeit nicht deutlich ansgesprochen, für welche Formen diese Beobachtung besonders Geltung hat. Das Sarcoplegma geht also nach außen über in das erwähnte Sarcodictyum. Seinen Ursprung nimmt es aus der Sarcomatrix, dem Pseudopodien-Mutterboden, welcher in ungleichmäbig verteilter Schicht die Zentralkapsel umgibt. Dieses letztere, für alle Radiolarien bezeichnende Organ ist bei den 
A ulacanthiden von amähernd kugelfömiger Gestalt. Wie schon durch den Namen Tripyleen angedentet ist, steht ihr Inhalt durch drei Öfnungen mit dem umgebenden Protoplasma (an diesen Stellen soll die Sarcomatrix eine größere Ausdehnung haben) in Verbindung. Nan unterscheidet ihn im Gegensatz zu letzterem, dem Exoplasma, als Endoplasma des Rarliolarienkörpers. Die Wandung der Zentralkapsel, durch welche diese teilweise Trennung vollzogen wird, besteht ans zwei Membranen, einer derberen, äußeren, der Ektokapsa und einer feineren, inneren, der Endokapsa. Beim lebenden Tiere liegen beide fest anemander. Das von der Ektokapsa losgelöste, zerknitterte Aussehen der iunem Membran, wie es gewöhnlich bei toten 'Tieren zur Betrachtung gelangt, beruht wahrscheinlich auf der Einwirkung von Reagentien, die behufs Konservirung angewendet wurden.

Wie bereits erwähnt, sind diese Hïllen an drei Stellen durchbrochen und gestatten dem Encloplasma, und wie win sehen werden, anch anderen Stoffen den Austritt in das Extracapsulum. Wir kömen eine grölsere Hauptöfinung an dem einen Pol der Kapsel, der den Namen oralen Pol erhalten hat, von zwei Nebenöffnungen unterscheiclen, welche zu beiden Seiten des entgegengesetzten, aboralen Poles liegen. Die erstere wird auch als Astropyle bezeichnet, die letzteren tragen den Namen Paraylen. Die beide Pole verbindende Linie bildet die Hauptaxe des Körpers; die Ebene, in welcher die drei Öffnungen liegen, heisst Frontalebene.

Die Astropyle ist gekemnzeichet lurch einen in der Mitte durchbohrten, brustwarzenförmigen Deckel, das Operculnm, welcher, von oben betrachtet, scheinbar eine radiäre Streifung besitzt. Diesulbe lat sich jedoch bei näherer Untersuchung als dem Endoplasma angehörig herausgestellt und wird durch radiär in das Innere gerichtete Lamellen von verschiedener Breite hervorgerufen. Auf Querschnitten zeigen dieselben ein ähnliches Bild, wie die Septen einer Aktinie.

Die Parapylen haben einen etwas komplizierteren Ban. Wir unterscheiden bei ihnen den sogenannten Bulbus, welcher den Endoplasma entstammt und anch in demselben gelagert ist. Anf ilm erhebt sich der Öffnungskegel, in dessen Spitze sich die Mündung der Parapyle befindet. K. Hertwig (3) führt ihn als Abkömmling der innern Kapselnembran an, während er nach A. Borgert(29) in direkter Beziehung zum Bulbus

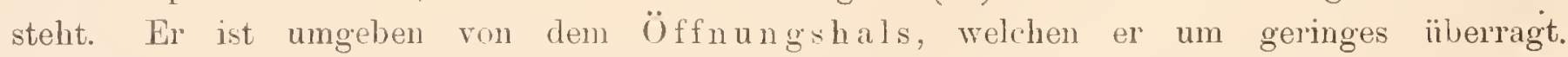
Letzterer ist bei Aulacantha ein Produkt der Ektokapsa, entstanden durch Verdickung derselben. Das Ganze hat Ähnliclıeit mit dem Bilde, das wir von einem Vulkan mit Krater und Eruptionskegel erhalten. Anch in der Ungebung der Parapylen zeigt das Endoplasma eine strahlenförmige Anordmung. Dieselbe rülnrt jedoch diesmal von radiär ausstrahlenden feinen Fibrillen her, die nach dem Bulbus hin zusammenlaufen.

Las bereits mehrfach erwähnte Endoplasma besitzt eine alveoläre Struktur, welche diese Eigenschaft nur in der Nähe der Öffnungen rermissen lälit, woselbst sie in die oben angeführten Bildungen übergeht. Ls ist ron zahlreichen Vakuolen und dïnnen, geschlängelten Kanälen durehsetzt. Eine in den Taknolen befindliche, wasserhelle Flüssigkeit 
umschließt einzelne oder zu kleinen Hänfchen vereinigte Körnchen, welche von R. Hertwig (3) mit Fett identitiziert werden.

In dieses Endoplasma ist nun der Zellkern eingebettet, der nach A. Borgert (29) eine etwas eifömige, mit der Spitze nach dem olalen l'ol zn gewendete Gestalt hat. Er liegt nicht genau in cier Mitte, sondern ctwas meh nach dem aboralen Pol zu verschoben. Eine dentliche Kernmembran ist vorhanden, welche den Abschlub gegen das umgebende Endoplasma bikfet. Was Chromatin erscheint (im Ruhestadium) 》als grob-spongiöses Gerüst, welches eine Aichter gelagerte zentrale Masse von unregelmäßig begrenzter, rundlicher Form umschliel.t. Das Maschenwerk in Unkreis der letateren zeigt einen mehr oder minder dentlich hervortretenden radiüren Bau. Es besteht aus dickeren mnd dünneren Strüngen und enthält in seinen Ǩnotenpunkten oft gröliere, verästelte Klumpen. An der Peripherie lanfen die Stränge in unregelmäbige Verzweigungen aus«. Ferner berichtet A. Borgert, daß auch einzelne isolierte Massen vorkommen und fäht fort: »Eigentliche $\mathrm{N}$ u cle ol en sind nicht vorhimden; dagegen finden sich zwischen den Chro matinst r ängen stets noch Kügelchen mu Fasern ans anderer Substanz«, bei welcher es sich wahrscheinlich einerseits nm Teile des blobgelegten Liningerüstes, andererseits un Paranuclein bandle. Eine Kermmembran grenzt der Kermanm gegen has nmgebende Protoplasma ab. Sie bildet ein zartes Häutchen, welches gegen Farbstoffe unemptindlich ist (Borgert).

Bei Darlegmng mserer bisherigen Kenntnisse vom Ban des Aulacanthiden-Köruers ist ein regehmäBig vorkonmender Bestandteil desselben nnerwähnt geblieben. Da seine Stelhng zum ïbrigen organischen Anflrau der Anlacanthidenzelle noch nicht geklärt ist, möge er jetzt besonders seine Erwähnung finden. lch meine das schon in der historischen Einleitung genannte P'haendium. Es ist dies eine grünlich bis dunkelbram gefärbte Masse, welche im Extracapulum vor der Astropyle gelagert ist und die Zentralkapsel zu mugefäln einem Jrittel, wie eine Wolke umgibt. Bei genanerer Betrachtung setat sich dasselbe ans den verschiedenartigsten Bestandteilen zusimmen; einesteils ans Körpern, die von auben in die Zelhmasse hineingelangt sind, andererseits ans Gebilden, die ilure Lintstelung dem A n a cant hi d en leibe selbst verdanken. Ton ersterentreten z. B. Diatomeen auf und andere ptlanzliche Überreste, ferner kleinere Radiolarienaten und Orustaceen. Die andem Gebilde bestehen ans rmdlichen oder ellipsoiden Körpern von verschiedener Grösse (nach A. Borgert von weniger als $1 \mu$ Durchmesser bis $20 \mu$ Durchmesser). Sie haben den Nạnen Phaeodellen erhalten und besitzen eine bald körnige, bald faserige, dann bisweilen wieder geschichtete und mitunter auch vollkommen lomogene Struktur. Sie treten einzeln und zu gröheren Massen zusammengeballt auf. Groß̉e Verschiedenheit zeigen sie anch in der Färbung, die von fast glashellen Pha eodellen bis zn undurchsichtig schwarzen alle Zwischenstufen. gelb, brann, hellgrün, dnnkelgrün durchläuft. »Die Grundmasse der Phaeodellen mmschlielit aulier dunkleren, fast schwar arscheinenden l'artikeln von verschiedener Grölie, noch kleine helle, stark lichtbrechende Körnchen, Kügrelchen und Stäbchen.« Manche Plhaeodellen entbehren solcher Linschlïsse ganz. Andererseits können letztere auch isoliert zwischen ersteren zerstrent vorkommen. 
Der Vollständigkeit halber sind schließlich noch die bis jetzt vorhandenen Angaben anzuführen, welche zusammenfassend anatomisch für das Skelet in Betracht kommen. Es wird dies in wenig Worten geschehen sein. Dasselbe besteht demnach aus ,isolirten Stacheln«, welche der Zentralkajsel lose aufsitzen, das Calymma durchbonren und mit dem andern Ende ans der eigentlichen Körpernasse heransragen. Hier kann der Stachel die mannigfaltigsten Gebilde tragen, welche ron Häckel zn einem System der A ulacanthiden verwendet worden sind. Sonst erfahren wir nur, dab diese Stachehn im Innern hohl sind und teils eine zerbrechliche Röhre, teils eine derbe Kenle darstellen. Außer diesen radiär gerichteten Stacheln ist ein Mantel von »dümnen hohlen Kieselnadeln« zn erwähnen, welche »tangential《 geligert den Weichkörper umgeben. Sie sind an beiden Enden offen und nach E. Häckel (12) von einem Sarcodefaden durchzogen, ein Verhalten, dem sich die Beobachtungen R. Hertwigs (1. c.) nicht anschlieBen, wie anch dieser Forscher der Angabe E. Häckels, dal.j die Radiaktacheh an beiden Enden geöffnet seien und der Sarcode Einlaß gewährten, entgegentritt. Diese letzteren, wie auch die meisten vorhergehenden, kömnen natiirlich zunächst nur für Aulncanthe scolymantha Häckel in Betracht kommen, welche zur Zeit der Veröffentlichnng derselben die einzige bekannte Anlacantlide darstellte. Mit Ansnahme der Endbildungen des Skelets sind jedoch alle bisher bekannten übrigen Gattungen so übereinstimmend in ilrem Ban, dab man das für Aulacantha scolymantha Häckel angefïhrte olne Besorgnis verallgemeinern kanu.

Im Voranstehenden wurde alles morphologisch Wichtige angefïhrt, was als Resultat aus früheren Untersuchungen hervorging und zwar insoweit, als dasselbe nötig war, uns ein Bild vom innern Aufban des Aulacanthiden-Körpers zn geben. Ich habe mich anf das beschränkt, was nach meiner Ansicht ein wenigstens vorlänfiges Ergebnis darstellt, wie es sich aus genanen Untersuchungen, nach Widerlegung von Irrtïmerm, die mit untergelanfen waren, im Lanf der Zeit herausgebildet hat. Wo es am Platze schien, habe ich auch verschiedene einander gegenüberstehende Neinungen registriert, um an späterer Stelle in dieser Abhandhnng darauf Bezug nehmen zu können. Dies auch im allgemeinen durchzuführen, würde viel zn viel Raum beanspruchen. Für jede eingehendere Orientierung in solchen Fragen, wie auch für genaneres Studium von Einzelheiten, die hier nur flüclıtig berïhrt werden konnten, verweise ich auf das dieser Arbeit beigefügte Literaturverzeichnis. An der Hand der Nummern diirfte man sich leicht zurecht fiuden.

\section{Physiologisches Verhalten.}

In gleicher Weise, wie wir morphologisch in unseren Betrachtungen vorgingen, soll dies anch in physiologischer Richtung geschehen. Die Beobachtungen der Forscher, welche ich nun zur Darstellnng bringe, beziehen sich sämtlich auf Aulacantha scolymantha Häckel, als der einzigen Anlacanthide, welche bisher auch in lebenden Zustande eingehender untersucht worden ist. Namentlich Dank der Untersuchungen W. Ka rawaiew's (18, 23) und A. Borgert's $(21,22,29)$ sind wir iiber die Fortpflanzungsverhältnisse aufgeklärt. 
Die Vermehrnng kann auf drei verschiedene Weisen erfolgen:

1. Aurch mitotische Kernteilung;

2. durch einfache Kernteilung;

3. durch Schwärmerbildung.

Mitotische Kernteilung: Indem ich in bezug anf die feineren Einzelleiten aut die Arbeiten von A. Borgert und W. Karawaiew verweise, lïbt sich nach den genannten Autoren dieser Fortpflanzungsvorgang in Kürze folgendermaßen schildern. Die zmächst radiär angeordnete chromatische Substan\% des Kerns verschwindet und macht einem dicht verschlungenen Knänel von Fïden Platz, auf welchen las Chromatin einen Ưberzug bildet, welcher bald durch eine gewisse Verteilung desselben ein perlschnurartiges Aussehen erhält. A. Borgert spricht die zu Grunde liegende Fadensubstanz als Linin an. Diese Knäuelbildung hat jedoch nicht den gesanten Vorrat an Linin und Chromatin aufgebraucht, welche Substanzen noch in Resten im Kern verteilt sind. Die erste Spaltung erfolgt dadurch, daß sich jedes Chromatink ïgelchen des Lininfadens in zwei neue Kugehn trennt, wodurch auch der Faden der Länge nach geteilt wird. Nach A. Borgert haben wir es jedoch nicht mit einem einzigen zusammenhüngenden Gebilde bei letzterem zu tun. Diese Tochterfäden teilen sich abermals und zwar in einer Längsrichtung, die rechtwinklig zur ersten Teilungsebene steht. Alle diese Teilungsprohkte rïcken anseinander, strecken sich in die Länge und bilden ein zweites Knänelstadium. Während dieser Periode hat auch der Kern als solcher eine andere Gestalt angenommen. Er plattet sich ab und erhält am aboralen Pol eine kleine Einbuchtung. Die Abbildungen, welche A. Borgert gibt, zeigen, außer diesem Verhaiten, noch verschiedene Umformungen, welche der Kern äßBerlich erfährt infolge von Umlagerung von Bestandteilen des Endoplasma (die Bläschen ordnen sich bisweilen ringförmig zu beiden Seiten der Astropyle), welche mit anf die Kerngestaltung einzuwirken scheinen. Die Chromosomen ordnen sich nunmehr zur Äquatorialplatte an. In derselben nehmen sie jedoch zunächst nur die äußeren Seiten ein, an welchen sie sich parallel neben einander lagern, während die Mitte von kurzen Stïckchen erfïllt ist. Erst späterhin rïcken sie anch nach der Mitte vor. Die $\ddot{A} q u a t o r i a l p l a t t e$ selbst ist gekrümmt, wobei die vorlin erwähnten ringförmig angeordneten Bläschen einen merkwürdigen Einfluß ausüben. Die Trennung in die Tochterplatten erfolgt durch Spaltung der ganzen Fläche nach, wobei es jedoch nicht zu einer typischen Mitose der Chromosomen zu kommen scheint. Beide neu gebildeten Platten entfernen sich voneinander. Gleichzeitig verringert sich ihr Durchmesser, was seinen Grund in einem engeren Zusammenrïcken der Chromosomen hat. Haben die Platten das Maximum ihres Abstandes erreicht, so beginnen sie ihre Ränder nach außen zu krümmen, und zwar anf der oralen Seite etwas melır, als auf der entgegengesetzten. Nit der immer fortschreitenden Krïmmung nimmt anch die Dicke der Platten wieder etwas zu. Entsprechend der Höllıng der Platte wölbt sich las Endoplasma vor, bis es schließlich nur noch durch einen dünnen Stiel mit dem übrigen Endoplasma in Zusammenhang steht. Zunächst findet sich zwischen den beiden Tochterplatten ein schwerer fürbbares vakinolenfreies Protoplasma. 
später jedoch gleichen sich diese Unterschiede wieder ans und die Takuolen, die vorher nur an der AnBenseite sieh zusammendrängten, stellen sich anch hier wieder ein. Ungefähr um dieselbe Zeit, wo sich eine Krïmmung der Tochterplatten vollzielst, machen sich anch die ersten 'T'eilungserscheinmgen der Zentralkapsel bemerkbar, indem sie sich in der Richtung der auseinander getretenen 'Tochterplatten verbreitert. Dann beginnt eine Einkerbung gregenïber der Astropyle die Zentralkaples von der aboralen nach der oralen Seite hin in zwei Teile zu trennen. Schließlich, noch ehe der Kern jeder Hälfte seine völlige Rundung wieder erlangt hat, vollzieht sich anch die Zweiteilung der Astropyle und vollkommene 'T'rennung in zwei neue Zentralkapseln. Jede derselben besitzt eine Parapyle der Mutterkapsel; die zweite wird neu gebildet, nud zwa beginnen die Phasen ihrer Entwicklung schon ziemlich frühzeitig, indem ein winziges »hutförmigus Körperchen« sich im Endoplasma an die Zentralkapselmembran dicht anlagert. ln der Nähe dieser Stelle fehlen die äblichen Vakuolen; anch zeichnet sich hier das Protoplasma durch geringere Färbbarkeit ans. Ans diesem Körperchen entwickeit sich der Bulbus der Palapyle, indem es zunächst dicht an die Membran helanr ïckt, sich sodann wieder etwas vou ihr entfernt, wobei es mit seinem Rande mit der Zentralkapselmembran in Verbindung bleibt. Diese letztere wird innerhalb des Umlkreises des so entstandenen Zylinders immer dünner, bis es schlieblich in der Nitte zu einem Durchbruch kommt. Der bisher hutförmige Körper hat muterdessen rine mehr kugelige Gestalt angenommen. Lin Fortsatz wächst aus ilın herans durch die entstandene Öffunng der Kapselmembran hindurch und

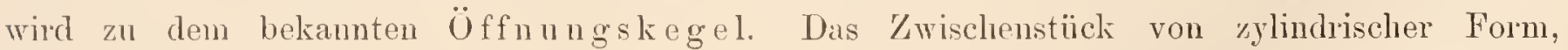
welcher Endokajsa und Bulbus rerbindet, wird durch Annäherung des letzteren an die Kapselwandung fast ganz zum Schwinden gebracht. (Die hier angefïhte Anschaunng ist die A. Borgerts, welche in gewissen Einzelheiten, wie bereits erwähnt, derjenigen R. Hertwigs widerspricht. Was letztere anbelangt, so verweise ich anf frïher angerlentetes und auf das Werk des Forschers über den Bau der Radiolarien.) Die 'T'eilung (ler Astropyle erfolgt sehr spät. Erst nachdem die Trennung bis zum li iissel vorgeschritten ist, erfolgen zwei neue kreisförmige Anordnungen um zwei nen entstandene Öffnmgen. Von den extrakapsulären Bestandteilen werden alle in die 'Tochterindividnen mit übernommen: Indem die auseinander rïckenden Tochterkapseln je ein gesondertes Zentrum für die ïbrigen Körperbestandteile bilden. werden sowols Pha e odinm, als anch Stacheln und Tangentialn a deln in swei neue Gruppierungen gesondert. Die Trenung folgt ganz allü̈hlich. Möglicherweise kann sie anch bisweilen unterbleiben, wie wir suäter noch sehen werden.

Direkte Kernteilung: Über dieselbe lïht sich nur sagen. dab durch sie der Kern gespalten wirl und zwar nicht infolge einer allmählichen Durchschnürnng. Die Kerne bilden also zmmächst zwei »Halbkugeln«, welche dnrch einen schmalen Zwischenraum getrennt sind. Erst darurch, dah die Kernhälften auseinander rïcken, wird ihnen Gelegenheit gegeben, sich abzurunden und zwei nene kngelförmige Kerne herzustellen. Die 'T'eilung der 7entralkapsel erfolgt, inclem sich zunächst eine Hache ringförmige Finche mit scharf markierten Rändern bildet. Dieselbe liegt in dex gleichen Ebene, wie der Spalt zwischen den 
geteilten Kernen, d. h. senkrecht zur Frontalebene. Sie halbiert die Hauptöffnung, statt deren sich zwei nene ansbilden. Yon den P'araplen muli je eine nen gebildet werden. Bei der Teilung der Kentralkapsel, sei es mu dal. diese dureh Mitose oder auf direktem Wege zustande kommt, ist nicht immer auch eine Teilung des übrigen Körpers die Folge. Es können Kolonien entstehen, wie z. B. W. Karawaiew eine solche mit acht Zentralkapseln beobachtete.

Sehwärnerbildung: Dieselbe wird ron A. Borgert nur ganz kur\% herihht. Bei ihr wird nach diesem Autor das Chromatin durch das ganze Hndoplasma verteilt. Es tritt also kein eigentlicher Kern auf. Spüter findet man den »Hohhram des Skelets《 mit zahlreichen vielkernigen Kügelchen erfüllt. Eine weitere Beobachtung, die A. Borger.t machte, äußert sich darin, daßs an Stelle des Kerns eine Blase mit verdiekter Wandung tritt. »Innen ist dieselbe mit einem protoplasinatischen Wandbelag ausgekleidlet. Das Anffälligste dieser Stadien besteht jedoch in dem Vorluandensein vieler größerer und-kleinerer Kügelehen, welehe mit Osmium oder mit osmiumhaltigen Gemischen schwarz werden und in der Hanptsache aus Fett zn bestehen scheinen. Sie liegen in einer Kngelschale angeordnet der imnern Wandung an. In andern Fällen trifft man ähliche Bildungen auBerhalb des Kerns im Ėndoplasma. Bald ist es nur eine oder zwei, bahl eine grölere '/ahl, bis zwölf oder mehr derartiger Blasen. Bei ihrem Auftreten nnterliegt der Kern gewissen Veränderungen, ja er kamn als soleher vollstïndig zugrunde gehen; anch am Endoplasma spielen sich degrenerative Erscheimungen ab.« Ob dieses letzte Verhalten, das ich wörthieh ans A. Borgerts Abhandlung anführe, wirklich das Vorstadium einer Schwärmerbildung darstellt, scheint mir nieht wahrscheinlich, wohl aber glaube ich von den vorher genannten Umbildungen das annehmen zu dürfen aus Gründen, die ich im weiteren noch anführen werde.

Auber den Beobachtungen, die über die Fortpflanzungsvorgänge bei Anla eanthiden gemacht wmrlen, liegen nur wenige weitere äber dieselben vor. Auf das merkwürdige Phaeodium wurde bereits hingewiesen. Seine Restimmung hat schon die verschiedensten Auslegungen erfahren. Der Umstand, dal.s untriiglich Nahmugsreste in seiner Masse enthalten sind, legten die Annalıme einer verdauenden Wirkung desselben nahe. Seine Färbung wnrle mit einer Empfindlichkeit für Licht in Terbindung gebracht. Anch die Frage einer Symbiose mit einzelligen Algen wurde bezüglich der Phaeodellen ron L. Häckel in Erwägnng gezogen. Für letatere glaubt A. Borgert festgestellt zu haben, dab sie dem In tracapsulum entstammen. Schon R. Hertwig bemerkte unter der Hanptöfnung im innern Kapselra a m kleine Körnchen, die er für Fettgrmula hielt. A. Borgert macht nun auf die grobe Ähnlichkeit diestr Gebilde mit den Phaeodellen aulherhalb anfmerksan. Die größeren Phaeodellen sind seiner Meinmg nach dnch Znsimmenballen solcher Kïgelehen entstanden. Es scheint sich darnach also $11 \mathrm{~m}$ Abscheidungsprodukte des Zentralkapselinhalts zu handeln. Daß sie gerade hier vor der Astropyle mit den ïbrigen Nahrungsesten vermengt regelmäbig in größerer Anzahl anzutreffen sind, hat erstens seinen Grund in eben dieser Öffnung, zweitens vielleicht in der zur Schwimmfähigkeit nötigen Oberfläehenvergrößerung und in einer für die Stellung angemessenen Schwerpunktslage. (Dabei müßte allerdings erst mit 
Sicherheit festgestellt werden, wo sich bei freilebenden Individuen der orale Pol befindet, oben oder unten.) Die Phaeodelleu sind äußerst resistenzfähig gegen chemische Einwirkungen. Die Versuche A. Borgerts laben gezeigt, daß es sich bei diesen Abscheidungsprodukten nicht um Harnsäure handelt.

Über das Verhalten des Calymma und des extracapsulären Protoplasma sind die Untersuchmngen noch sehr im Rückstande. Für das skelet hat A. Borgert die Beobachtung gemacht, daß die Nadeln zumächst häntig präformiert werden und erst sekundär Kieselsäure durch Einlagerung in sich aufnehmen.

\section{Ergänzende Beobachtungen bei Aulacanthiden der Plankton-Expedition.}

Weichkörper: Um genanere Untersuchungen betrefts des Weichkörpers, namentlich der extrakapsulären 'Teile anstellen zn können, bedarf es lebenden oder in geeigneter Weise abgetöteten Materials, das in frischem Zustande zur mikroskopischen Prüfung gelangt. Bei den mir vorliegenden Aulacanthiden war die Zentralkapsel und ihr Inhalt, mit Ausnahme des Verhaltens der Membranen, meist gut erhalten; dagegen konnte ich niemals etwas von der Struktur des Calymma, noch eigentlich dieses selbst wahrnehmen. Noch weniger vermochte ich irgendwelche Abgrenzung gegen speziell protoplasmatische Substanz zu erkennen, soweit sie sich anf Sarcodictyum, intercalymmare Psendopodien sowohl, als anch begreiflicherweise die extracalymmaren und die Sarcomatrix bezieht. Wohl denteten die Schlammmassen, welche den Körper, resp. die Zentralkapsel in einiger Entfernuıy umgaben, darauf hin, dab der Zwischenraum durch eine vollkommen klare Substanz ausgefült sein mußte (dieselbe reichte bei manchen Exemplaren bis an die distalen Stachelenden heran), aber es gelang mir bisher mit keiner Färbemethode irgendwelche Differenzierumg zu erreichen. Nur die äubersten Schichten nahmen Berlinerblau in sich auf, nachdem der ganze Körper zmüchst längere Zeit in eine Lösung von Ferricyankalium gelegt und darauf in eine solche von Eisensulfat gebracht wurde. Es zeigte sich daranf eine dïnne membranähnliche Schicht, welche keine weitere Struktur aufwies.

Vom Kapselinhalt und Kern erhielt ich bei verschiedenen Färbemethoden (meist jedoch Doppelfärbung mit Hämatoxylin und Eosin) recht dentliche Bilder. Sie bestätigten im ganzen das im vorigen Abschnitt mitgeteilte. Bei verschiedenen Präparaten bemerkte ich, daß hauptsächlich die Randalveolen des Endoplasma mit kleinen Ḱngeln, welche wieder eine dunkler gefärbte Masse enthielten, gefültt waren und zwar ganz dicht, so daß diese Zone las Aussehen eines mehrschichtigen Epithels gewann. Jedes einzehne dieser Kügelchen machte rollkommen den Lindruck einer winzigen Zelle. Die Alveolen, die dem Kern näher lagen, waren leer. Letzterer beanspruchte oft einen groben Raum, obwohl er sich, wie sein Inhalt zeigte, im Ruhestadium befand. Bisweilen glaubte ich anch eine kleine Verschiebung nach (ler Astropyle hin zu bemerken. Die Lage des Kerns scheint demnach keine vollkommen konstante zu sein.

Sehr hänfig traf ich anch Starlien mit zwei, ja auch mit drei Zentralkapseln, die unter sich meist die gleiche Gröbe zeigten und bereits vollkommen getrennt waren. Sehr 
merkwürdig war ein Stadium, welches sich bei Aulacanthiclen aus dem Golf von Neapel (Herr Professor Dr. K. Brandt war so liebenswürdig, mir dieselben als Vergleichsmaterial zur Verfügnng zu stellen) befand. Es unterschied sich von den übrigen durch vollkommenes Fehlen der Zentralkapsel. Statt dessen lagerten im Weichkörper (es handelte sich um eine Aulacantha scolymantha Häckel) zerstrent zahlreiche, durch Hämatoxylin violett gefärbte, rundliche Gebilde, welche mit kleinen Kngeh angefüllt waren. Jedoch war dies nicht bei allen der Fall. Bei einzelnen konnte ich nur einen körnigen Inhalt wahrnehmen. Manche der größeren waren (wahrscheinlich durch Deckglasdruck) geplatzt und der Inhalt teilweise herausgetreten, der vollkommen die Gestalt kleiner Kügelchen zeigte. Wahrscheinlich haben wir es hier mit einem Fortpflanzungsvorgang zu tm, welcher vielleicht der von A. Borgert angefïhrten Schwärmerbildung entspricht. Das betreffende Tier schien, nach dem Aussehen der Stachehn zu urteilen, sich noch in einem jugendlichen Stadium zu befinden. Von etwaigen T'eilungs- oder Verfallanzeichen des Weichliörpers oder des Skelets war nichts zn bemerken, anch wohl kaum mit Genaugkeit zu konstatieren, da infolge von Quetschnng des Treichkörpers Dislokationen der einzelnen 'leile eingetreten waren. Überreste einer Zentralkapselmembran ließen sich jedoch nirgends bemerken. Ich glaube nicht, daß es sich bei diesen rundlichen Gebilden um die gleichen Bestandteile handelt, wie ich sie bei mehreren Schnittpräparaten als imnern Wandbelag der Zentralkapsel beobachtete; denn diese Kugeln hatten ein durchaus anderes Aussehen, enthielten anch lange nicht so viele kleinere Kügelcheu, wie ich sie bei dem vermutlichen Schwärmerstadium sah. Man wäre versucht, jenen Wandbelag, mit Berücksichtigung der Borgert’schen Angaben ïber ähnliche Vorkommnisse, mit den Phaeodellen in Verbindung zu bringen. Dagegen spricht aber die ganz dentliche Farbstoffaufnahne, welche derselbe zeigte und welche die in gleichen Schnitt vorhandenen außerhalb der Zentralkapsel befindlichen P'haeodellen nicht erkennen ließen. Fraglich ist ja auch, ob die von mir beobachteten Vaknoleneinschlüsse mit denen A. Borgerts identisch sind. Für Fettkörnchen kann ich dieselben anch nicht halten. Der jahrelang wirkende, Alkohol müßte dieselben längst zerstört haben.

\section{Untersuchungen über das Skelet.}

Wie bereits bei Beginn dieser Arbeit angedeutet wurde, war bei dem Erhaltungrzustand des Materials die Aussicht auf eine ergiehige histologische Untersuchung nicht groß. Nur um auch die Verhältnisse bei bisher noch nicht in dieser Hinsicht beschriebenen Gattungen und Arten mit bekannten bei Aulacantha scolymanth Häckel in Vergleich zu ziehen, wurde die Untersuchung in dieser Richtung fortgesetzt. Was etwa bei dieser Gelegenheit an Beobachtungen sich ergab - und es ist, wie aus dem kurz vorher angeführten hervorgeht, nicht viel - wurde rer Vollständigkeit lalber zur Kenntnis gebracht.

So war es denn eine andere Anfgabe, welche ich mir neben lerjenigen der faunistischen Verbreitung, wie sie der Zweck der Expedition ergab, stellte. Die relative Mannigfaltigkeit des Materials ließ von vomherein die Unterschiede der änern Form in den Vordergrund treten. Diese wiederum beruhen ausschließlich in der Skeletbildung. Was letztere anbelangt, 
so haben wir im vorhergehenten gesehen, dab. die bisherigen Bearbeitungen meist in Kürze über diese Verhältnisse hinweggehen. Selbst da, wo eine nähere Erörterung derselben, wie bei cler Systematik, sich von selbst ergibt, ist eine Erwähnung der äußern Form der einzelnen Nadeln das Einzige, was wir finden. Wie bereits dargelegt wurde, begnügt man sich meist mit der Angabe, claß dieselben ans hohlen Kieselröhren gebildet werden. Darnach hat es den Anschein, als ob der Skeletban der Aulacanthiden, von der äußeren Gestaltung abgesehen, ein sehr einförmiger sei. Die Durchmusterung des Materials der Plankton-Expedition zeigte mir, daß dies durchaus nicht der Fall ist. Eine Beobachtung sehr merkwïrdiger Art, die ich dabei machte, wurde bereits vor einiger Zeit als vorläufige Mitteilung im »zoologischen Anzeiger veröffentlicht. Im Zusammenhang mit den übrigen Erscheinungen wird sie hier etwas ansführlicher behandlelt werden.

Wemn wir eine grölere Anzahl von verschiedenen Aulaca nthiden, gleichviel welcher Gattung, bei schwacher Vergröherung betrichten, so wird uns anffallen, daßs der Mantel, welchen die dümen gleichsam verfilzten 'T'angentialnadeln bilden, sehr verschieden in bezug anf Dichte ist. Bei manchen Formen sehen wir eine dicke Hülle, bei anlern wieder nur einen dïnnen Schleier, der sogar bis auf wenige spärliche Nadeln ganz verschwinden kann. Anch diese letzteren werden bisweilen vernißt, wenigstens in der bekannten Gestalt. Nicht nur bei Vertretern verschiedener Gattungen und Arten ist eine solche Verschiedenheit zu beobachten, sondern auch bei Angehörigen ein und derselben Spezies. Ein ähnliches Verhalten zeigen die Radialstacheln. Wir finclen Arten, welche sich durch relativen Reichtum an solchen Gebilden auszeichnen, während andere sich nit einer geringeren Zahl begnïgen. Auch innerhalb der einzelnen Spezies läBt sich eine Zu- und Abnahme verfolgen und zwar am dentlichsten bei solchen Arten, welche in manchen Füllen durch eine sehr große Menge von Stacheln sich auszeichnen, während bei den Formen, welche sich auf den Besitz von nur wenigen radialen Skeletnadeh beschränken, die Verschiedenheit der Anzahl nur innerhalb enger Grenzen schwankt. Schon von friiheren Autoren ist die Vermutung ausgesprochen worden, daß, mit dem Alter des Lebewesens auch die Menge der Kieselgebilde zunehme. Meine Beobachtung kaun eine solche Annahne nur bestätigen. Wir haben demnach bei Vorfinden einer größeren oder kleineren Anzahl von Skeletnadeln verschiedene Altersstadien vor uns, indem zunächst nackte Formen einen mit der Zeit an Dichte zunehmenden Mantel von Tangentialnadeln bilden und in gleicher Weise die Zahl der Radialstacheln mit der Lebensdaner zunimmt. Aber dies läbt sich nicht ohne Einschränkung aussprechen. Nach dem eben Gesagten möchte es scheinen, als ob das Wachstum, wie es in den verschiedenen Altersstufen zum Ausdruck kommt, soweit es sich auf die Skeletteile bezieht, einzig und allein auf einer zahlenmäßigen Vermehrung von deren Einzelstïcken beruhe. Dies ist durchaus nicht der Full. Es wurde bereits hervorgehoben, daß.) gewisse Formen über eine verhältnismäßig geringe Zahl von Stacheln nicht hinangehen orler wenigstens kaum eine nennenswerte Vermehrung von solchen zeigen. Wenn also das Wachstnm auch in der Skeletbildung zum Auschuck kommt, dann muf es hier in anderer. Weise geschehen, als bei den Formen, bei welchen wir eine starke Vermehrung der Zahl der Nadeln konstatieren können. Durch weitere 
Beobachtungen ließ sich dies erweisen, ja es kann gezeigt werden, daß noch eine andere Art der Körpervergrößerung vorhanden ist, die beide Wege, den bereits angedeuteten und einen im Verlanf der Abhandlnng noch zn beschreibenden benutzt, un zım Ziel zu gelangen. Sie bildet gewissermaßen den Übergang zn den Formen, wo nicht mehr die Nadeln an Gesantzahl, sondern die einzelnen Stacheln selbst an Masse zunehmen.

Um uns hierüber Klarheit zn verschaften, wird es nötig sein, den Skeletanfbin von einem nenen Gesichtspunkt ans zu betrachten. Zn diesem Zweck vergleichen wir die einzelnen Stacheln der verschiedenen Gattmingen miteinander mul wir werden gewisse priuzipielle Unterschiede finden. Zum Beispiel werden die Gattungen Aulocoryne (Fowler) und Aulospathis Häckel eine Stachelform zeigen, deren Wantungen, wo wir dieselben anch mustern mögen, einen durchaus gleichartigen Charakter äulern. Überall, wenigstens soweit unser Blick uns ïberzeugen kann, die gleiche Stärke der Wandung, die keinerlei Struktur aufweist; überall ein innerer Hohlraum, der sich entsprechend der gleichbleibenden Wandungsdicke, der ganzen äußerr Form des Stachels anpassen muli. Nur gewisse einzelne Stellen machen eine bemerkenswerte Ansnahme: Es ist dies einmal der äuberste distale Abschlul. der an diesem Ende befindlichen Bildungen, die gewöhnlich aus melıeren bis zahlreichen 'Terminalästen bestelıen. (Letztere können entweder direkt von dem Radialstachel ihren Ausgangspmkt nehnen, oder, wie bei Aulocoryne (Fowler) und gewissen Formen von Aulospathis Häckel, es kann sich ein blasenartiges Gebihle zwischen beide schieben und den Übergang vermitteh.) Diesen Abschluß also der' sekundären Stacheln bewirkt ein Kranz von mehreren Höikchen, Spathill in weiteren genannt. Derselbe ist entweder' einfach und die 'Zähnchen sind dam meist etwas nach auben zurïckgebogen, oder sie ordnen sich zu zwei (in seltenen Fiillen anch drei) konzentrischen Kreisen, wobei die Krümmung des Innern abnimut und ihre Richtung mehr mit derjenigen des Endastes zusammentällt. Nur wenige Formen äberhaupt, welche sonst eine lomogene, strukturlose Wandung zeigen, entbehren dieser Endzierde, aber selbst bei diesen finden wir mit einer einzigen Ausnalıme (wenn wir, wie bei Aulographis pandora Häckel die Einzahl der. Spitze als solche be\%eichnen wollen) entsprechende ähnliche Bildungen. Ein solches Spathill sagt uns gewissermaßen, daß danit der Stachel fertiggestellt ist. Die Formen von Aulospathis Häckel zeigen diese Eigenschaft nicht nur an den 'l'erminalstacheln, sondern auch an den lateralen Verzweigungen. Wir können noch weiter gehen und das Gems Auloceros Häckel anführen, wenn anch hier bereits Verhältnisse vorliegen, die erst im folgenden besprochen werden sollen. Auch die bekannte Aulacantha scolymantha Fäckel liebe sich im Prinzip mit einreilıen, wemn nicht die Verteilıng der ihr eigentümlichen Häkchen und Zähnchen eine Sonderstellung fuir sie beanspruchte. An der Stelle, wo das Spathill sich befindet, sehen wir eine minimale Verdickung der Wandung, welche durch den Verschlul. zustande kommt, wie wir es ja anch beim Ausziehen und Zuschmelzen einer Glasröhre beobachten können. Ferner muß man wohl als Verdickungen die zalhnartigen Ansätze, welche sich bisweilen längs der 'T'erminaläste vorfinden, bezeichnen. Aber schon durch den Ausdruck »Ansatz« möchte ich darauf hinweisen, daß die Beziehnug zur eigentlichen Stachelwandung eine änßerliche ist. Ich halue vorhin gesagt, daß das Spathill die vollendete Ausbildung des Stachels dokunentiert. 
Es wird uns daher nicht wundern, wenn wir bei allen Besitzern eines solchen eine gemeinsame Eigenschaft auffuden können. Ein Stachel, der fertig ist, wird kein weiteres Wachstum mehr aufweisen. Wächst also das Tier, und soll das Skelet damit Schritt halten, so ist dies nur möglich durch vollstäudige Nenbildung von Kieselnadeln. Wo wir ein echtes Spathill wahruehmen. ist eine anderweitige Substanzunahme des einzelnen Stachels ansgeschlossen. Aus diesem Grunde dürfen wir die Hakenbildungen bei Aulacantha scolymantha Häckel nicht hierher rechnen, wie ja die Sonderstellung dieser Aulacanthide bereits betont wurde. Anch stehen die Fortsätze bei dieser Form zum innern Hohlramm in einer gewissen Beziehung, indem sie, wenn auch minimale, Ansstiilpungen der Wandung darstellen. Wo wir also ein echtes Spathill finden, dïrfen wir annehmen, daB bei der betreffenden Art orler Gattung die Stachelzahl mit dem Alter zmminme und zwar wird sie erheblich zmnehmen bei solchen Arten, bei welchen siclı der Hakenkianz direkt an den Abschluß des innern Holnlraums aureilht. Die Beobachtung bestiitigt dies, inclem gerade die Gattungen Aulocoryne (Fowler) und Aulospathis Häckel meist durch eine ungeheure Zahl von Radialnadeln ausgezeichnet sind, welche jedoch, wie bereits bemerkt, bei Jugendstadien bis auf wenige herabsinken kaun.

Zwei Gattungen waren es, welche bei dem bisher Besprochenen zwar Erwähnung fanden, jedoch eine Sonderstellung forderten: Das Genus Aulacantha Häckel nud das Genus Auloceros Häckel. Bei beiden kömnen wir zwar anch mit dem Alter eine Zunahme der Anzalıl der Kieselgebilde konstatieren. Gleichzeitig bemerken wir jerloch eine Zunahme an Substanz bei dem einzelnen Stichel und zwar bei beiden Gattungen in verschiedener Weise: Wir beobachten, daßs die Wandung in zentrifugaler lichtung an Stärke zunimmt; bei Aulacentha etwas unregelmäBig, indem wir Nadeln mit verschiedener Wiunlungsdicke, die oft erheblich im Maß schwankt, wahrnehmen können; bei Auloceros äußerst regelmäBig, so lange der Stachel ungeteilt bleibt. Wolsl finden wir anch hier Unterschiede, aber sie sind geringfiigiger Natur und beziehen sich meist auf Differenzen bei verschiertenen Iurlividnen, wobei Lokalvarietäten eine Rolle spielen. Während nun bei Aulacantha die Znuahme an Substanz auf das distale Drittel der Nadel beschränkt ist mo hier mit dem Ende des innern Hohlram ihren AbschluB findet, wächst bei Auloceros der Stachel ïber denselben in kompakter Masse hinaus und bilket sekumdäre und tertiïre Verzweigungen, bis anch diese schlieblich bei den meisten Formen mit Bildung eines Spathills ihren Wachstumshöhepunkt erreichen. Von da ab ist jede weitere Vergrößerung ansgeschlossen und eine Substanzveruehrnng der Skeletbestandteile dieser Aulacanthide kamn nur durch Vermehrung der Stachelzahl erfolgen.

Etwas unklar blieb mir die Stellung, die Aulographis (Häckel) einnimmt. Hier haben wir es anch mit kompakten T'erminalästen zu tun, aber eine Längenzunalıme, wie ich sie bei Auloceros durch weitere neue Astanlagen beobachten konnte, war hier nicht festzustellen. Alle zur Untersuchung gelangten lixemplare zeigten an gleichen Stachel stets auch gleichlange Terminalïste, obschon deren MaB bei verschiedenen Nadeln desselben Individuums oft schwankte. In solchen Fïllen bewies das Spathill, das der Stachel bereits fertig ausgebildet war. Als eme Ansnahme könnte man die Fomen betrachten, bei welchen ein Spathill fellte (Aulographis pundora Häckel), doch habe ich auch bei diesen nie ein Stadium entdeckt, 
das als in einer Wachstumsperiode begriffen hätte bezeichnet werden können, und die äußerst regelmäBigen Endgebilde denteten anf einen vollendeten Abschluli hin. Anch zeichnen sich alle Arten von Alulographis (Häckel) durch eine relativ grolie Menge von Radialstacheln ans, was mit einer frïhzeitigen Beendigung des indivilnellen Stachelwachstums zusammenhängt. Sie schließen sich in dieser Hinsicht eng an die Gattung 》Aulocoryne« (Fowler) an. Wir sehen daraus, daß Ungleichheiten in der Wandungsdicke und massive Endiste nicht ohne weiteres für eine Substanzzunalıme in Sinne des Alterswaclıstmms in Anspuruch genommen werden dürfen. Damit kehren wir zn letzterer zurück.

Selten beobachtete ich bei Aulacontha Häckel Stacheln von verschiedener Dicke an dem gleichen Individum, aber selbst in sanz eng begrenzten Bezirken, ja bei direkt aneinander lagernden Exemplaren konnten solche mit ganz dïnnwandigen und solche mit kräftigen Nadeln gefunden werden, so daß es kaum erlaubt ex'scheint, hier verschiedene Varietäten oder gal' Arten anzmnehmen (nicht zn verwechsehn mit Jokalvarietäten, wie sie bei der Gattung Auloceros Häckel vorzukommen scheinen). Wir werden eher geneigt sein zn der Meinung, daß es sich lier um verschiedene Altersstufen handelt. Das Wachstum scheint sich demnach bei Aulacantha ziemlich g]eichmäßig anf alle Stacheln eines Individumms zu erstrecken. wem anch hier und da Nachziigler zn bemerken sinł. Anders verhält es sich bei der Gattung Auloceros Häckel, wo wir nicht nm Nadeln mit verschiedener '/ahl von 'f'erminalästen bei ein und demselben 'Tier, sondern anch solche mit sekmü̈ren Verzweigungen und solche mit hinzutretenden tertiären unterscheiden können. Hier ist das Stachehwachstum jerlenfalls ein ungleichmäßiges. Entweder treten hier gewisse Nadeln erst später anf und sind infolgerlessen im Rückstand ader sie werden in der Substanzanflagerung von andern ̈̈berholt. Da jedoch die äußern Einfliisse bei der Klembeit des Tieres voranssichtlich auf dessen Oberfläche iiberall die gleichen sind, so ist die erste Annahme wohl die berechtigtere.

Fassen wir die bisherigen Beobachtungen, soweit sie sich auf die Substanz-Vermelnung des Skelets beziehen, zusanmen, so können wir folgende Unterschiede im Wachstum konstatieren:

1. Der einzelne Stachel ist keiner Vergrößerung fähig. Das Wachstum des T'ieres ist mur mit einer Vermelırung der Radial- resp. Tangentialnadeln verknüpft. Hierher gehören die Gattungen Aulosputhis Häckel, Aulocoryne (Fowler) und die später noch näher zn beschreibende Gattung Aulophyton nov. gen.

2. Ein Wachstum des einzelnen Stachels ist nicht direkt nachweisbar, doch läßt sich eine Substanzanhäufung am distalen Ende beobachten, welche an ganz bestimmte sich bei allen Stacheln wiederholende, enge Grenzen gebunden ist und stets ein gleiches Endprodukt zur Folge hat. Hier ist die Gattung Aulographis (Haïkel) anzufülnen.

3. Die Substanzvermelnung ist auf das distale Ende beschränkt und ist, was den eigentlichen Stachel anbelingt, an bostimmte, für alle äbereinstimmende Grenzen gebunden. An den T'erminalästen tritt sie jedoch als direkt zn beobachtendes Wachstmmsmerkmal auf und hat Nenbildungen zur Folge, welche zwar in allgemeinen anch nach gesetzunäBigen Regeln erfolgen, die jedoch nicht ein bei jedem Stachel notwendig gleiches Endprodukt hervorbringen. Dies gilt für Auloceros Häckel. 
4. Die Substanzvermehrung erstreckt sich auf einen grofen 'Teil des Stachels, alle Unebenheiten desselben iiberziehend, wobei letztere dentlicher hervortreten. Sie bestehen größtenteils in kleinen zahn- oder hakenförmigen Bildungen. Solche Verhältnisse reigt die allgemein verbreitete Aulacantha scolymantha Häckel.

Die Art der Skeletvergrößernng, wie sie in diesen vier Abschnitten angeführt ist, tritt in Gegensatz zn einer weiteren. Konnten wir in den bisher genannten Fïllen nur aus der verschiedenen Dicke und der Anlage kleiner Neubihdungen auf ein bestehendes oder voraufgegangenes Wachstum schließen, so sind wir bei den nun folgenden Formen imstande, gewissermaßen direkt ein solches zu beobachten und die einzelnen Phasen desselben zu rerfolgen. Bei den bereits erwähnten Skeletbildungen bleibt die Substanz trotz der Vermehrnng im allgemeinen homogen. Kaum finden wir eine sichtbare Spur, aus welcher sich der Vorgang der T'ergrölsermng rekonstrnieren ließe: Kleine Unregelmäbigkeiten in der innern Struktur, bemerkbar durch etwas verschiedenes Lichtbrechungsvermögen, ist alles, was wir bei der genanesten Beobachtung' bei den meisten Objekten sehen können. Anders verhalten sich in dieser Beziehung Arten, bei deren Untersuchung wir den bisher eingeschlagenen Weg gehen wollen.

Bei der Durchmusterung des Materials fielen mir gewisse Exemplare anf, die sich dmrch ungewöhnlich starke Stacheln vor den übrigen auszeichneten. Merkwürlig war anch, lak dieselben nie in größerer Ziahl bei dem Individum auftraten. Zehn waren vielleicht das höchste, was ich konstatieren komnte. Auch tangential gelagerte Gebilde reigten sich und zwar in verschiedener Dichte. Ähnlich wie dies bei Auloceros Häckel und Aulographis (Häckel) mihi der Fall war, nahm anch hier der Stachel in zentrifngaler Richtnng an Stärke zu. Der innere Hohlraum (oder wenigstens das, was bei anderen Formen diesem entsprach) hörte bei Beginn der Endbildungen auf. Letztere waren äußerst ungleichartig im Aussehen, oft auch bei dem gleichen Individunm. Bisweilen traten nur einfache Zacken auf, deren Anzahl zwischen zwei und vier schwankte. Erschienen sie in größerer Menge, so ordneten sie sich gewöhnlich kreisförmig, nm schräg nach außen zn divergieren. Von iłrem gemeinsamen Ansgangspunkt konnten dieselben sich frei erheben oder sie waren mit ihren Nachbarn durch diimere Kiesellamellen verbunden. Das distale Ende der einzelnen Äste zeigte mitunter (gewöhnlich zwei) zackenartige Fortsïtze, teils gleichzeitig mit eben erwähnten Kiesellamellen, teils bei freien Zacken. Anders gestaltete sich das äußere Ende dadurch, daß nur gewisse Richtungen bevorzugt wurden und ich lerartige Zackenansammlungen an zwei oder drei, manchmal anch vier primären Endästen vorfand. Hierbei komnte es zmr Verschmelznng der sekundä1'en Gebihle kommen, oder dieselben nahmen durch Verlängerung die Form von Ästen an, um ihrerseits num wieder mit Zacken nnd Höckern versehen zu werden. Selbst diese waren bisweilen abermals zu tertiären Ästchen geworden, welche dasselbe Spiel wiederholten. Durch Terschmelznng und weitere Ansätze komnten also die mannigfaltigsten Gebilde entstehen: sehr zier.hiche, die den Vergleich mit den äbrigen Gattungen wohl anshielten, und sehr grob modellierte, die durch massiges Aussehen die Aufmerksamkeit erregten. Ähnlichkeiten in der äuBern Gestalt mit len übrigen Gattungen machten sich wohl geltend, wenı auch nicht in sehn hohem Grade. Aber etwas unterschied sie prinzipiell von ihnen. In den Stachelwandungen war dentlich eine 
Schichtung wahrzmnehmen ('lafel II, Fig. I nnd 2), Arren einzelne Blätter öfters durch einen minimalen Zwischenranm (Luft:) getrennt waren, weleher ein anderes Jichtbrechmosvermögen als die Kiesellage zeignte und nicht selten schwarz nudurchsichtig wurde. Die Schichtenfolge nahm nach dem distalen Ende des Stachels hin \%u nud erstreckte sich anch über die Endbildungen. Ja diese wurken direkt durch dieselben hervorgebracht, inden hier die Schichtung in verschiedenem Malbe und nach verschiedenen lichtungen erfolgte. Die proximalen Enden waren. wenn anscheinend erhalten, wie bei den übrigen grschlossen, liefen jedoch im Gegensatz rn diesen meist in eine langgezogene Spitze aus. Ninchmal endete der stachel auch vollkommen umregelmäßig ('Tafel Il, Fig. 2 und 3), so daß es numöglich ist, hier eine bestimmte Norm anzugeben, wälrend dies doch bei den ïbrigen Genera durchaus der Fall ist. Das was wir bei den iibrigen Anlacanthiden-Stacheln als immern Hohlranm bezeichneten, schien hier ebenfalls vorhanden und endete meist in eine exzentrisch laug ansgezogene Spritze (Tafel 1I, Fig. 1), nicht selten aber war er anch gerade odter schrïg abgeschutten (T'afel II, Wig. 2, 3, 4). Da sich die einzelnen Schichten nun direkt dariber lagerten, so ist leicht einzusehen, dab von der Art, wie der »Flohlnanm《 atuslief, die Gestalt der Endbildungen in hohem Grade abhängig war (siehe 'Tafel I, Fig. 2).

Eine Sonderstellung, wie die Rarlialstachehn, nahnen auch die tamgential gelagerten Stücke ein. Wo sonst ein meln oder weniger dichter Mantel von l'angentialnadeln vorhanden war, da bestanden dieselben ans bald stärker, bald schwächer gekriinmiten hohlen Rölnchen von eben mebbarer Dicke, die verhältnismälibg lang (jedoch wechselnd) und an beiden Enden offen waren. Ander's in tem vorliegenten Fall: Hier fanten sich die verschiedensten Gebilde, die nu das Eine gemcinsam hatten, daß man ihnen eine (auf dem optischen Durchschnit) stïbchenförmige Gestalt zusprechen kounte. Wenn wir einige Exemplare von Aulokleptes nov. gen. betrachten, so finden wir neben gerade gestreckten, anffüllig weiten, anch gekrümmte Röhren, die bald schr kur\%, bald aber anch von ziemlicher Länge sind. Enden die bisher bekamten Tangrentialnadeln einfach offen, so sehen wir hier verschiedenartige Abschhobildungen und Spitzen teils gekrïnmt, teils gerade gestreckt, ganz genan so, wie wir sie bei gewissen Diatomeenschalen finden. Eine nïhere in dieser lichtung angestellte Untersnchmng ergab demn anch, dial.s ich es hier mit solchen Gehänsen su tun hatte. Schalenzeichnmgen nnd vor allem die deutlich sichtbaren 'Teilungsnarben lieben keinen Zweifel darïher. So ganz unerwartet war diese Beobachtnng auch gar nicht. Wurde doch schon angedentet, daß an den Anlacanthiden-Weichkörper sich leicht andere fremde Bestandteile anheften. Her Dr. K. Apstein hatte die Liebenswürdigkeit mir zur Bestimmung dieser Fremdkörper-Dia tom een Literaturangahen, resp. Keichnungen, die er sich ans schwer zugänglichen (wie das ron I'eragallo) Werken koppiert hatte. zur Verfügung zu stellen und mir selbst seine Unterstïtzung zn 'T'eil werden zu lassen, indem el' mich anf das Charakteristische der einzelnen ihm bekannten Formen anfmorsam machte. Meinem Dank fïr seine Bemühungen habe ich hereits an gebührender. Stelle Anstruck gegeben. Ohne T'ergleichsmaterial oder eigene Anschamm ist es schwierig die eimelnen Arten der Diatomeengruppen zu unterscheiden. Ans diesem Grunde wage ich es nicht fïr die vollständige Richtigkeit meiner Resultate in 
dieser Hinsicht einzutreten. Immerhin ist das Vorkommen der Gattungen sicher gestellt, wenn anch die Spezies bei weniger läufigen Formen mit einem Fragezeichen versehen sein mag. Es bleibt dies auch olme Belang, da von diesen A ulacanthiden keine Auswahl bei der Aneignung der Fremakörper getroffen wird. Ich fand die Angehörigen von durchaus verschiedenen Diatomeenfamilien auf dem gleichen Weichkörper. Am läufigsten war die Gattung Rhizosolenia zn beobachten, lamn aber nicht minder selten Thalassothix, anch Symedra glaube ich bemerkt zu haben, wenn schon letztere nicht in freier Form, ein Umstand, welcher in nachfolgendem zur Besprechung gelangt. Von Rhizosolenien waren sehr zahlreich vorhanden die Arten: Rhizosolenia semispina Hensen und Rhizosolenia alata Brightwell, welche letztere in ihren beiden Varietäten auftrat. Dann aber fanden sich auch Schalen von Rhizosolenia calcar aris Schultze, Rhizosolenia obtusa Hensen, Rhizosolenia setigera Hensen, Rlizosolenia hebetata Radley, Rhizosolenia atlantica Y'erogallo, Rhizosolenia styliformis Brightwell. Neben diesen traten auf die langgestreckten Gebilde von Thalassothrix Cleve, vertreten hauptsächlich durch die Spezies Thalassothrix Frauenfeldii.

Bemerkenswert ist, daß meist Einzelstadien sich vorfanden mod zwar kürzere Formen, während Kettenbildnngen und sehr lange Individuen hänfig in anderer Weise ihren Platz erhielten. Eine genane Beobachtung der Radialstacheln bei schwacher Vergrößerung zeigte nämlich, dab das, was bei den übrigen A ulacanthiden-Stachehn den imnern Hohhraum der Röhre darstellte, hier bisweilen aus mehreren Abteilungen bestand, die durch schräg gestellte Zwischenwïnde voneinander getrenut schienen. Die einzelnen Abteilungen glichen in ihrer Gestalt durchaus den tangential gelagerten Fremukörpern. Bei stärkerer Vergrößernng und geeigneter Beleuchtung stellte sich đeun auch heraus, daß diese scheinbaren Teilräume ebenfalls leere Diatomeenschilen waren. Am dentlichsten trat dies an den Enden hervor, namentlich am distalen Abschluß. Trotz der darïber lagernden, neu gebildeten Kieselsänre-Schichten, liek sich doch die chanakteristische Spitzenbildung der verschiedenen Rhizosolenienarten erkennen. Durch sie ward das Bild des spitz zulaufenden, scheinbaren, immern Hohlraums hervorgebracht. Jeder Zweifel schwand, als sich anch hier Teilungsnarben in Gestalt von 'Tränen- oder Handschnhfingerartigen Überresten nachweisen ließen (Tafel II, Fig. 5). Zuerst ließ ich mich durch den überstehenden Rand bei der letzteren Form tüuschen und hielt den Eindruck für eine abgebrochene Nachbarspitze. Eine solche Auslegung findet sich auch noch in meiner vorlänfigen Mitteilung. Inzwischen jedoch wurde ich durch weitere Literaturangaben und den Umstand, daß.3 diese schembar abgebrochenen Spitzen dem doch eine allzu regehmäßig wiederkehrende Bruchstelle zeigten, veranlaßt, neine bisherige Annahme anfaugeben und die Gebilde für Teilungsnarben mit sehr vorstehendem äuRem Rand anzusehen. Luf die Form des Handschulfingers hat bereits V. Hensen (10) hingewiesen. In gïnstigen Fällen traten auch die Spiralen ('Trafel II, Fig. 3) der den Rhizosolenien eigenen Schalenverdickungen anf und auch die Schuppenbildung mit der bezeichnenden Felderung konnte zur Beobachtung gelangen (Tafel II, Fig. 2 und 6). Letztere trat besonders schön hervor, wenn die Schale durch irgend einen Umstand mit Lnft gefiillt war und so einen dunkeln Hintergrund bot. 
Diese Entreckung veranlaßte mich natürlich, alle Stacheln anf ein solehes Verhalten hin zu untersuchen, aber nur die daraufhin neu aufgestellte Gattung Aulokleptes seheint anf diese Weise ihr Skelet zu bilden. Bei dieser Durchmusterung fand ieh dann Teilungsstadien von Rhizosolenien imnerhalb der Stacheln in Menge. Bisweilen war eine Nadel aus drei, sogar anch vier aneinanderhängenden Einzelgehäusen zusammengeset»t. Nieht selten aber auch traf es zu, daß ein Stachel - anch solche von bedentender Länge — aus einer einzigen Rhizosolenie gebildet wareu. Natmgemäb trat ein solches Verhalten ein, wenn die Grundlage der Nadel dureh eine Thalassothrix oder Symedra dargestellt wurde (Tafel II, Fig. 4). In ersterem Falle kounte fast stets eine 'Tordierning des Diatomeen-Gehäuses um seine Längsachse beobachtet werden, was die Untersuchung erheblich ersehwerte. Anch zeichneten sich diese Fälle dadurch ans, daß an den Enden kleine Substanzansammlungen vorkamen, die ich mir nur als Überreste der Kittmasse denten kann, da sie sich ziemlich regrelmäßig wiederholten und nur an diesen Stellen auftraten. Billete eine Thalassothrix oder Synedra die Stachelgrundlage, so kounte das distale und auch das proximale Ende des Binnenraumes natïrlich nicht in eine Spitze auslaufen, wie dies bei den oben erwähnten Fällen angefïhrt wurde, sondern derselbe endete plötzlieh, wie abgeschnitten. Das Gleiche konnte beobachtet werden, wenn nicht ganze, mversehte Rhizosolenien zur Stachelbildung verwendet wurden, sondern Bruchstïcke, entweder von Einzelgehäusen oder von Kettenstadien. Hierbei war dann das Ende ganz willkïrlich gestaltet, wie eben der Bruch es hervorgebracht hatte (Tafel II, Fig. 2 und 3). Da nun die Kieselschichten, welche ron dem Radiolar auf diesem Fremdköper abgelagert wurden, sich der Form desselben anpaßten, war selbstverständlich die Gestaltnng des zum distalen Ende gewordenen Schalenabschlusses von großer Bedeutung auf die Endbildungen des Stachels selbst.

Ehe diese Entstehungsverhältnisse eine genanere Erörterung erfahren, halte ich es für passend, der Frage nüher zu treten, wie solche Fremdlïrper überhaupt zu der radialen Stellung kommen. Hierbei scheint mir vor allem bemerkenswert der schon hervorgehobene Untersehierl in der Länge. Wie wir gesehen haben, bestehen die tangential gelagerten Schalen meist ans kürzeren Formen und Einzelstadien. Nur in ganz seltenen Ausnahme-Fällen treten langgestreckte Gebilde, wie wir sie in der Gattung Tlualnssothrix Cleve kennen, tangential gelagert auf. Es ist dies anch ganz erklärlich, weun wir die Tätigkeit dẹ Pseudopodien in Betracht ziehen, die doch in erster Linie die Ansammlung der Fremdkörper verursacht. An einem knrzen Gebilde finden die Protoplasmafüden leicht in seiner ganzen Ausdehnung Angriffspunkte, um dasselbe dem eigenen Körper zu näheru. Die Folge dieser gleichartigen Anziehung wird sein, dab der Frendkörper sich iiberall mit sciner längsachse senkrecht zur Richtung der P'seudopodien zu stellen sucht, soweit dies möglich ist, und auf diese Weise seine tangentiale Lagerung erhält, die übrigens ja nicht ganz regelmälig zu sein brancht, wie sich jeder durch den Angenschein überzengen kann. Anders wird sich die Sache verhalten, wenn ein langgestreckter Gegenstand in den Bereich der Psendopodien gelangt. Hier wird es stets nur ein Teil sein kömen, an dem die Psendopodien angreifen und wohl in den seltensten Fällen gerade die Mitte. Für gewöhnlich wird das Wasser dem freien Ende des 
Stabes bei der Annäherung Wirlerstand entgegensetzen und hierdurch bleibt dasselbe im Verhältnis zu dem von Protoplasma bereits amflossenen Stücke in der Bewegmng zurück, d. h. der Stab wird sich immer in die Richtung der l'se udopodienachse, also radial, einstellen. So setzt sich anch dem Eindringen in den Körper der geringste Willerstand entgegen. Diese eingebohrten Gebille nun sind es, welche schichtenweise mit Kieselsäure äberkleidet werden, wobei wir sehen, daß dies hauptsächlich an der äubern Hälfte geschieht, und daß, wie bereits gesagt, die Gestaltung des Endes auf die neu entstehende Form von großem Einftuß ist. Bisweilen besitzt der ganze nadelförmige Körper außer dem eigenen also noch einen sekundären Überzug, oder der letztere beschränkt sich nur auf die distale Hälfte (oder Drittel), während im übrigen die ursprüngliche Kieselhülle der Diatomeen in ihrer bisherigen Terfassmg bleibt. Was die verschiedenartigsten Endbildungen anbelangt, so zeigte es sich. daß sie nichts weiter waren, wie nach bestimmten Richtungen hin vermehrte Anhäufung solcher Schichten. Man konnte sozuságen das ganze Werden an fertigen Stachel noch verfolgen, ganz abgesehen von den zahlreichen Zwischenstadien, die sich als solche zu erkennen gaben. Es stand zu erwarten, dab dieses Verhalten äuberst günstig war, am einiges Licht zu werfen auf rlie Skeletbildung bei A u lacanthiden überhaupt. Deshalb glaube ich, dab numehn der Zeitpunkt gekommen ist, auch dieser Frage näher zn treten. Bei ihrer Erörterung werden auch Einzelheiten der Formentstehmy dieser Stacheln geböhrende lirwähnung finden. An die Bilder, welche sie liefern, werden wir uns zu halten haben, wenn wir Schlüsse ziehen wollen für die Formen, bei welchen anf dem Wege ihrer Entwicklung keine deutliche Spuren hinterblieben sind.

Aus dem bisher Besprochenen entnehmen wir als Tatsache, dal.s der Protoplasmaleib der Aulacanthiden befähigt ist, an ganz bestimmten Stellen aufgenommene Kieselsänre wieder abzuscheiden; es geschieht dies anf zweierlei Art: Erstens auf einer bereits vorhandenen kieselsäurehaltigen Grundlage, die aus irgend welcher Ursache in den Körper 'hineingelangt ist, und zweitens ohne jene Fremdkörper, in Gestalt von hohlen geschlossenen Röhren mit mannigfaltiger Ausbildnng am distalen Ende. Bei dem zuerst angeführten Fall können wir fermer konstatieren, daß nur aliejenigen Fremdkörper (in unserm Fall Diatomeenschalen) nit einem sekundären Kieselüberzug ausgestattet werden, welche eine radiire Stellung eingenommen haben, während die tangential Gelagerten ihre ursprüngliche Gestalt beibehalten. Suchen wir nach einem Grund dieser Verschiedenheit, so können wir die Ablagerung von nineralischer Substanz zunächst einmal aus dem Reize herleiten, den der eingedrungene Fremdkörper auf das Protoplasma ansübt. Für diese Erklärung würde der Umstand sprechen, daß die nur angelagerten Stücke von weiterer Überkleiłnng frei bleiben. Dagegen läbt siclı einwenden, daß gerade der in den Weichkörper eingedrungene Abschnitt der Fremdkörper nur greringe oder gar keine Schichtenbildungen zeigt. So können wir die Kieselsäure-Ablagerung wohl nur dem Umstande zurechnen, daß die radiären Stachehn in engste Beziehung zu den Psendopodien danernd treten. Schon bei liswähnung der Endbildungen wurle auf liese Beziehung lingewiesen und im systematischen 'T'eil dieser Abhandhmg werde ich noch einmal darauf zurückkommen müssen. Halten wir den gemachten Unterschied zwischen tangential gelagerten und radiür gestellten Fremdkörpern fest, daß nur das Protoplasma der Psendopodien die Kieselsïnre-Abscheidung 
zu vermitteln imstande sind. Das gelit sclion daraus hervor, daß dieselbe nacl den distalen Eude hin zunimmt und jene kenlenähnliche Form der Stacheln hervorbringt, ferner dab die Endbildnngen gewissermaken die fixierte Gestalt der Psendopodienstrahlung darstellen. Ich glaube nicht fehl zu gehen in der Annahme, dab die Diatomeenschale die liolle eines Katalysators spielt, welcher die von den Psendopodien aus der Ungebung aufgenonmene Kieselsänre wieder zur Absclieilmug veranlabt, so dala letztere kaum orler gar nicht weiter in den Aulac anthidenkörper verschleppt wird. Nur so läßt es sich erklären, dab die tangential gelagerten Schalen, die ja durch ihre Stellung die Beziehungen zn den Psendopodien verloren haben, von der weiteren Terkieselung frei bleiben. Ein reiner WaclistmmsprozeB, wie er bei der Krystallisation statthaft, lïbt sich jednch in unserm Fall nicht feststellen; vielmehr bemerken wir eine Schichtenfolge, welche sich in älulicher Weise vollzielıt, wie wir dies z. B. bei Stärkekörnern sehen. Vielleicht mag das seine Trsache darin haben, dal's die Kieselsäure nicht rein anftritt oder nm als eine Verbindnng, sondern in Form einer innigen Einlagernng in eine organische Substanz, wie ja anch die Diatomeenschale nicht ans einer chemischen Kieselsäure-Verbindung allein besteht, sondern als Grundlage ein Protoplasmaprodukt enthält.

Man könnte sich den Vorgang so vorstellen, daß das als Pseudopodinm dem Fremdkörper entlang tliebende Protoplasma nach anben eine Modifikation allerfeinster Art, wie wir sie ja auch als sogenanntes Ubertlächenläutchen bei Flüssigkeiten kemnen, bildet, welche beim Zurückströmen sich an den Frendkörper anlegt. F. Dreyer hat eine Beobachtung Ter'worn's bei der Pseudopodien bildung veröffentlicht und anch abgebildet (16) (Tafel XVIII, Fig. 57), aus welcher hervorgeht, daß der periphere 'Teil derselben ein anderes Verhalten zugt, als die Mitte, und etwas an Beweglichkeit einbübt. Er bleibt beim Einziehen zuriick und bildet, wenn das innere flüssigere Protoplasma bereits wieder von der Zelle aufgenommen ist, eine kleine Erhöhmng über dem Zellrande. Da in unserm Falle die Diatomee als stütze vorhanden ist, kommt es nicht zu einer Einstülpung, sondern beim Rückflub wird sich diese Anbenschicht als die weniger Bewegliche von selbst an die Unterlage anlegen. Das nachströmende Protoplasma Hiebt dann darüber hinweg, und der Prozel. wiederholt sich. Dieses modifizierte Protoplasma, für welches ich rorlänfig eine Bezeichmmng, wie » Hant«, vermeiden will (es ist vielleicht nichts anderes als ein Ineinandergreifen der Molekularsysteme der beiden in Beröhrung tretenden Medien), bildet nun voraussichtlich die Grundlage für neitere Kieselabscheirhng', wobei die in der Diatome enschale bereits vorhandene vielleicht als auslösendes Mroment fungiert. Fïr die eben ausgesporochene Annahme zeugen die Befunde bei vielen Anlokleptesstacheln. Durch sie läßt sich am ehesten die so dentliche Schichtenbildung erklären. Es kann ja anch vorkommen, daß zwischen einer Schicht und der nächstfolgenden ein schmaler Zwischenraum stellenweise bleibt, was anch sehr zu gumsten meiner Annalume spriclit. Bei den von mir untersuchten Exemplaren waren solche Spalten meist mit Luft (vielleicht auch einer anderen gasförmigen Substanz) gefïllt. In wenigen Fäillen fand sich eine fremdartige feste Zwischenschicht. Anch die Eischeinungen bei den Endbildungen machen eine solche Entstehungsweise wahrscheinlich. Hier kam es natirlich nicht zu einem einfachen Anschmiegen 
an die Grundlage kommen, da das Pseudopodium sich wohl in den meisten Fällen über das Ende der Diatomeenschale hinaus erstreckt. Es mul. also hier beim Einziehen zu Faltungen kommen (ganz ïhnlich. 'wie wir sie bei der von F. D r e yer erwähnten Ver wo rn'schen Beobachtung kemnen lemten). Indem sich die gegenüberliegenden Lagen der Falte entweder ganz oder unter Zurücklaswng eines spaltfömigen Zwischenrams aneinander schmiegen, bewirken sie lappon- oder spitzenfömige Bildungen, wie wir sie an Encle von A ulokleptesstaclı ln walnrnehmen können. Auf diese Weise lälit sich auch am ehesten die Einsenkung der mittleren Partien im Gegensatze zu denjenigen am Rande erklären. Man kann oft noch ganz deutlich am äuBem spitzen Enle der Diatomeenschale drei oder mehrere Ausstrahlungen in Gestalt von spaltförmigen Hohlräumen ('Tafel I, Fig. 5 und Tafel II, Fig. 2) erkemen, welche durch nicht vollkommenes Aneinanderlegen der äubern P'seudopodien-Partien beim Zurückziehen der innern entstamlen sind. Beim Erhärten bilden diese Unebenheiten md Auszackungen wieder die Cirmullage zn nenen Formationen, nur mit den Unterschied, daßs nun an den bereits vorhandenen Stiitzen die neuen Ablagermugen sich wieder mehr in Gestalt von regelmäbigen Schichten absetzen können, wie dies ja anch lüngs der ursprünglichen Schale der Fall war. Anf diese Weise erfolgt das Dickenwachstum und Terschmelzung (wenn die neue Lage zwei benachbarte Erhöhnngen gleichzeitig überzieht, ohme erst wieder eine Einsenkung in dem früheren Maßstabe zn bilden), während Längenzunahme und Neubildungen durch die vorhin erwähnte Faltung zustande kommt. Ein gamz analoger Vorgang, wie iln die Geologie bei der Gebirgsbildung lehrt, nur dal, wir von einer Abtragung und Verwitterung absehen miissen. Auch die zunächst entstanlenen Endfomationen des Stachels werden sich allmählich verdicken, 1 m je mach Gestalt und Protoplasmanenge des Pseudopodiums, resp. Pseudopodienbüschels distal aufs nene Sprossungen zu veranlassen. In je geringerer Menge. das fließende Protoplasma die feste Grmndlage ïberzieht und ïberragt, $\mathrm{mm}$ so regelmäßriger werden die Stachelformen werden, da hierbei wohl am wenigsten Gelegenheit zn Faltungen gegeben wird. Der ersten Entstehnngsart werden die Stachehn von Aulokleptes flosculus (Häckel) und Aulokieptes gemmuscens (Häckel) (Tafel IH, Fig. 1-4, T'afellV, Fig. 1-3, Tafel V, Fig. 1-5) entsprechen, während Aulokleptes corona ('Tafel VI, Fig. 1) mihi wohl der zweiten seine Gestalt zu verdanken hat. (Über beiderlei Formen wird in systematischen Teil dieser Abhandlung noch näher eingegangen werden.) Ebenso sind wohl die astförmigen Endbildungen nach anfänglicher Faltung mehr durch die Protoplasmastrahlung, welche stetig in der Richtung der ersten Faltenachsen erfolgte, hervorgebracht worden.

Daß3 die Kieselsäure, in welcher Form sie auch aufgenommen verde, aus dem Proto1)lasma gleich wierler answcheidet, daran mag, wie gesagt, der Fremdkörper Schuld sein; daß sie nur durch die l'seudopodien aufgenommen, resp. abgeschieden wirl, sehen wir daraus, daß nur deren nächste Ungebung Kieselbildungen anfweist, während sonst der Körper vollständig davon frei bleibt. Würde die aufgenommene Kieselsäure durch den Körper verteilt und erst nachitrïglich ansgeschieden werden, dann wäre kein Grund vorhanden, einzusehen, weshalb die zahlreichen Diatomeenbruchstiicke, die sonst anf der Oberffäche verteilt sind und welche sich anch im Phaeodiun vorfinden, davon frei bleiben. Daß die Nenbildung 
von Schichten anf die Art, wie ich sie beschrieben habe, erfolgt. dafür spricht anch der Umstand, daß wir lisweilen Extravasate innerhalb der einzelnen Latgen vorfinden, die ihrem Aussehen nach nur dadurch entstanden sein können, dab sie nach anhen abgeschlossen wurlen, während sie selbst noch in einem relativ Hïssigen Medium sich befanden. So lange jedoch der Vorgang nicht durch direkte Beobachtung, die nur an lebendem Material erfolgen kann, sicher gestellt ist, sind es nur Vermutungen, die ich im obigen anfïhrte: Vermutungen allerdings, dic seln viel Tihrscheinlichkeit für sich haben, indem einzehe Stadien der Lntstehung gewissermaben fixiert sind und hierdurch Schlïsse zulassen.

Was die Radialstachelentstehmg aller iibrigen Gattmgen anbelangt, so mub ich leider anf eine genügende Erklärung verzichten. Direkte Beobachtungen in lieser Hinsicht an lebenden Material liegen keine vor. Verwchierlene Entwicklungssturlien der Stacheln, wie sie uns bei Aulokleptes entgegen traten, fehlen hier so gnt, wie ganz, mul die dürftigen Anzeichen eines unfertigen Zustandes, wie ich sie bei wenigen Nadeln gefunden zu haben glanbe, reichen nicht ans, eine Mutmaßnng über den Bildungsvorgang daraus zn schöpfen. Wemn auch wohl kaum anzunehmen ist, daß bei den hier in Betracht kommenden Radialnadeln andere Momente fïr die Entstehnng sich geltend machen, als bei denjenigen von Aulokleptes, so sind doch grobe Unterschiede von vornherein zn beachten.

Zunächst fehlt diesen Stachehn, wie die Beobachtung zu lehren scheint, jede kieselig imprägnierte Fremulkörpergrundlage. Wrir sind also hier nicht in der Lage, eine katalytische Einwirkung, wie im vorhergehenden Fall anzunehmen. Es mülite denn sein, daß andere Stoffe dieselbe Wirknng haben. Wir sehen ferner, chab die Radialstachelı eine ziemlieh geränmige Höhlung nmschließen, welche bei den bisher erwähnten von der Diatomeenschale in Anspruch genommen wurde. Wir finden schlieblich außer den Radialstacheln noch hohle kieselige 'l'angentialuadeln, für die vorläufig eine exogene Herkmnft nicht nachgewiesen worden ist. So lange müssen wir sie also als vom Körper selbst abgesonderte Gebilde halten. Es ist dies $11 \mathrm{~m}$ so bemerkenswerter, als wir bei Aulokleptes an den tangential gelagerten Fremdkörpern keine weitere Kieselabsonderung konstatieren konnten. Anf dies letztere Verhalten hin labe ich oben die Vermutung ausgesprochen, dal.s nur das Psendopodien-Protoplasma imstande ist, Kieselsäure abzascheiden. Über die Psendopodienbildung bei Anlacanthiden sind wir noch fast gar nicht muterrichtet. Nur Audacantha scohmmantha Häickel ist genauer lebend mutersucht worden, doch wird anch hierbei von den Autoren bemerkt, daß. der Weichkörper änherst schwer zu sehen und überdies noch meist mit Schmut\% und Schlamm bedeckt sei, sodaß Einzelheiten sich vollkommen verbergen. Ton den übrigen Anlac anthiden wissen wir so viel wie gar nichts in dieser Beziehung und es ist fraglich, ob wir die Psendopodiengestalt und ïberhaupt die exoplasmatischen Bildungen in der Form, wie wir sie bei genauer, anch lebend mutersuchten Radiolarien kennen, sn ohne weiteres anch anf die Aulacanthiden übertragen dürfen. Bildet das sogenannte sarcodictym einen dünnen Überzug oder eine schaumige Masse? Ist es ein Flechtwerk ron Protoplasmafälen? Wir wissen nichts genaneres darüber. An dem mir zur Terfügung stehenden konservierten Material war es natïrlich nicht möglich, die ursprüngliche Struktur dieser l'artien zu 
erkennen. So wage ich es nicht, über die Herkunft der 'Tangentialna deln eine bestimnte Behauptung aufaustellen. Da sie hohl sind und äulberst dünn und fein, so könnte man annehmen, daßs sie Protoplasmafüden ihren Ursurung verdanken. Ob dieselben sich aber da atusplannen, wo wir die Nadeln als verfilztes Gewebe finden, ist bei toten Tieren nicht zu ermitteln. Es wäre ja auch möglich, dali. sie mehr peripher entstünden als Ausscheidung von Fäden, welche mit den Psendopodien in direkter Beziehung stehen. Diese werden eingezogen oder rerschwinden sonst und lassen als Überrest die Röhren zurïck, welche sich mit andern bereits vorher gleichartig entstandenen allmählich un den kompakteren Weichkörper ansammelt, mit der Zeit einen dichten Mantel bildend. Die Beobachtnng, daß wir bald Indiriduen mit einem Schleier von zahlreichen Nadeln erblicken, bald solche, wo sich erst wenige lährchen auf der Oberflüche des Weichkörpers abgelagert haben, würde der gemachten Annahme nicht widersprechen.

Was nun die Radialstachelbildmng olme zugrunde liegenden Fremdkörper anbelangt, ist es weniger die äuBere Gestalt, welehe einer Erklärmg Schwierigkeiten bereitet, als viehnehr der innere Hohlranm des Stachels. Die Dreyer'sche Gerüstbildungstheorie beschäftigt sich wohl mit der äulbern Form, sie lälst ms aber im Stich, wenn wir nach einer Erklärmng dafür suchen, wie der immere Hohlranm des Stachels und seiner Adnexa, soweit diese nicht ans kompakter Masse bestehen, zustande kommt. Wemn nach eben genannter Theorie die Skeletstücke der Radiolarien teilweise verkieselte Berührungskanten und -Flächen durch gegenseitigen Druck polyëdrisch gewordener Blasen und Bläschen sind, deren Begrenzungrsflïche ans Protoplasma zumächst gebildet wird, so gibt uns das keinen Aufschlul., darüber, wodnrch der Hohlranm wieder innerhalb dieser Hartgebilde entstanden ist. Man könnte hierbei ebenfalls an Vakuolen denken, mit welchen ja der A ulacanthidenkörper nach Mitteihụng der Beobachter reichlich ausgestattet ist. Soweit diese Höhlung für den Stachelstab in Betracht kommt, ist eine solche Annahme nicht direkt von der Hand zu weisen. Die Beobachtung zeigt, dal. bei allen Narleln die Spindelform die häufigste ist, wenn auch bisweilen sehr langgestreckt. Selbst dis, wo äußerlich eine zylindrische oder schwach kenlenförmige Röhre mit ge:chlossenen Enden auftritt, bewahrt der innere Hohlraun seine Spindelgestalt. Die Wandungsdicke nimmt nämlich in den meisten solchen Fällen nach dem distalen Ende hin zu, so daß die stattfindende Verjüngnng des imnern Hollranms wieder ansgeglichen wirl, ja sogar dadurch, daß die Verdickung der Wandung noch weiter fortschreitet, kann trotz des sich hier verengernden innern Hohlranms sogar ein keulenförmiges Gebilde entstehen. Ich erwähne diesen Unstand deshalb, weil man sich die Spindel ans einer sonst kugelförmigen Blase durch Zug an zwei entgegengesetzten Punkten entstanden denken kamn. Dieser Zug wäre in zentrifugaler Richtung durch ein sich ausstreckendes Psendopodium, in zentripetaler durch die Kohäsion les gesamten Radiolarienliörpers erklïrbar. Für diese Annahme ist anch noch die Voransetzung zu machen, daß diese Streckung des Hohlraums zur Spindel stets noch innerhalb des eigentlichen Körpers und unter gleichzeitigem seitlichen Druck stattfindet, da sich sonst die Oberflächensfannung geltend machen mülste. Nun haben wir allerdings Anzeichen dafür, dab, wo der Seitendruck anfhört, eben diese Oberflüchensuanmung die Oberhand gewinnt, indem gerade 
am distalen Ende kolbenförmige Auftreibungen, z. B. bei Aulocoryme und einzelnen Formen von Aulospathis, zu beobachten sind. Der röhrenförmig zurïckgebliebene liest des Stachels mïßte seine Erklärung einerseits in einen Reibungswiderstand, andererseits in dem dort noch zur Geltung gelangenden, zentripetal wirkenden Zug finden. Dab trotz der ausgesuriten Pseudopodien noch ein zentripetaler Zug, ler sich gleichzeitig in tangrentialem Seitendruck äulucrt, vorhanden ist, geht aus folgender Überlegung hervor: In ler äubern Gestalt des nackten Protozoenkörpers halten sich Kohäsion und Adhïsion (der Bezng anf das nmgebende Medium) das Gleichgewieht. Sind beide allerorts gleich wirksan, so mnß ler Körper, den Gesetzen der Oberflächenspannung gehorchend, Kugelgestalt annehmen. Bei örtlicher ungleichnäBiger Verteilung der einander entgegenwirkenden Kräfte wird es zu Erscheinungen kommen. wir wir sie in der Psendopodienbildmg kennen lernen. In dem gleichen Maßse wie durch die Adhäsion ein Ausfließen des Protoplasmas an einer bestimmten Stelle stattfindet, zieht sich der Körper, gleichbleibendes Volumen vorausgesetzt, im übrigen zusammen, d. h. die Kohäsion sucht das Gleichgewicht zn bewahren. Würde die Adhäsion ïberall überwiegen, so müßte in gleicher Weise die Kohäsion abnehmen, (1. L. der Zusammenhang des Körpers sich lockern, um in dem Angenblick, wo die Kohäsion gleich Null wird, in Lösung des mmgebenden Mediums überzugehen. Das Gleiche mübte geschehen, wenn die Adhäsion in einer bestimmten Richtung nnendlich grob wird. Hierbei mühte sich ein ansgesandtes Pseudopodinm ins Unendliche strecken, was gleichbedentend mit der Anflösung les Körpers ist, der ja nur ein begrenztes Volumen besitzt. Da die Pseudoporlien eine gewisse Länge nicht ïberschreiten, muß eine Kraft der Adhäsion entgegenwirken, es mul., also ein Zug in zentripetaler Richtung trotz des Pseudopodimms noch vorhanden sein. Gleichzeitig wird an derselben Stelle der Seitendrnck erhöht. (Natïrlich bezichen sich diese Betrachtungen nur auf Lebewesen, die ïberall von einem fliissigen Mediun umgeben sind.) Wie gesagt, soll mit dem Erwähnten keine Behauptung aufgestellt werden, da wir keinen Anhaltspunkt an tatsächlichen Beohachtungen haben. Einer solchen Auffassung stellt sich anch die Schwierigkeit entgegen, dah bei manchen Formen Lindund Seitenäste vorhanden sind, welche, ebenfalls hohl, mit dem Binnenram des Stachels in Zusammenhang stehen. Bei der schleimigen Beschaffenheit iles Protoplasmas, über dessen physikalische Eigenschaften wir in dieser Hinsicht noch wenig wissen, wäre es vielleicht möglich, dal.) die von Schleim gebillete Blase zu solchen Gebilken ansgezogen werden komnte. Bereits vorhin erwähnte ich solche wahrscheinlich vorhandenen inneren Reibungen, die möglicherweise die Oberflïchenspannung modifizieren. Die Entstehung dieser Seitenäste ist ja anfs engste mit der Psendopodienbildung in Znsammenhang zu bringen. Gerade im Anschlul.s an die klebrige Beschaffenheit des Protoplasmas möchte ich noch anf einen Unstand hiuweisen; der sonst leicht zu Bedenken Veranlassung geben kann. Nan nimmt an (fiir Aulucantha scolymanthu ist dies durch Beobachtung festgestellt) daßi. lie Stachehn beim lebencien Tier ïljer die Oberfiäche des Weichkörpers hervorragen, also an dieser Stelle kenem durch die Kohäsion hervorgerufenen seitlichen Druck mehr ausgesetzt sind. Trotzdem bemerken wir nichts. Was die Wirkung eine Oberflüchenspannung deutlich machte (mit Ausnahme der vorhin erwähnten Formen). Es ist dies ein sehr schwer wiegender Einwand gegen die bisher erörterte Annahme. Allerdings 
wissen wir nicht, ob diese Stellung der Stacheln die gleiche auch während ibrer Bildungsperiorle ist; ferner muß, wie bereits bemerkt, die Konsistenz des Protoplasmas berücksichtigt werden nud drittens haben wir nichts zu vergessen, daß es ja allem Anschein nach nur die Endbildungen sind, welche sich in die eigentlichen Pseudopodien hinein erstrecken. Bei Aulacantha scolymantha, von welcher allein genauere Beobachtungen in dieser Hinsicht vorliegen, haben wir als Lndbildung rie ganze Strecke zu betrachten, welche mit Zähnehen besetzt ist nnd imnerhalb dieses Abschnittes zeigt anch der Hohlranm keine regelmäBigen Wandungen mehr, indem er ron den Zähnchen in Mitleidenschaft gezogen wirk. Im Prinzip liegt also hier walhrscheinlich derselbe Vorgang zngrunde, wie bei den Stacheln mit hohlen Endästen.

Weit weniger möchte mir die Annahme bezïglich der Stachelentstehung zutreffend erscheinen, welche sich den Hohlram ursprünglich als Protoplasmastrang denkt, welches nach Abscheidung einer Wandung nach außen sich aus dieser Hülle wieder größtenteils zurüickgezogen habe. Etwas Ähmliches setzten wir ja bei der Entstehung der Tangentialnadeln voraus. Da liegen die Verhältnisse aber anch wesentlich anders. Bei diesen feinen Röhrchen haben wir es wahrscheinlich mit Protoplasmasträngchen zn tun, welche außerhalb des eigentlichen Körpers in irgencl einer Weise ausgespannt sind. Hier haben wir eine richtige Grenzschicht und können uns ganz gut denken, claß der Faden nach außen eine Membran, die sich später verkieselt, abscheidet. Geht der Faden ein, so bleibt die leere Röhre anf dem Körper liegen. Daß diese Gebilde ohne protoplasmatischen Inhalt für gewöhnlich sind, lat schon R. Hertwigg beobachtet. Anders verhält es sich mit den Radialstacheh. Hier sind es nur die distalen Enden, welche noch in protoplasmatischen Zustand als Psendopodien eine Grenzschicht bilden. Wohl könnten wir auch im Körper eine solche annehmen, wenn wir das Vorhandensein von Vakuolen in Erwägung ziehen. Der Protoplasmastrang bildete damn die Zwischensubstanz zwischen den einzelnen Vakuolen. Damn aber ist nicht verständlich wie der Stachel zn seiner glatten Oberfläche kommt. Es mübten damn Verhältnisse eintreten, wie wir sie bei manchen Endbildungen vorfincten, ganz abgesehen davon, daß diese Erklärung vollkommen versagt, sobald wir den 'T'eil des Stachels ins Auge fassen, welcher sich nicht mehr im eigentlichen Körper befindet. Auch die ganze Form des Stachels ließe sich nur schwer mit der eben erwähnten Annahme in Finklang bringen.

Der zuerst angefühnte Enklärungsversnch, wie namentlich auch dieser zweite machen keinen Anspruch daranf, die wissenschaftliche Grundlage für weitere Untersuchnngen zn bilden. Der Zweck ihrer Erörterung ist lediglich der, die Möglichkeiten angeführt und, so gut es mit wenigen Worten ging, ihre Berechtigung kritisiert zu haben. Dab damit alle erschöpft seien, behaupte ich nicht. Vielleicht hilft alser das Erwähnte auf eine neue richtigere Spmr. Auf einer solchen glanbe ich mich betreffs der Entwickelung bei Aulokleptes zu befinden. Wie dort, so werden wir anch hier in der Psendopodienbildung die Entstelungsursache des Radialskelets zn suchen haben.

Im Torangehenden habe ich stets von »Hohlraum《 gesprochen. Es bleibt noch zu untersuclsen, ob wir es wirklich mit einem leeren Raun in diesen Fïllen zn tun haben. Es dürfte das Resultat eines solchen Erörterung anch sehr für die Entstehnngsfrage in Betracht 
kommen. Soweit meine Beobachtungen reichen, glaube ich einen flïssigen lnhalt annehmen zu kömren, wenn derselbe anch beim ansgebildeten Stachel nicht mehr den ganzen Raum in Anspruch nimmt. Der Umstand, daß ich in vollständig geschlossenen Stacheh Gasblasen beobachten konnte, sprricht dafür; denn wäre 11 n. Gas in den Röhren, dann nüßBte dasselbe sich im ganzen Raum gleichmäßig verbreiten. Anch L. Häckel bildet Stachehn ab, in welchen Gasblasen erkennbar sind. Allerdings geht aus den Fignren nicht herror, ob dieselben wirklich ganz muverletzt und nach außen abgeschlossen waren.

Brandt bemerkte bei Versuchen, die er in Neapel an Aulacanthiden vornahm, daß sich bei Linwirkung von Säuren Gasblasen immerhalb der Stachehn und TangentiahnadeIn entwickelten. Auch verringerte sich die Wandungsdicke meist bis auf lie noch eben sichtbaren Konturen der Röhren. Die Gasblasen verschwanden später wieder. Ich erkläre nir dies Phänomen durch die Anwesenheit von Flüssigkeit in Stachelhohlraum, welche durch die bei den vorgenommenen chemischen Reaktionen freiwerdende Wärme teiweise in Dampfform umgewandelt wird. Nach erfolgter Abkiihlung kondensiert sich der Dampf wieder und lieraus erklärt sich das Verschwinden der Gasblasen. Was die Vermindermg der Wandungsdicke anbelangt, so geht daraus hervor, daß dieselbe nicht überall aus Kieselsänre bestehen kann, sondern daß nur die änßerste Schicht damit imprägniert ist. Merkwürdig scheint der Umstand, daß gerade die äußere Kontur erhalten bleibt. Ls sind da zwei Möghichkeiten vorhanden: Entweder durchdringt die angewendete Sänre die Stachelwandung und wirkt lösend anf den Wandbelag, als was wir demnach die scheinbare ïbrige Wandungsdicke anzusehen haben. Oder aber das Verschwinden des letzteren und damit das Dünnerwerden der Wandung ist eine Folge der sich entwickelnden Wärme, dmch welche der flïssige Inhalt ein größeres Lösungsvermögen erhält. Für die erste Amnahme spricht die Tatsache, daß der Wandbelag nicht wieder zum Torschein kommt, was bei einer Lösung durch Wärme allein beim nachfolgenden Erkalten doch geschehen miißte. Das Durchdringen der Säure durch die Wandung halte ich wohl für möglich, da die Kieselverbindung ja keine vollstïndig znsanmengeschlossene Masse bildet, sondern, wie bereits früher hervorgehoben wurde, eine allerdings selır dichte Einligerung in eine organische Grundsubstanz clarstellt. Die Vermengming ist dabei eine so innige, dal.s eine Intfernung einer der beiden Komponenten nichts an der änßern Form ändert. Dasselbe können wir ja bei kieselhaltigen P'flanzen, wie z. B. Diatomeen beobachten, wo nach Zerstörung der organischen Substanz durch Hitze keine Ver̈̈nderung des Aussehens erfolgt. So kann anch die Säure durch Zerstörung der organischen Grundlage meines Erachtens ganz gut auf den Inhalt des Stachels wirksam werden. Die Wärmeentwicklnng mit ihren Folgeerscheinungen ist darum nicht ausgeschlossen. Daß die Hohlstacheln nicht vollkommen leer sind, läßt sich aus Einschlïssen entnehmen, die bisweilen als fein snspendierte Massen auftreten. Auch E. Häckel scheint derartige Beobachtungen gemacht zu laben, wie aus einigen seiner Abbildungen hervorgeht. In einigen wenigen Fïllen bemerkte ich bei Formen, welche sonst massive Endbihhngen besaßen, daß bei einzehnen diese im tnnerı wie zerfressen aussahen. Vielleicht handelt es sich hierbei wirklich um einen Auflösungsprozeb. Ob dabei die Anwendung gewisser Reagentien, welche frülıer stattgefunden hatte, Schuld war, ist fraglich. Es 
bestand bei solchen Stacheln (ich konnte es nur bei zwei Exemplaren bemerken) ein enger nuregelmäßig hohler Gang, vom Binnenraum der Tube ausgehend, welche sich unregelmäBig in Auslänfer verzweigte. In mehreren anderen Fällen war die Oberfläche des Stachels wie marmoriert und mitunter wie mit feinen Sprüngen durchsetzt. Möglicherweise haben wir es hier mit Stadien zn tnn, bei welchen die Ablagerung der Kieselsänre eben erst begonnen hat und deshalb noch sehr nnregelmäBig verteilt ist.

Damit glanbe ich alles erwähnt zu haben, was im allgemeinen iiber den Bau und die plıysiologischen Verhältnisse der Aulacanthiden anzuführen ist. Einzelheiten werden gelegentlich der speziellen Beschreibung noch folgen, der wir uns nummehr zuwenden wollen. 


\section{Spezieller 'Teil.}

\section{Systematik.}

Mit Bearbeitung der Radiolarien der ChaLbexgek-Expedition hat E. H ä ckel anch gleichzeitig das erste grundlegende System für dieselben geschaffen und damit auch den Anlacanthiden ihren Platz im Protistenreiche angewiesen. Wie wir gelegentlich der Angabe der listorischen Daten gesehen haben, war es die Legion der Pl a eodarien, welcher H. Häckel unsere Familie endgültig unterordnete. Weitere Betrachtungen haben uns des Näheren ïber' die morphologische und physiologische Bedentung des Phaeodiums, soweit unsere hentigen Kenntnisse reichen, anfgeklärt, welches die Veranlassung zu der Bezeichnung gegeben hat. Vorher bedeutete der Name Punsolenic für die gleichen Formen den Besitz eines Skelets von hohlen Kieselröhren, während die von E. Häckel in späteren Jahren vorgenommene Umändertung in Camopylea darauf Bezng nahm, daß die Hauptöffnumg der allen diesen Tierformen zukommenden Zentralkapsel einen rüsselartigen Fortsatz trägt. Die Gründe, weshalb E. Häckel von den beiden letztgenannten Bezeichnmgen abging, hat er in seiuer Monographie der Radiolarien lilargelegt. Der Name 'Tripyleen stammt, wie auch bereits kurz erwihnt wurde, von R. Hertwig. Er legt Wert auf das Torhandensein von einer Hanptöffunng und zwei Nebenöffnungen in der Zentralkapsel. Anch dieses Verhalten hat seine eingehende Betrachtung in vorhergehenden Abschnitt gefunden. Ich sah mich jedoch verantaßt an dieser. Stelle nochmals daranf zurückzıkommen, weil jede dieser Bezeichnungen für die Familie der Anlacanthiden in systematischer Beziehming verwendbar wäre. Es gilt jerloch mur für diese. Nach A. Borgert dïrfte die richtigste allgemein giiltige Benennung die der 'Tripyleen sein. Torderhand jedoch, bis wir zur Anfstellung eines revidierten A ulacanthidensystems gelangen, mögen beide Bezeichnungen l'haeodarien und 'Tripgleen gleiche Berechtignng laben.

Wie alle bisherigen Bearbeiter dieser Gruppe die Einteilnng E. Il äckel's ihren Ausführungen zugrunde legten, so wird anch hier von diesem rystem ausgegangen werden, wie dies ja anch in der Tat bei meinen Untersuchungen geschehen ist. Erst im Verlanfe derselben stieß ich auf Schwierigkeiten, fand in der Literatur Bestätigung meiner Vermutungen und wurde schließlich durch eigene neue Beobachtungen und Überlegungen veranlaßt, eine Änderung. vorzunehmen, die äußerlich vielleicht nicht bedentend scheint, im Prinzil' aber durchgreifend 
ist. Damit dies dentlich werde, möge die Einteilung E. Häckel's zunächst angefülnt werden und eine nähere Besprechung finden.

Bekanntlich liat E. Häckel mehrere Einteilungsversuche gemacht. Hier soll nur der zeitlich letzte, im Chablenger-Werk und der Monographie der Radiolarien veröftentlichte, als der Endgültige, den Ausgangspunkt für msere Erörterungen bilden, wie ihn anch A. Borgert seiner Bearbeitung der nordischen Tripyleen zugrunde legte und zwar um die neneren Untersuchungen mit eimbeziehen zu kömen, in der Form, wie sie von A. Borgert in der eben genannten Publikation Anwendung gefunden hat.

\section{A. Tripyleen Hertwig 1879 \\ (Phaeodaria, Cannopylea, Pansolenia Häckel).}

Radiolarien mit doppelter, ans einer derberen Hetocapsa und einer feineren Endocapsa bestehender Zentralkapsehmembran, die drei Öffnungen aufweist: eine Hauptöffnung (A stro p y le) umd zwei Nebenöfnungen (Paraplen). Im Extracapsulnm das aus Ausscheidungsprodukten des Tieres amd Nalnrungsresten gebildete, meist braun oder braungrïn gefärbte Pha eodium, das besonders die durch die Hanptöffunng bezeichnete orale Hälfte der Zentralkapsel bedeckt. Sie zerfallen in vier Ordnungen:

I. Phaeocystina,

II. Phaeosphaeria,

III. Phaeogromia,

IV. Phaeoconchic.

Fiir nus kommt die erste in Betracht:

\section{T. Ordnung: Phaeocystina.}

Skelet fehlt oder besteht aus einzelnen Stiieken:

a) Skelet fehlt rullstämlig ................... Phaeodinida.

J) Skelet ans zahlreiehen isolierten Nadeln, Ringen oder Gitterstäeken bestehend . . . . . Cammomhapliila.

c) Skelet ans zahlreichen einzelnen, von der Zentralkapsel radiär nach allen Seilen ausstrahlenden Stacheln gebildet: anferdem meist noeh ein dichter Mantel aus tangential gelagerten feinen Röhrehen . . . . . . . . . . . . . . . . . . . . Anlacanthida.

1. Familie der Aulucarthida.

a) Rarlialstacheh einfaeh, zylindriseh oder spindelförmig, ohne Lateral- nnd Terminaläste:

๔) Ohne Mantel ron tangentialen Nadeln. . . . . . . . . . . . . . Genus: Aulactinium.

ß) nit einem diehten Hantel von verwebten, hohlen, tangentialen Nadeln. . . . Genns: Iulacantha.

1) Radialstaeheln ohne laterale, aber mit einem Quir] oder einer Krone von Terminalästen. Tangentialnadeln vorhanden:

«) Terminaläste der Radialstaeheln einfaeh . . . . . . . . . . . . Genns: Aulographis.

ß) Terminaläste der Radialstaeheln gegabelt oder verästelt. . . . . . . . . Genus: Auloceros.

c) Radialstacheln mit lateralen nnd terminalen Asten. T'angentiahadeln vorhanden:

a) Lateraläste der Radialstacheln quirlig angeordnet . . . . . . . . . . Genus: Aulorpathis.

B) Lateraläste der Radialstaelıeln unregelmäBig zerstrent stehend, nieht quirlig angeorduet Geuus: Aulodendron. 
Es scheint vielleicht etwas weitlïnfig, daß bei Aufführung des $1 /$ ï ckel'schen Systens, soweit es für die Familie der Aulacanthiden in Betracht kommt, anch die iibrigen ron dem Antor zur Ordnung der Phaeocystima gerechneten Familien der Thaeodiniden und Uannorrhaphiden Erwähnung fanden. Wir werden aber sehen, daß ihr Charakteristiknm sich sehr wohl im folgenden verwenden läßt, indem wir sie als Übergänge auffassen können, die an die nen anfznstellende Gattung Aulokleptes anknïpfen, welche ihrerseits einen stammesgeschichtlichen Übergang zu bezeichnen scheint. Nach A. Borgert sind die ron E. Iläcke] als Phaeodinida bezeichneten skeletlosen 'l'ripyleen augenscheinlich nur jugendliche Individuen von skeletfïhrenden Formen, die noch keine derartige Stïtzsubstanz ausgebildet, in anderen Fällen vielleicht anch 'Tiere, welche dieselbe durch irgend welchen Zufall cingebüßt haben. Ebenso $\mathrm{nm}$ eigentlich skeletlose Individuen handelt es sich nach dem gleichen Autror bei Cannorrhaphiden, da die Untersuchungen ergaben, daß die bei Cannorrhaphiden gefundenen Skeletstiicke keine Eigengebilde, sondern Fremdkörper und zwar Kieselgehänse von Silikoflagellaten sind. Anch hier haben wir es also mit ursprünglich skeletlosen Formen zn tun. Die Ergebnisse meiner Untersuchungen, die zur Anfstellung der Gattung Aulokleptes fülırten, sprechen selır zugunsten dieser Amnahme. Anch hier setzen wir ja zunächst unbewehrte Jugendstadien voraus, welche später Fremdlörper aufnehmen, aber es nicht nur beim Agglutinieren bewenden lassen, sondern dieselben teilweise durch eigene Ausscheidungsprodukte umformen und damit gewissermalien zu Eigengebilden machen. I) nicht in Radialstacheln umgewandelte Rest an Diutomeenschalen bleibt tangential gelagert und repräsentiert somit den Entwicklungszustand der Cannorhaphiden, bei welchen allerdings nach den bisherigen Befunden nicht Diatomeen die Hartgebilde liefern. Wir haben es also bei Aulokleptes mit einer höheren Stufe der Spezialisierung zu tun, welche uns hinïberleitet zu den voraussichtlich echten Eigenskeleten der übrigen stachelbewehrten Anlacanthiden. War somit die Anführung dieser beiden Familien gerechtfertigt, so werden die folgenden Darlegungen die ansführliche Wiedergabe der Häckel-Borgert'schen Charakterisiernng der einzehnen Gattungen verständlich erscheinen lassen.

Wie wir darans entnehmen, hat sich E. Häckel in seiner systematischen Übersicht der Genera hauptsächlich, ja man kamn sagen ansschließlich anf die Endbildungen der Stacheln gestiitzt, die ja allerdings als solche sehr in die Augen fallend sind, aber bei dem Spielranm, welcher dem Variieren der Arten bei diesen Genera gegeben ist, sehr leicht zu Unklarheiten Veranlassung geben können, die eine Unterscheidung sogar der Gattungen nach diesem Prinzip) erschweren. Wie wir in einem früheren Abschnitt gesehen haben, lälit sich nicht immer der fertig ansgebildete Zustand des Stachels als solcher erkemen, da weiterhin durch Auf- und Anlagermng von Kieselsäure Nenbildungen entstehen können, so duß wir nicht immer im stunde sind, eine Bildung als wirklich definitive anzusprechen. Auf diese Weise kam es vorkommen, daß Stachelformen bei ein- und demselben Individumn zur Beobachtnng gelangen, welche die Charakteristika nicht nur verschiedener Arten (in der bisherigen Anorinung), sondern sogar verschiedener Gattmngen zeigen. So ist es zum Beispiel keine Seltenheit, daß Aulographis pundora Häckel bisweilen sekundäre Verästelungen (siehe Häickel's Radiolarienwerk) bildet und so 
kanm $7, n$ unterscheiden ist von bestimmten Formen von Auloceros. Eimen ähnlichen Fall finden wir bei Aulographis triaena Häckel, wo ebenfalls das Unterscheidungsmerkmal, Seitenstachel und Seitenast, vollkommen als solches verwchwinden kamn, so daß eine Identität mit Auloceros Häckel vorgetäuscht wird. Häckel selbst spriclıt gerade in letaterem Falle von Übergängen, während bei Zugrundelegung des im folgenden anzuführenden Einteilungsprinzipes von einem solchen absolut nicht die Rede sein kann, de facto auch nicht statthat. Es handelt sich hierbei nur um morphologische Konvergenz; der Weg, der zu dem älmlichen Formenzustand geführt hat, ist ein durchaus verschiedener. Selbstverständlich sind bei den angeführten Beispielen nur die von Häckel mit diesem Namen bezeichneten verstanden, Artbezeichnungen, die ich zwar im folgenden tunlichst beibehalten habe, aber des öfteren zu beschränken mich genötigt sah.

Die Aufstellung der Gattung Aulokleptes, welche so wie so eine Änderung im bisherigen System veranlaßt hätte, wurde durch Beobachtungen herbeigefïhrt, die bereits in einem frïheren Abschmitt behandelt worden sind. Sie lenkten mein Angemmerk darauf, mehr der Stachelentstehung als der Gestalt nur als solcher bei einer Unterscheidung Wert beizmessen. Tch suchte die Faktoren ausfindig zu machen, durch welche sich dieser Bildungsgang auch durch ein sichtbares Zeichen dokumentierte. Gelegentlich der Besprechung der Wachstums- und Vermehrungserscheinungen beim Skelet sah ich mich schon veranlaßt, auf die Ausbildung des Hohlraums im Stachel Gewicht zn legen: Er ist es ja schon, ron dem die Anlacanthiden ihren Namen herleiten; anch nach der bisher angewendeten Methode bei der Benenmung liegt in der für die Zngehörigkeit zur Familie maßgebenden Wortsilbe 》Anl-« ja schon eine gewisse Bedentung, die nicht zu mnterschätzen ist. Wir werden sehen, dah eine genane Beobachtung des Stachel-Hohlraums, in Beziehnng zm änBern Form gebracht, ein ganz brauchbares Mittel abgibt, um die einzelnen Genera unterscheiden zu können. Dabei ist der Vorteil gewahrt, daß eine hierauf beruhende Einteilung auf die Entstelnung und damit auf die Stammesgeschichte und natioliche Terwandtschaft lïicksicht nimmt. Die Beobachtungen lehren, dal, skeletführende Formen aus skeletlosen hervorgegangen sin $\left(,^{1}\right)$ indem letatere zunächst Fremdkörper an ihrer Körperoberfläche festlegten. Aus bereits erörterten Gründen wurden einzehe solche radiär gestellt und gelangten so in eine Sphäre, welche ihre teilweise Überkleidnng mit Kieselwäure ermöglichte. Eine zentrifugal fortgesetzte Substanzvermehrung führte zur Ausbildung von Terminalverzweigungen. Durch Vererbung haben wir es zu erklären, đaß eine selbständige Stachelbildung ohne fremrle Grundlage zustande kam, zmä̈chst mit nur hohler Röhre, aber soliden Endbildungen, welche noch des Wachstums durch weitere Substanzablagerung nicht entbehrten. Diese wurde allmählich anfgegeben und schließlich war die änfere Form im Prinzip soweit fixiert, daß sie gleich bei der Stachelentstehung mit in Betracht kam, daß nun also auch die Endbildungen, gleich dem Stachel selbst, mit einem Hohlram versehen sind. Wie bereits früher näher erörtert, kommt hierbei wohl den Vakuolen eine Bedeutung zu, die vielleicht üherhanpt die röhrenförmige Gestalt des Stachels veranlassen. Was nun die äußere Form dieser Endbildungen anbelangt, so haben wir gehört, dab sie hauptsächlich hervorgerufen

1) Sehr lehreich ist hierfür die Entdeckung A. Borgert's bezüglich des Skelets von Spongornymms (siehe Literaturverzeichnis 36 ). 
wird durch die Art und die Richtnng, nit wehcher die Pseudopodien in das umgebende Medium ansgestreckt werden. Diese sind also der zwejte Faktor, mit welchen wir zu rechnen baben. Schon daraus geht hervor, daß es weniger zahlenuähige Angaben sein werlen, anf welche wir bei Beschreibung der Endäste Gewicht zu legen haben, sonrlern dab es neben der innern Beschaffenheit vor allem anf die Gestalt, ferner anf die kichtungs- und 'Teihungs-, resp. Terschmelzungstendenz der Ps ud o podien ankonmt, welche dieses Bestreben ihrersuits anf die Stacheln ïbertragen. Erst wenn die Anzahl del Endstachehn und Endäste sich bei einzehen Formen einmal vollständig durch Weitervererbung fixiert haben werden, ist es nöghlich und auch nötig, darauf Budacht zu nehmen. Dann wird aber auch eine höhere Stnfe der Entwicklnng erklommen sein. Voränfigr können wir bei Anzahldifferenzen nur von Tarietïten sprechen. Kommen dieselben doch hänfig grenng bei ein und lemselben Individnum ror, und gehört es zu den Seltenheiten bei gewissen Formen, daß, ein 'Tier bei ałlen seinen Stacheln wirklich einen reinen 'Typus bewahr. Wo sich eine bestinmte Ciestalt oder Anzahl von Terminalbildungen für einzelne speries abgrenzen lassen, wird bei der weiter unten folgenden Einteilung Räcksicht genommen werken mïssen; aber in erster Iinie haben wir unser Angenmerk auf die Gestalt $n \mathrm{ng}$, das heibt anf das Bildungsprinzip zu lenken; denn die angenommene Regelmäßigkeit wird vorłänfig mur Geltung haben für die beschränkte Zahl der wirklich beobachteten lixemplare. Jede Zmnahme des Vergleichsmaterials kann hier ̈̈nderungen bringen. In Häckel's Radiolarienwerts sind so mehrere Nadeln besclnielsen und abgebildet als zu verschiedenen Spezies gehörend, die ich nicht nur einmal, sondern res öfteren auf rem gleichen 'Tier nebeneinander gefunden habe. Dies trifft beispielsweise zn für die Häckel'schen Arten: Aulographis pistillum, Aulographis flosculus und lulographis murtugon, die nach meiner Einteilung nur verschiedene Ausbildungsstadien ein und derselben Aulokjejtesart (Aulokleptes flosculus (Häckel) mihi) darstellen, ałso auch ganz gut gleichzeitig nebeneinander vorkommen können, wenn wir im Ange behałten, wie der Aulokłeptesstachel sich aufbant. Wem zufällig der gleiche Ausbiłknngsgrad bei allen Stacheh eines 'Tieres erreicht ist, sei es nun ein fribherer oder späterer (von einem endgiiltigen kann nur in wenigen Fällen gesprochen werdeii), clann dürfen wir allenfałs von einem solchen Jxemplar als von einer Tarietät sprechen, aber selbst liese Anschucksweise ist nur erłanbt als Notbehelf, um ein solches Stalinm sprachlich zu fixieren. Wir haben eben in manchen Fällen wahre Kollektivtypen vor uns, die bald dieses, bals jenes Aussehen melir zur Geltung lsommen lassen.

Wie mich der Umstand, dal. das Hanptgewicht anf die Ausbihdung des Hohlranms der Stachehn zu legen ist, zur Anfstellung des Genus Aulokleptes veranlalite, so sah ich mich anch genötigt, eine weitere Umgruppierung vorzunehmen, indem ich eine von G. H. Fowler einst aufgestellte, aber von A. Borgert kassierte Gattung wierler zur Geltung brachte. Sie betrifft abermals einen Teil des bunt zusammengewürfelten Genus Aulngraphis Häickel. Für eine mm in einem Exemplar vertretene Form war ich ebenfalls zur Schaffung einer nenen Gattung veranlaßt, die nach dem bisherigen Vorgehen, wenn sie bekannt gewesen wïre, wahrscheinlich anch als Art bei dem Genus Aulographis ihren Platz gefunden hätte.

Es fiel mir auf, dab nach Absonderung der Aulokleptesarten, die mit ihrer Fremdkörpergrundlage eine rollkommen abgeschlossene Gruppe bilden, ferner nach Ausschaltung von 
Aulncantha und Auloceros und Aulospathis, welche beide ebenfalls gut umgrenzt sind, noch drei in ihrem Aufban verschiedene Bildungen zur Anschanung kamen. Während ich das eine Mal Formen mit massiven Terminalbildnngen beobachtete, die jedoch einfach blieben, was man an gewissen kleinen Endbildungen sehen kann, kommen solche mit hollen 'Terminalästen vor und zwar, um die häufigeren Bildungen vorweg zu nelımen, pllegen dieselben ihren Ausgangspunkt ans einer kolbenähnlichen Aufblälıung zu nehmen. Sie sind stets mit einem Endsprathill nnd meist mit seitlichen kleinen Zähnchen versehen (schon durch letzteren Umstand von gewissen Formen von Aulospathis unterschieden, welche ja anßerdem noch Lateraläste trägt). Da der Name Aulocoryne, welcher von Fowler für die von ihm benannte Spezies Aulocoryne zetesios gebrancht wurde, bezeichnend ist fïr das Charakteristische der eben erwähnten gut umschriebenen Gruppe (demn wir finden nie neben Stacheln mit dieser Aufblähung solche olne dieselbe glèichzeitig) und anch die von Fowler benannte Art alle Merkmale besitzt, welche ich für die besprochene Gruppe als bezeichnend dargestellt habe, so hielt ich es für angemessen, diese Bezeichnung auf die ganze Anzahl ron Formen anzuwenden, welche die geforderten Eigenschaften, von denen ja eine sehr in die Augen fallende durch den Namen angedeutet wird, in sich vereinigen. Es war dies um so leichter möglich und vollkommen angebracht, als die Kolbenform eine Begleiterscheinung des innern vollständigen Hohlraums (auch der Endäste) bildet, welcher in der Art seiner Ausclehnung ja unserer 'Einteilung zugrunde liegt. Außer' bei diesen Formen und bei Aulospathis, welche Gattung ja durch ihre Lateraläste ansgezeichnet ist, kommen hohle Endbildungen sonst nur noch bei einer Art vor, welche ich sonst nirgends unterzubringen vermochte. Äußerlich nähert sie sich der Gattung Aulographis, sie besitzt jedoch hohle Terminaläste, aber ohne Anfblähung. Das kommt zwar bei Aulogpathis anch vor, aber mnserer Art fehlen auch die Seitenäste. Es blieb nir daher nichts anderes übrig, als eine weitere Gattung aufzustellen. Ich wählte hierfür die Bezeichnung Aulophyton.

Was die Gattungen Auluctinium Häckel und Aulodendron Häckel anbelangt, so kenne ich dieselben nicht ans eigener Anschauung, weil sie im Material der Plankton-Expedition fehlen. Da die bisherigen Beschreibungen und anch die vorhandenen Abbildungen der damaligen Auffassung entsprechend mehr Gewicht anf andere äßere Ligenschaften legten, kam gerade das, was für mich zu der Beurteilung der Stellung, welche diese beiden Gattungen zu den übrigen eimnehmen, von Wichtigkeit war, weniger zum Ausdruck, so daß ich mich nit einer provisorischen Platzanweismg begnïgen muß. Von großem Nachteil ist dieser Umstand nicht, da vorliegende Arbeit ja in erster Linie den Aulacanthiden der Plankton-Expedition gilt nnd erst in zweiter Linie alles zur Vervollkommung Wissenswerte auch der sonst noch bekannt gewordenen Formen anzuführen hat.

Gehen wir also von dem Prinzip) ans, daß der Weg der Stachelentwicklung maßgebend sein soll für eine systematische Einteilung der Aulacantlidenfamilie, so gelangen wir zu folgender Aufstellung, welche gleichzeitig als Bestimmungstabelle gelten mag. In ihr sind auch die Borgert'schen Einwände berïcksichtigt und auf eine Anerkennung der Familien der Phaeodiniden und der Cannorrhaphiden aus angeführten Gründen verzichtet worden. Die Ordnung der l'haeocystina wird numnehr also folgende Definition haben. 


\section{Ordunng der Phaeocystina.}

Tripyleen mit einem Skelet aus einzehen isolierten Stücken:

A. Skelet ans zahlreichen, cinzehen von der Zentralkapsel rudiär nach allen Seiten ausstrablenden hohlen Stacheln gebildet. AnBerdem meist noch ein Mantel von tangential gelagerten Kieselgebillen:

$$
\text { Familie der Aulacanthideu. }
$$

I. Radialstachehn mit dentlich herrortretender Schichtenbildung in der Wandung und in den Endästen. Die Grundlage der. Stacheln sowie die tangential gelagerten Gebilde bestehen aus Fremdkörpern . . . . . . . . . . . . Gattung lulokleptes.

II. Radialstacheln einfach, ohne Lateral- nud Terminalïste. Die schwache Zunahme der Wandungsdicke bauptsichlich in distalen Drittel und meist anf Bildung von kleinen Zähnchen beschränkt:

a) mit Tangentialnadeln................... Gattung Aulacentlec.

b) ohne Tangentialnadeh . . . . . . . . . . . . . Gattung Aulactimim (prov.)

III. Wandung des Strchels zentrifugal an Dicke zunehmend. Der innere Hohlraum setzt sich boi ansgebildeten Stacheln nicht in die Endbildungen fort:

a) dieselhen meln oder weniger verzweigt in sekundäre und lisweilen auch weitere Äste. Ohne Seitenstacheln . . . . . . . . . . Gattung Auloceros.

b) dieselben ohne sokundäre Terzweigung in Äste . . . . . . . . Gattung lulograplie.

IV. Stachelwandung iiberall gleichmäbig: der innere Hohlranm setzt sich in die Endund eventuell vorhandenen Seitenäste fort:

a) ohne Seitenäste und ohne Aufbliilnng am distalen Ende . . . . . Gattung Aulophyton.

1) olure Seitenäste, jedoch stets mit Aufblähung am distalen Ende. . . . Gattung Aulocoryme.

c) mit quirlig gestellten Seitenästen; mit oder ohne Aufblähung am distalen Ende Gattung Lulosputhis.

d) mit zahlreichen umregelmïbig verteilten Seitenästen......... Gattung Aulodendmu (prov.).

Nicht unmöglich wäre es aıch, dal. Aulodendrum. Häckel in näherer Verwandtschaft zur Gattung Aulacantha Häckel stïnde, dam käme ilm eine andere Stellung im System zu. Da ich jedoch, wie gesagt, kein Exemplar untersuchen konnte und die vorhandenen Abbildungen (Häckel CHahlexgek-Report) auf äuberst regelmäßige Wandungen hinweisen, erlielt das Genus den nummehr ihm provisorisch zugewiesenen Platz.

In folgenden wird eine umfassende Beschreibung der bei der Plankton-Expedition erbenteten Aulacanthiden-Gattungen mnd -Arten gegeben. Sie hält sich in der Reihenfolge an das zuletzt aufgestellte System.

\section{Aulokleptes novum genus.}

Die Gattung umfaßt teils neme Arten, teils auch solche, welche neben andern von Häckel in dem Genus Aulographis Häckel und anch in einzelnen Fiillen bei dem Genus Auloceros Häckel untergebraclıt waren.

Die Gattung ist leicht erkennbar an den deutlich hervortretenden Schichten, in der Wandung des Stachels. Tangential gelagerte Kieselgebilde sind bald in geringerer, bald in größerer Menge vorhanden, ans leeren Diatomeenschalen bestehend. Die Grundlage des Stachels wird ebenfalls von Diatomeen gebildet.

Wats das Vorkommen von Diatomeenschalen anbelangt, so sind dieselben durchaus untereinander verschieden an Größe und Länge sowohl, wie an Dicke. Meistens kommen 
Rhizosolenien in Betracht. Unter diesen wieder wird Phizosolenia alata Brightwell und Rhizosolenia semispina Hensen am häufigsten beobachtet, doch fehlten auch Rh. setigera Hensen, Rh. atlantica Peragallo, Rh. hebetata Radley, Rh. shrabsolei Peragallo, Rh. styliformis Brightwell, Rh. calcaravis Schultze nicht, wenn dieselben sich auch mehr veremzelt zeigen. (Bei den untersuchten A ulacanthiden konnte wegen Undentlichkeit die Existenz einer oder der andern eben erwähnten Diatomeen nur vermutet werden.) Von andern Diatomeen tritt Thalassothrix und Synedra auf. Sie werden fast ausschließhich zur Stachelbildung verwendet, wie es bei der bedeutenden Länge dieser Formen wohl zu erwarten ist. Ton Rhizosolenien kommen bei der Stachelbildung meist nur außergewöhnlich lange Einzelstadien zur Verwendung oder Kettenformen, deren Teilungsstelien im Innern des Stachels mitunter sehr klar zu sehen sind, während die kürzeren die Rolle der Tangentialnadeln vertreten. Auch Kettenfragmente finden sich zuweilen in den Radialstachelu, und zwar wird das Bruchende meist nach außen gerichtet, was wohl erklärlich ist, da die Spitze leichter in den Körper einzudringen vermag. Manchmal erstreckt sich der sekundäre Kieselüberzug ïber den ganzen Stachel und zwar ist dies fast stets der Fall, wenn eine Thalassothrix und Synedra die Grundlage bildet; mitunter ist das proximale Ende in urspriünglichem Zustand oder anch nur mit einer minimalen Schicht überkleidet, während in distaler Richtıng der Überzug durch weitere Schichten rasch an Dicke zunimmt, wodurch der Stachel ein keulenähnliches Aussehen gewinnt. Bisweilen scheint es, als ob zwischen den einzelnen Lagen eine dünne Luftschicht sich befinde, renn auf dem optischen Querschnitt wird die 'Trennung derselben durch mehr oder weniger breite, schwarze Linien dentlicl. Für die Bestimmıng der Diatomeen, obwohl dies für die Stacheln durchaus ohne Belang ist, da hier keine regelmäßigen Beziehungen, noch irgend welche Gesetzmäßigkeit zu herrschen scheint, kommt vor allem die Stelle in Betracht, wo die lindbildungen ihren Anfang nehmen. Hier ptlegt sich das Charakteristische der betreffenden zugrunde liegenden Diatomee am dentlichsten zu ̈̈uBern, abgesehen natïrlich von den Fällen, wo dies Ende durch ein abgebrochenes Kettenstïck gebildet wird. Namentlich als Beweis für das wirkliche Vorhandensein einer Diatomeenschale kann hier die in den weitaus meisten Fällen sichtbare Teilungsnarbe angesehen worden, die eine für die verschiedenen Arten bekannte charakteristische Gestalt zeigt, wie dies anch bei der Spitze der Fall ist. Letztere, namentlich wem sie lang sind, haben allerdings öfter das äußerste Ende eingebïßt. Sind die Schichten gut durchsichtig, daun glückt es mitunter, die Schalenzeichnungen, wie Spiralen, Felderung, Schuppenbildung zu beobachten. Dies gelingt jedoch eher am proximalen Ende, wo wiederum leider manchmal der Weichkörper des 'lieres mit seinen Verunreinigungen hinderlich für die Betrachtung wird. Die Zeichnungen treten an schönsten nach meiner Beobachtung hervor, wenn sich das Gehäuse nit Luft gefiillt hat und so einen dınkeln Hintergrund bildet. Was die 'T'eilungsstellen anbelangt, so schwankt die Deutlichkeit sehr: Manchmal sind alle Einzelheiten zu erkemnen, ja sogar die äubere Gestalt des Stachels wird in Mitleilenschaft gezogen (T'afel 11, Fig. 2), indem sich hier Verengungen und 'Tordierungen bemerkbar machen; manchmal zeig'en sich an den Teilungsstellen mr ganz schwach erkembare schräge Linien. Natürlich kommt dabei anch sehr in Betracht, mit was für einer Diatomee wir es zu tun haben. Sehr schön, wohl am besten, 
habe ich solche T'eilungsstellen bei Rhizosolemia styliformis Brightwell gesehen (Tafel II, Fig. 6). Diese schon durch ihre Breite sich auszeichnente Diatomee hat noch den Torzug einer besondern Spitzenmodifikation, wodurch das Bild mehr differenziert wird. An wenigsten dentlich überhaupt sind die Einzelheiten bei Thulassothrix Ehrenber'g und symedra Cleve zn erkennen. Bestehen doch die Gehäuse dieser Di atomeen ans äulerst schmalen, dabei sehr langen Kieselgebilden. Dazu kommt noch, daß dieselben meist stark tordiert sind, wodurch der Anblick bei den oft sehr dichten Schichten noch komplizierter wird. Immerhin gelang es mir, grewölnlich allerdings nur mit Hilfe sehr starker Vergrößerung und geeigneter Beleuchtung (wechselnde Lichtstrahlenrichtung) die für Thrlassothrix Frauenfeldii Grun. charakteristischen Schraffierungen und Punktierungen nachzuweisen. Das Vorhandensein von Synedra kann ich vorläufig nur vermuten, da die betreffenden Naleln leider kein klares Biłd lieferten und eine größere Auswahl nicht vorhanden war.

Der Formenreichtum, welchen die Gattung Aulokliptes liefert, ist ein selır großer. Vor allen Dingen finden wir hier eine erhebliche Menge von Übergängen innerhalb der einzelnen Bildungsrichtungen. Letztere lassen sich in verschiedene Gruppen sondern, welche wir als Arten auffassen könıen, indem beim Einschlagen dieser Richtung stets eine ganł bestimmte Formengruppe entsteht, die nur durch den höheren oder niechrigeren Ansbildungsgrud im einzelnen verschierlen sein kann. Bei Betrachtmng der Stachelentwicklung habe ich gezeigt, daß die Psendopodien die direkte Veranlassung zu der Form der Endbildungen sind. Es wird also eine Trennng in die oben angedenteten Gruplen in engster Beziehung stehen zu der Art und Weise, wie sich die P'seudopodien im umgebenden Medium verteilen. Wir können dabei folgende Möglichkeiten miterscheiden:

a) Das einzelne Psendepodium teilt sich sehr bald in einen Kranz stark dirergierender Äste: Fs entstehen Formen mit einer Stachelkrone. . . . . . . Aulokleptes coronu.

b) Das Pseudopodium löst sich lald in einen Bäschel auf. dessen einzelne Stränge sich wieder teilen könuen . . . . . . . . . . . . . . . . . Lulokleptes doserulus und Tar.

c) Das Pseudopodium hildet mehrere Hauptstränge. welche sich jectoch alsbald in Büschel anflösen. . . . . . . . . . . . . . . . . . . . Lulokleptes gemmascens und Tar.

d) das Psendepodium bildet mehrere Hauptstränge. welche sich teilen, ohne jedoch eigentliche Büschel zu bilden. Die Tremung pflegt orst in einiger Entfernung von der Ursprungsstelle zn erfolgen . . . . . . . . . . . . . . sluhlileptes ramosus und Tar.

1. Aulokleptes corona mihi (Aulographis penicillatu Häckel?).

(Tafel VI, Fig. 1 a und 1b.)

Dadurch ausgezeichnet, dab sich am Ende des Stachels ein feiner stark divergierender Zackenkranz bildet, der jedoch meist keine bedentende Höhe erreicht. Bei den von mir beobachteten Individuen reigte diese Form auffallend häufig Thalassothrir als Grundlage, deren schlanke Gestalt vielleicht sehr zn dieser Bildung disponiert. Sie unterscheidet sich ron einzelnen ähnlichen Stadien der nächstfolgenden Art dildnrch, da sie niemals Abweichungen in der äubern charakteristischen Form zeigt, wenn anch natürtich länge, Dicke nnd Zahl der Stacheln bei den einzehnen Nadeln verschieden sein kann. Folge der sofortigen Auflösung der 
Pseudopodien in stark divergierende einzelne Fäden ist anch der Umstand, daß es zu keiner Lamellenbildung zwischen den einzelnen Zacken kommt. Dabei ist auch die Feinheit der Fïden in Betracht zu ziehen.

$$
\text { Fundorte: }
$$

Plankton-Expedition: Nördlicher Ast des Golfstroms $59.2^{\circ} \mathrm{N}$. Br., $11.8^{\circ} \mathrm{W}$. L., 0-400 m Tiefe, Tertikahnetz. Irminger See $60.3^{\circ} \mathrm{N}$. Br., 27.0 W. L., 0-600 m Tiefe, Vertikalnetz.

Bemerkung: Möglicherweise steht diese Form in Beziehnng zu der Häckel'schen Spezies Aulographis penicilluta, wo jedoch von gekrümmten Endïsten gesprochen wird, was ich in unserm Fall nicht beobachten konnte. Als Fundort wird der nordatlantische Ozean (Nähe der Antillen) angegeben.

\section{Aulokleptes flosculus mihi.}

Anloypaphis flosculus Häckel zmin Teil, auch Borgert 1901.

Die Endbildung besteht aus einem Kranz von starken, etwas nach oben und innen gekriimmten Zacken, deren Zialıl verschierlen sein kann, jedoch meist 6-8 beträgt. Durch weitergehende Kieselablagerung kamn es zur Bildnng von Lamellen zwischen den einzelnen Zacken komnen; ferner können seitliche Zacken durch Faltung oder dadurch entstehen, daß die Substanzablagermng bis zu einer sekundären Teilnngsstelle des Psendopodiums vorgeschritten ist; daher finden wir solche Seitenbildungen meist in der Nähe der Spitze der Primären. Auch zwischen diesen Ansätzen kommt es bisweilen bei fortschreitender Verkieselung zur Entstelıng von Lamellen, ja schlieblich beschränkt sich die Verschmelzung nicht nur auf die benachbarten Zacken, sondern das ganze Lindgebilde wird zu einer mit mannigfaltigen Spitzen versehenen, kompakten Masse, welche jedoch bei genauer Betrachinng schon in der ganzen Gestalt ihren Ursprung verrät. Diese einzelnen Stadien können auf verschiedene Individuen verteilt sein, kommen jerloch auch bei ein nud demselben Exemplar vor. Zur Bezeichnung der einzehnen Stadien, die bei öfter's vorkommender individueller Abgeschlossenheit wohl anch als Unterarten aufgefalit werden dünfen, greife ich in folgenden teilweise auf von Häckel bereits gebrauchte Benennungen zurïick.

Wir erhalten auf diese Weise fünf Varietäten:

a) Endkrone frei, obne Lamellenbildung und ohne sekundäre Endzäckchen Aulokleqtes flosculus var. pistillum mihi $=$ Aulogrreplis pistillum Häckel (Tafel V, Fig. 1).

Fundorte:

Plankton-Expedition: Irminger See $60.3^{\circ} \mathrm{N}$. Br., $27.0^{\circ} \mathrm{W}$. L., $0-600 \mathrm{~m}$ Tiefe, Vertikalnetz.

Challexger-Exp e ditio n: Nordatlantischer Ozean innerhalb 3000 m Tiefe, Station 354.

b) Endkrone durch Lamellen verlunden ohne Seitenzacken . . . . Aulokleptes flosculus var. inermis mihi (Tafel III, Fig. 1). 


$$
\text { Findort: }
$$

Plankton-Expedition: Irminger See $60.3^{\circ} \mathrm{N} . \mathrm{Br} ., 27.0^{\circ} \mathrm{W}$. L., 0 -600 m 'Tiefe, Vertikalnetz.

c) Endkrone frei, ohne Lamellenbildung mit sekundären Zacken . . Autokleptes flosulus var. tridentuhus mihi (Tafel VI, Fig. 3).

(Diese Varietät ist möglicherweise identisch mit Aulogruphis murtagon Iläckel. Für letztere gibt $\mathrm{H}$ ïckel allerdings den Sïdatlantischen Ozean als Fundort an; anch sind nach seiner Beschreibnng und Abbildung die sekundären Zäckchen riemlich regehmäßig längs der zwei einander gegenïber liegenden Seiten der primären Zacken verteilt, während sich dieselben bei Aulokleptes tridentatus mihi meist nur in der Zweizahl (doch kommen anch mehrere vor) und an äubersten Ende vorfinden. Aus allen meinen Beobachtungen kaun ich zu der Ansicht, duß diese Seitenzïhne schr wechselnd in ihrer Zahl sind, woshalb kein allzu großes Gewicht anf ihr Vorhandensein gelegt weıden darf. Jedenfalls berulıt aber die Häckel’sche Form anf dem gleichen Billungsprinzip, und da sie im CHaLwaviwk-Repont unter dem Subgenus Aulographella angeführt wird, welches ansschließlich Aulokleptesarten enthält, so wird die Vermutung trotz der verschiedenen Fundorte wohl richtig sein.)

\section{Fundorte:}

Plankton-Expedition: Irminger See $60.2^{\circ} \mathrm{N} . \mathrm{Bl} \mathrm{l}^{\circ}, 22.7^{\circ} \mathrm{W}$. L., 0 - $400 \mathrm{~m} \mathrm{Tiefe,}$ Vertikalnet\%. Irminger See $60.3^{\circ} \mathrm{N} . \mathrm{Br}^{*}, 27.0^{\circ} \mathrm{W}$. L., $0-600 \mathrm{~m}$ Tiefe, Vertikalnetz.

Bemerkung: Mahangaben können hier, wie überhaupt bei Aulokleptes aus begreiflichen Gründen nicht in Betracht kommen. Auch wo solche späterhin der Vollständigkeit halber nach früheren Vorbildern angefïhrt sind, lassen sich dieselben, wie schon aus den verschiedenen Angaben hervorgeht, kaum systematisch verwerten.

d) Krone mit Lamellenbildung und sekundären Zacken. Das Ganze

macht den Eindruck eines Blumenkelches........... Anlokleptes fosculus typirus mihi = Aulographis flosculus Häckel ('Taf. VI, Fig. 2 u. Taf. T, Fig. 2).

Fundorte:

Plankton-Expedition: Nördlicher Ast des Golfstroms $59.2^{\circ} \mathrm{N} . \mathrm{Br}, 1_{1} 1.8^{0} \mathrm{~W}^{\mathrm{L}} \mathrm{L} .$, 0-400 m l'iefe, Vertikalnetz. Irninger See $60.3^{\circ} \mathrm{N} . \mathrm{Br}$., $27.0^{\circ} \mathrm{W}$. L., 0-600 m Tiefe, Vertikalnetz.

CHALLENGER-Expedition: Nordatlantischer Ozean, Golfstrom, Faroe-Kanal innerhalb 1090 m 'Tiefe.

e) Die ganze Endhildung ist zu einer zusammenlıängenden Masse rer-

sehmolzen, nur die einzelnen spitzen bleiben frei....... Aulokleptes floseuhs rar. confluens mihi

(Tafel TI, Fig. 4).

(Möglicherweise gebört anch die im Süd-Pacifik gefundene Aulographis fummabuncta Häckol hierher.)

Fundort:

Plankton-Expedition: Irminger See $60.3^{\circ} \mathrm{N} . \mathrm{Br} ., 27.0^{\circ} \mathrm{W}$. L., $0-600 \mathrm{~m}$ Tiefe, Vertikalnetz. 


\section{Aulokleptes gemmascens mihi.}

Anloginghis grmmasiens Häckel (wabrscheinlichi).

Die Endbildung besteht aus einer Zackengruppierung nach zwei oder auch mehr Richtungen. Je nachdem die sekundären Zacken gleich oder erst im Verlauf auftreten, können wirkliche Encläste, die nach verschiedenen Richtungen auseinandergehen, unterschieden werden, oder wir haben nur Zackengrupen vor uns, die aber deutlich nach verschiedenen Richtungen divergieren. In ersterem Falle schließen sich die Zackengrupjen erst an voraufgehende stiimmige Terminaläste an. Jede solche wird gewöhnlich ans einer alle übrigen überragenden Hauptspitze gebildet. um welche sich die ïbrigen nnregelmäßig herumstellen, indem sie mit ihr and unter sich durch Kieselablagerung in den Zwischenräumen größtenteils verschmelzen. Häckel hat für eine entsprechende Form, die er auch abbildet (CHallexger-Report, Pl. 105, Fig. 11) die Artbezeichnung gemmascens gewählt. Die Abbildung im CHALLExGER-Report läßt darauf schließen, daß sie den oben erwälnten Fall darstellt, wo die Seitenzacken zugleich mit der' 'T'rennung in Terminaläste entstehen, so daß diese letzteren nicht mehr zur Geltung kommen. Aber deutlich können wir auch bei dieser Figur drei verschiedene Richtungen in den Zackengruppen erkennen. Sie sind also nicht in einem Kreise angendnet, wie bei Aulokleptes fosculus. Charakteristisch ist ferner das Dominieren je einer Spitze, welche gleichzeitig die Richtung für die betreffende Gruple angibt. Selbst da, wo wir die Zackenhanfen an dentlich ausgeprägten, divergierenrlen Endästen finden, gewinnen sie nie das Aussehen von Seitenzweigen. Kommt es zu einer teilweisen Verschmelzung der Gruppen, so erhalten wir eine Bildung, die seln an Aulokleptes flosculus erinnert, nur mit dem Unterschiede, daß dabei das 'Jy'sche der Ähnlichkeit mit einer Blnmenkrone fehlt. Der Charakter des Bildes einer anfbrechenden Knospe bleibt auch da noch erhalten, und ich zögere nicht, die Stachelform, auf welche sich diese Schilderung bezieht (Tafel V, Fig. 4 und 5), hier einzureihen. Nur wiederum, um dem Bedürnis nach einer Bezeichnung des jeweiligen Stadiums der Kieselbildungen entgegen zu kommen, mögen die drei erwähnten Fäille in eben so vielen Tarietäten Platz finden, wobei wir im Auge zu behalten haben, daß diese nur durch besondere Umstinde von Fall zu Fall hervorgerufene verschiedene Ansdrucksweisen ein und desselben Bilhungsprinzipes sind, welches fïr die drt bezeichnend ist. Wir erhalten also die Unterschiede:

a) Zackengruppen dentlich auf einzelne Terminaläste verteilt. . . . Aulokleptes gemmuscens var. bi(tri)-partitus mibi ('Tafel V, Fig. 3).

Fundort:

Plankton-Expedition: Irminger See $60.2^{\circ} \mathrm{N}$. Br., $22.7^{\circ} \mathrm{W}$. L., $0-400 \mathrm{~m}$ Tiefe, Vertikalnetr.

b) Zackengruppen einzeln diveroierend, direkt am Stachelende aufsitzend

Aulokleptes :"emmascens tiprions mili $=$ Aulographis gemmascens Häckel (wabrscheinlich),

Findorte: (Tafel V, Fig. 4).

Plankton-Expedition: Golfstrom (Nördlicher Ast) $59.2^{\circ} \mathrm{N}$. Br., $11.8^{\circ} \mathrm{W}$. L., 0-400 m Tiefe, Vertikalnet\%.

Chaldaxger-Expedition: Tropischer Atlantischer Ozean innerhalb $4100 \mathrm{~m}$. Station 347. 
c) Zaekengruppen divergierend, abev zu einem Ganzen verschmolzen . Autokleptes gemmuscens var. scrytmm mihi ('Tafel T, wig. 5).

Fundort:

Plankton-Expedition: Irminger See $60.3^{\circ} \mathrm{N}$. Br., $27.0^{\circ} \mathrm{W}$. L., 0-600 m 'Tiefe, T ertikalnetz.

Bemerkung: Es ist gewiß, daß durch die Lindform des im Stachel eingeschlossenen Fremdkörpers die Endbildungen in ihner Gestalt beeinflnbt werden können. Bei den bisher, namentlich jetzt eben zuletzt geschilderten Formen war dies zwar nicht in besonderem Maße der Fall. Doch sei daranf hingewiesen, um damit anfs Nene hervorzuhehen, wie wenig die äußere Gestalt zn einer Bestimmung tangt. Das 'Typische der die Substanz-Ablagerung hervorrufenden Pseudopodienverteilung wird jedoch auch in solchen Fällen am Skelet noch erkembar sein und eine Einreihnng ins Srstem gestatten.

\section{Aulokleptes ramosus mihi.}

Das distale Stachelende lünft in mehrere Endïste ans, die an Zahl verschieden sind (2-3 konnte ich beobachten) und welche Tendenz zeigen, sich weiter zn verzweigen. Das Ganze erhält hierdurch ein banmförmiges Aussehen und ähnelt der später noch zn erwähnenden Gattung Auloceros in mancher Beziehnng, ist von derselben aber klar unterschieden durch die stets vorhandene Fremdkörpergrundlage nnd durch größere Derbheit der einzelnen Stachelteile.

Diese Art bildet wohl die mannigfaltigsten Formen und doch ist es nicht möglich, für alle diese Bildnngen weitere Unterarten anf/ustellen, denn, wie anch ans den Abbihlungen ('Tafel IV, Fig. 1, 2 nud 3) hervorgeht, finden sich oft die größten Verschiedenlieiten bei ein und demselben Individnum. Zwei Bildungen wiederholen sich öfter und zeigen Charakteristisches, so daß wir zur Not die Organisnen danach gruplieren können, wenn anch das vereinzelte Vorkommen von Abbildnngen der einen Gruple bei der der andern uns daran erimert, wie künstlich die Trennung ist. Wir erhalten also, wemn wir wollen, zwei Varietäten, von denen die eine die Tendenz zeigt, nur längere, oft zahlreiche sekundäre Äste zn bilden, während die andere dies $n m$ vereinzelt tut und sonst eine Menge kleiner Höcker und Zacken aufweist. Nit der Pseudopodienverteihng und der damit verbundenen Kieselablagernng wird es zusammenhängen, daß wir hier am linde des ungeteilten Stachels nicht diese Schichtenanhäufung finden, ja es kommt vor, daß wir statt deren eine Verengerung vor der 'T'eilnng in Äste konstatieren können, die dem spitz zulanfenden Ende der zugrunde liegenden Diatomeensehale entspricht. Gerade diese Spitze mag vielleicht mit zu der Gestalt der Endbildung überhaupt beigetragen haben. Allerdings kommen anch bei stumpf endigendem Diatomeeneinschluß Verästelungen vor, doch fehlt dann grewöhnlich die Verjüngung. Da die verschiectensten Schalenendigungen nun bei dem gleichen Tier vorhanden sein kömnen, ist es begreiflich, daß sich hier kamm eine Norm aufstellen läßt. Wenden wir uns zumächst der einen Varietät zu:

a) Die sekundären Zacken sind meist lang und astförmig nnd zeigen Tendenz, sich wieder zu teilen oder wenigstens Zäckchen zu bilden. Die primären Verzweigungeu sind glatt und zeigen keine Erhebungen,

Immermann, Die T'ripyleen-Familie der Aulacanthiden. I. L. 
anch ist keine Neigung zum Verschmelzen der einzelnen Kacken (Haupt- sowohl, wie Nebenzacken) rorhanden. Die sehr einfachen Formen (Tafel ITI, Fig. 2 a-d, Tafel IV, Fig. 2 c und 3 d) mit zwei, drei, rier oder aucb melur głatten Endzacken (die nicht von einer gemeinsamen Trenumgsstelle auszugehen braucben) sind als Anfangsstadien aufzufassen, denn ich habe solche mit weiter, in der beschriebenen Treise ausgebildeten Stacheln zusammen bei dem gleichen Tier beobachtet. Man kann diese Formengruppe von der nächsten unterscheiden und nnter folgendem Namen zusammenfassen . . . . Aulokleptesmosus var. longispinamihi (Tafel III,

Fig. $t$ und 5, Tafel IT, Fig. 1, 2, 3).

Fundorte:

Plankton-Expedition: Labradorstrom 50.8 N. Br., 47.3 $\mathrm{W}$. L., 0-500 m Tiefe, Vertikalnetz. Nördlicher Äquatorialstrom $10.2^{\circ} \mathrm{N}$. Br., $22.2^{\circ} \mathrm{W}$. L., $0-1000 \mathrm{~m}$ Tiefe, Vertikahetz. Südlicher Äquatorialstrom 5.70 S. Br., 26.50 W. L., $0-400 \mathrm{~m}$ Tiefe, Vertikalnetz.

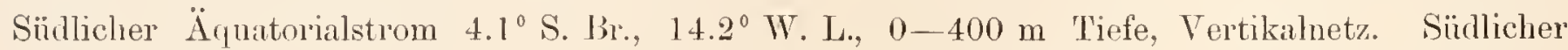
Äquatorialstrom 2.6 ${ }^{\circ} \mathrm{S}$. Br., $14.6^{\circ} \mathrm{W}$. I., $0-400 \mathrm{~m}$ Tiefe, Vertikalnetz. Südlicher Äquatorialstrom $1.1^{\circ} \mathrm{N} . \mathrm{Br} ., 16.4^{\circ} \mathrm{W}$. L., $500-700 \mathrm{~m}$ Tiefe, Schließnetz. Südhicher Ä̈nutorialstrom $1.7^{\circ} \mathrm{N}$. Br., $17.3^{\circ}$ W. L., $0-500 \mathrm{~m}$ Tiefe, Vertikahnetz.

b) Bei den Endbildungen ist Neigung zum Verschmelzen vorhanden.

Die Äste nehmen daher proximal sehr an Ilicke zu und werden durch weiteren nachträglichen Substanzansatz mit unregelmäBigen Höckern hedeckt, welche auch bis nahe der Ursprungsstelle der primären Verzweigungen auftreten können. Für diese Form der Ausbildung, die trotz mancher Üborgänge einen wesentlich andern Charakter, als die vorige zeigt, schlage ich folgende Bezeichmng vor Aulokleptes ramosus var. multituberculutus mili (Tafel III, Fig. 3).

\section{Fundort:}

Plankton-Expedition: Irminger See $60.3^{\circ} \mathrm{N}$. Br., 27.0 $\mathrm{W}$. L., $0-600 \mathrm{~m}$ Tiefe, Vertikalnetz.

Bemerkung: Sehr wahrscheinlich ist, daß auch Aulographis triaena Häckel hierher gehört, die auf der Chaldexgen-Expedition im Siid-Pacifik gefmnden wurde. Anch für mehrere Auloceros-Spezies desselben Autors, wie Auloceros cervinus Häckel nnd Auloceros capreolus Häcke] halte ich eme Zngehörigkeit zu Aulokleptes ramosus miln für möglich. E. Häckel selbst sagt, daß bisweilen Aulographis triaena in Auloceros cervinus ïbergehe. Letztere Spezies kommt nach dem Chaldexger-Bericht im Sür-Atlantik vor. Aulograqhis trikena wird ja von E. Häckel auch zu der von ilım anfgestellten Untergattung Aulographella gezählt, von deren übrigen Zngehörigen es sich nummehr heransgestellt hat, daß ihre Stachehn säntlich Diatomeenschalen als Grundlage besitzen. Auch die Bezeichnnng der Form des Stachels als »kenlenförnig ist charakteristisch. Die Art teilt diese von E. Häckel angeführte Eigenschaft mit allen denen, bei welchen ich Diatomeen nachweisen komnte und die sich wahrscheinlich als mit der Häckel'schen entsprechenden Spezies identisch oder wenigstens nahe verwandt herausstellten. lïn so regelmäßiges Anftreten von drei weiter sich verzeigenden Endüsten, wie E. Häckel es bei seiner Aulographis triuena beschreibt, konnte ich bei den Exemplaren, welche auf der 
Plankton-Expedition erbentet wurden, nicht konstatieren. Ich sah deshalb auch davon ab, diese Bezeichnung zu verallgemeinern, obschon ich, wie gesagt, der Meinung bin, daß Aulographis triaena Häckel, wie anch Auloceros cervinus Häckel nur durch zufällige Ausbildung ihrer Äste von Aulokleptes ramosus mihi verschieden sind, in wesentlichen aber sonst auf den gleichen Bildungsprinzipien beruhen, wie ich sie als maßgebend fiir meine Klassifikation bezeichnet habe. Zwischen den von mir unterschiedenen beiden Varietiiten konmen anch Übergänge vor, sodaß es manchmal schwer ist, sich für die eine oder die andere Gruppe zu entscheiden. Auch kann sich die Zahl der primären Endäste so vermehren, daß wir Anklänge an Aulokleptes flosculus var. tridentatu mili sen Aulographis martagon Häickel finden. Immerhin läßt sich bei einiger Übung der Unterschied doch feststellen; anch werden wohl in den meisten Fällen andere Stacheln res gleichen 'lieres auf die richtige Führte verhelfen.

\section{Genus Aulacantha Häckel 1862.}

Neben einem mchr oder weniger dicht verfilzten Mantel von dïnnen, meist gekrümmten; hohlen Tingentialnarleln, welche auf beiren Seiten offen sind, ansgezeichnet durch den Besitz von hohlen Radialstacheln, welche in ihrem distalen Drittel beinahe immer mit kleinen Zähnchen besetzt sind. Letzter'e fehlen nur bei einer Art, die jedoch im Material der Plankton-Expedition nicht vertreten ist. Möglicherweise handelt es sich hierbei vielleicht anch nur um ein unausgebildetes Stadium der nachfolgend beschriebenen Aulacanthu scolymanthu Häckel. Weder Seitennoch Endäste sind vorhanden. Die Gattung ist bei dem Aulacanthidenmaterial nur durch eine Spezies vertreten:

a) Stachel rund, ohne Kanten, in seinem distalen J)rittel mit einer gröBeren

Zahl ron kleinen Zähnchen besetzt.

1. Aulacantha scolymantha Hiickel 1862.

(Tafel 1, Fig. 1, 2, 3.)

R. Hertwig 1879; E. Häckel 1887; Y. Hensen 1887: K. Möbius 1887; E. Vanhöffen 1897; E. Jörgensen 1900; A. Borgert $1901=$ Anlucantha laevissime Fowler 1898.

Diese Spezies stellt wohl die an allgemeinsten verbreitete vor. Sie ist dadurch charakterisiert, daß das distale Drittel des Stachels mit eincr größeren Zahl (mindestens zehn) von unregelmäßig verteilten, nach außen und gegen das Stachelende zu gerichteten Zähnchen besetzt ist. Bisweilen sind dieselben etwas gekrümmt. Es sind jedoch keine eigentlichen Ästchen, sondern sie zeigen mehr das Aussehen von Kerbschnitten. Am äußersten Ende pflegt der Stachel in zwei bis drei kleine Zühnchen ansgezackt zu sein, welche nicht zurückgebogen sind, wie wir dies lüufig bei ähnlichen Terminalbildungen anderer Gattungen sehen. Der innere Hohllanm erstreckt sich durch den ganzen Stachel. Bisweilen ist bei ihm schon durch'kleine Ausbuchtungen die Stelle markiert, dic nach anßen einen Zahn trägt. In einem Falle glanbe ich bemerkt zn haben, daß ein vom innern Hohlraum ansgehend'r feinster Kanal den Zaln durchzog. Ob derselbe sich nach außen öffnete, gelang mir nicht festzustellen. Bestätigen kann ich jedoch die Beobachtung R. Hertwigs, daß der Stachel an seinem distalen, wie anch an seinem proximalen Ende vollkommen geschlossen ist. Distal pflegt dies allerdings nicht immer durch eine »dünne 
Platte« zu geschehen, welche zwischen den Endzähnchen liegt, sondern dieselbe kann auch verhältnismäßig stark werden; ja es kommt vor, daß schon der ganze änßerste Teil des Stachels wie eine komprakte Masse erscheint. Dabei handelt es sich nicht um verschiedene Arten, denn dies Verhalten kounte bei verschiedenen Stacheln des gleichen Tieres beobachtet werden. Ich glanbe vielmehr: und ich habe dies anch an früherer Stelle näher ausgeführt, daß wir es hier mit älteren Skeletstücken zu tum haben. Ob wir dïnnere Wandungen der Stachehn und geringere Anzahl der Zähnchen als Lokalvarietäten oder gar als nene Arten aufzufassen haben, scheint mir fraglich; denn weun bei dem mir vorliegenden Material auch ein Fang meist uur Tiere mit dümwandigen Stacheln mo wenigen Zïhnchen mit heraufbrachte, so mag dies auf einem Zufall beruhen. Ich sith nümlich auch solche Exemplare, die an andern Stellen mit dickwandigen zusammen erbeutet wurden. Iclı glaube vielmehr, daß wir es in diesen Fällen mit noch jugendlichen Stadien zu tun haben. Die geringere Anzahl von Zähnchen, die meist nicht auf einer spärlicheren Verteilung bernht, kann anch mit einer größeren Ausdehmmg des Weichkörpers zusammenhängen, in welchem der Stachel noch größtenteils eingebettet steckt. Alle sekundären Stachelbildungen entstehen ja, wie wir gesehen haben, in der änßersten Zone und der Region der Psendopodien. Ich habe es vermieden, ein Maß für Stacheldicke nnd Iänge der Zälnchen anzugeben. Genan ist ein solches anch vicht festzustellen. Nur das läßt sich sagen, daß bei Aulacantha scolymantha Häckel die Länge der Zähnchen (gemeint ist der Abstand ilner Spitze vom Stachel) nie die Länge des Stacheldurchmessers erreicht. Die Stachelröhren selbst sind ammähernd zylindrisch, bisweilen etwas gekrümmt. Ihr proximales Énde ist abgerundet, jedoch keiner Calotte entsprechend, sondern mehr dem spitzen Pole eines Eis.

$$
\text { Fundorte: }
$$

Aulacantha scolymantha Häckel ist kosmopolitisch, nach den Berichten der CHALLEXGERExpedition, sowolı im Atlantischen wie im Indischen und Pazifischen Ozean heimisch. Auf der Plankton-Expedition wurde sie in allen berührten Stromgebieten gefunden (vgl. Tabellen). Wie bekannt, erbeutete Häckel diese Art als erste Aulacantlide im Mittelmeer bei Messina. Später wurde sie anch an anderen Küsten des westlichen Mittelmeeres gefangen. E. Vanh öffen stellte ihr Torkommen im Karajak-Fjord an der Westkïste Grönlands fest und E. Jörgensen teilt als Fundort die Westküste Norwegens mit.

Von E. Häckel sind noch folgende weitere Vertreter der Gattung beschrieben worden: Aulacantha tubulosa Fäckel 1887 ans dem Zentral-I'acifik. Station 271-274 Oberfläche. Aulacuntha spinosa Häckel 1887 ans den Nord-Pacifik. Station 241-253 Oberfläche.

Aulacantha cannelluta Häckel 1887 aus dem Süd-Pacifik. Station 292-293 Oberfläche. Aulacantha clavata Häckel 1887 aus dem Süd-Atlantik. Station 318 innerhalb $3733 \mathrm{~m}$. Aulacantha laevissima Häckel 1887 aus dem Nord-Atlantik (Faroe-Kanal) und ans der Grönland-See, westlich Spitzbergen (die Stationen sind die der Chaldexger-Expedition).

V. Hensen und K. Möbins erwähnen in den »Berichten der Kieler Kommission《 eine anch von A. Borgert zitierte Aulacantha temuis Hëckel, deren Beschreibung ich jedoch in keiner der mir zugänglichen Arbeiten anfznfinden vermochte. 
III. Genus Aulactinium Häckel 1887

(war im Material der Plankton-Expedition nicht vertreten. Beschreilung siehe II äckel CHALLExGER-Report die cinschlägigen Kapitel).

\section{Genns Auloceros Häckel 1887.}

Die Gattung zeigt in Änßern manche Ähnlichkeit mit Aulokleptes rumosus mihi, ist aber prinzipiell ditvon merschieden durch dis liehlen einer fremden Stachelgrundlage. Im innern Anfbau des Stachels schließt sich Auloceros eng an die nachfolgende Gattung Aulographis an, indem der eigentliche Stachel hohl ist, aber knmpakte Endbildungen trägt. V'on denjenigen bei Aulograplis sind letztere dadurch unterschieden, daß sie sich in eigentliche Äste verzweigen, in dem sie sekmuläre, bisweilen anch tertiäre und weitere Fortsïtze treiben. Eine bestimmte, stets wiederkehrende Regel scheint hierbei nicht zu bestehen, doch ist die dichotumische 'T'eilnng bevorzugt. Bei dem mir vorliegenden Material fand ich dic primären Endverzweigungen meist in der Zweizahl. Nach 1. Häckel läßt sich tas Genus in zwei Unterabteilungren trennen, in solche Formen mit einem Spathill an den Astenden und in solche, bei welchen der Zweig einfach spitz endet. Ob sich diese Trenmung stets durchfïhren lassen wird, bleibe dahingestellt. Bei dem von mir untersuchten Material waren alle Äste mit Gebilden verschen, die ich als Spathille ansprechen muBte. Letzteres war jerloch sehr verschieden in seinem Ausbildungsgrad. Ich vermochte nicht einen prinzipiellen Unterschied zu machen zwischen solchen Arten, welche unverkennbare Hakenkränze anfweisen, und denen, wo letztere nur durch wenige winzige Zülnchen angedentet sind; denm beiderlei formen kommen an gleichen Individum zuweilen vor. Es scheint, als ob auch hier die Pseudopodienstrahlung ihren Einfluß auf die Stachelbiliung ausübe, und daß clieselbe in ihrer Gestaltung nicht an ganz strenge Regeln gebunden sei; demn auch die Zahl der Verzweignngen der Äste geht nicht immer nach dem gleichen Schena vor sich, indem bei eimzelnen Ästen des gleichen Individuums eine solche vollkommen unterbleiben oder sich anf eine geringere Zahl beschränken kann. Nur einen Unterschied glaube ich bei dem untersuchten Material feststellen zu können: das ist die Art und Weise, wie die 'T'eilung stattfindet. Dis gleichzeitig' dieser Unterschied sich anch anf lokal getremnte Formen bezieht, die auch sonst im Habitus sich unterscheiden, so habe ich ihn bei der Art-Trennung benutzt. Eimmal nämlich sehen wir die Spaltung vollzogen in amnähernd einer Ebene; in andern Fällen schneiden die Ebenen, in welchen die sekundären Äste liegen, diejenige, in denen die primüren Äste verlanfen, im rechten Winkel. Ich betone, daß dies Terhalten sich nur auf die wenigen von mir beobachteten Vertreter der Gattung Auloceros bezicht. Möglicherweise ist es nur ein zufälliges. Weitere Untersuchnngen werden das vielleicht feststellen künnen. Der Stachel selbst ist spindelförmig oder auch seltener nahezu zylindrisch gebaut und endet proximal eifümig: abgestumpft. Seinem Äußern entspricht durchaus nicht der innere Hohlraum, der nach dem distalen Ende hin enger wird und spitz-kinplefförmig zwischen den beiden primären Endästen ansläuft. Die Verengerung beruht anf einer Verdickung der Stachelwandung in mentrifugaler' Richtung. Im Innern der lindäste bemerkt man oft hellere Linien, welche daratif hinclenten, daß auch hier die Stachelmasse noch nicht vollkommen homogen, sondern wahrscheinlich durch allmähliche Ablagerung entstanden ist. Bei der folgenden Beschreibung kommt nur das Häckel'sche 
Subgenus Auloceratium in Betracht, welches sich eben durch Besitz eines Spathills an den Astenden auszeichnet. Zwei Formen lassen sich wie bereits erwähnt, unterscheiden, welche ich jedoch mit Torsicht als Tarietäten zweier Häckel'scher Arten anführe, mit denen sie am meisten ïbereinstimmen. Möglicherweise sind es auch selbständige Spezies, wofür namentïch anch die räumliche 'Trennung von dem Fundort des 'lypus spricht. Allıngroßes Gewicht dürfte anch daranf allerdings nicht gelegt werden können. Bei beiden Arten kommen Tangentialnadeln vor.

a) Äste im gauzen schlink gebant. Die tertiären und sekmudären Verzweignugen, sorreit solche rorbanden. liegen annähernd in der gleichen Elsene jederseits. Spathill in seiner Entwicklung sehr rersehieden . . . . . . . . . . . . . . Auloreros spathillaster rar. biramens.

b) Äste meist etwas lerb, und kürzer als im vorigen Fall. Die l'eilungen liegen nicht in derselben Ebene bei jedem Ast. spathill dentlich vorhanden als doppelter Hakenkranz............ Auloceros arborescens var. dichodenelmum.

\section{Auloceros spathillaster (Häckel 1887) var. birameus milhi.}

(Tafel T. Fig. 10.)

Die Art (resp. Varietait) ist ansgezeichnet durch stark spindelförmige Röhren, deren Wandungen nach dem distalen Encle hin an Dicke zunehmen. Gewöhnlich finden sich zwei primäre Endäste, welche in fast tangentialer Richtung divergieren. Dieselben können sich ein- anch zweimal teilen; bisweilen unterbleibt die zweite 'Teilung bei dem einen Ast; seltener' bei allen beiden. Die sekundären und tertiären Äste liegen annühernd in einer Ebene mnd tragen ein Spathill von mehreren Häckchen, deren Zalll schwankt und die sehr verschieden in ihrer Ausbildnng sind. Manchmal können sie nur in ganz geringer Zahl rorkommen und dann nur durch winzige, bei starker Vergrößerung gerade noch sichtbare Zähnchen angedentet sein. Man gerät in Zweifel, ol, es sich hier nicht um eben beginuende neue Astanlagen handelt. Andere Zweige wiedermu tragen einen richtigen Hakenkranz, der unverkennbar ist. Die erste 'Teilung in sekundäre Äste erfolgt in cler Regel er'st in größerer Entfernung von der' primären Trennungsstelle am Ende des unverzweigten eigentlichen Stachels.

\section{Größenverhältnisse:}

Länge der Stacheln: $1,45-1,37 \mathrm{~mm}$.

Dicke im Querschnitt: Nitte 0,04 mm, Distal 0,03 nmm, Proximal 0,35 mm.

Länge der primären Äste bis zur ersten 'Teilung: 0,07—0,08 mm.

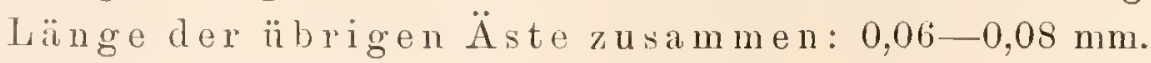

\section{Fundorte:}

Plankton-Expedition: Irminger See 60.2 $\mathrm{N}$. Br., 22.7 ${ }^{\circ} \mathrm{W}$. L., 0-400 m Tiefe, Vertikalnetz. Irminger See 60.3 N. Br., 27.0 W. L., 0-600 m Tiefe, Vertikalnetz. Labradorstrom $50.8^{\circ} \mathrm{N} . \mathrm{Br} ., 47.3^{\circ} \mathrm{W}$. L., 0-500 m Thiefe, Vertikalnetz. Sargasso-See $45.6^{\circ} \mathrm{N} . \mathrm{Br}$., 
$31.5^{\circ} \mathrm{W}$. L., $650-850 \mathrm{~m}$ Tiefe, Schließnetz. Nördlicher Äqnatorialstron 10.2 ${ }^{\circ} \mathrm{N}$. Br., 22.2 $\mathrm{W}^{\circ}$. L., 0-1000 m 'l'iefe, Schließnet\%. Golfstrom $41.1^{\circ} \mathrm{N}$. Br., $21.1 \mathrm{~W}$. L., 0-350 m Tiefe, Vertikalnetz. Grolfstrom 43.6 N. Br., $17.9^{\circ}$ W. L., 0-400 m T'iefe, Tertikalnetz.

2. Auloceros arborescens (Ḧ̈ckel 1S57) var: dichodendrum milii.

('Tafel $\mathrm{Y}$, Fig. 11 und 12.)

Diese Art unterscheidet sich von der eben beschriebenen schon durch den massigeren Bau im allgemeinen. Die Endäste sind viel kürzer und kräftiger im Verhältnis zur Länge, auch fast immer gerade. Die Stachelwandung ist meist ïberall dicker als bei Auloceros spathilluster var. birameus. Ein deutliches Spathill, ans einem doppelten Hakenkranz bestehend, ist stets wahrnehmbar. Die Äste teilen sich in der Regel so (wenigstens bei den untersuchten Exemplaren), daß das folgende Paar die vorhergehende Teilungsebene annähernd im rechten Winkel kreuzt. Es kommen einmalige und doppelte Astteilungen bei den Individuen vor. Bei dem einzelnen Stachel scheinen alle $\ddot{A}$ ste nur einer bestimmten Teilungsregel zu folgen. Über das Verhalten des Hohlraums ist dasselbe zư sagen, wie bei cler vorhergelıenden Art. Die in distaler Richtung stark zmnehmende Terdickung der Wandung läßt die Spindelform der Stacheln bisweilen nicht so sehr zur Geltung kommen, wie bei der vorher beschriebenen Spezies.

Größenverhältnisse:

Läng'e der Stacheln (meist zerbrochen): etwa $0,6 \mathrm{~mm}$.

Querdurchmesser: Nitte 0,06 mm, Distal 0,04-0,02 mm, Proximal 0,2 mm.

Länge der Endäste: Primüre $0,06 \mathrm{~mm}$, übrige $0,04 \mathrm{~mm}$.

\section{Fundorte:}

Plankton-Expedition: Nördlicher Äquatorialstrom 10.2 ${ }^{\circ} \mathrm{N}$. Br., $22.2^{\circ} \mathrm{W}$. L., $0-1000 \mathrm{~m}$ Schließnet\%. Sïdlicher Äquatorialstrom $3.6^{\circ} \mathrm{S}$. Br., 33.2 ${ }^{\circ} \mathrm{W}$. L., $600-700 \mathrm{~m}$ Tiefe, Schließnetz. Südlicher $\ddot{A}$ quatorialstrom $1.8^{\circ} \mathrm{S}$. Br., $38.1^{\circ} \mathrm{W}$. L., 0-600 m Tiefe, Vertikalnetz.

$\mathrm{Nicht}$ anf der Plankton-Expedition erbentet und anderweitig beschrieben sind folgende Arten von Auloceros Häckel:

Subgenus Auloceraea Häckel 1887 d. h. olıne Spathill:

Auloceros furcosus Häckel 1887 ans dem nördlichen Pacifik. Station 231-253, ChaldexcierExpedition, von der Oberfläche und aus verschiedenen 'I'iefen.

. Luloceros trigeminus tỵ. Häckel 1887 ans dem Nord-Atlantik. Station 353, ChatdexgelExpedition, innerhalb einer 'l'iefe ron $5425 \mathrm{~m}$.

Auloceros trigeminus var. Fowler 1898 aus dem nördlichen Ast des Golfstroms (Faroe-Kanal).

Auloceros capreolus Häckel 1887 ans dem sïdlichen Pacifik. Station 295, GhaldexgerExpedition, innerhalb einer Tiefe von $2745 \mathrm{~m}$.

Auloceros cervinus Häckel 1887 ans dem südlichen Atlantik. Station 325, CHAluexgerExpedition, innerhalb einer Tiefe voll $5049 \mathrm{~m}$.

Obertläche.

Auloceros elegans Häckel 1887 aus dem indischen Ozean (siidlich von Matura, Cevlon) 
Ferner ron dem Subgenus Auloceratium Häekel 1887 d. h. mit Spathill:

Auloceros chicranaster Häckel 1887 ans dem nördlichen Pacifik. Station 244-252, CHaLlengerExpedition, aus einer Tiefe zwischen $3750-5780 \mathrm{~m}$.

Auloceros spathillaster tỵp. Häckel 1887 ans dem südlichen Atlantik. Station 319, Chatianger-Expedition, innerhalb einer Tiefe von $4337 \mathrm{~m}$.

Auloceros arhorescens tỵ). Häckel 1887 aus dem südlichen Pacifik. Station 288-295, Cinaluexger-Expedition. ans einer Tiefe zwischen 2745-5490 m: (die Stitionsmmmern beziehen sich auf die CHALLENGER-Expedition).

Bemerknng: Bei den Torkommen von Übergängen zwischen Aulographis triaena Häckel und Auloceros cervinus Häckel, die der betreffende Autor erwähnt, ist mehr als wahrscheinlich, daß auch die Gattmng Luloceros Häckel Formen enthält, die eigentlich dem Gemus Aulokleptes mili zugehören; doch befand sich unter den von mir untersuchten Exemllaren kein solches, was schon darans hervorgeht, dab bei denselben immer ein Spathill konstatiert werden konnte.

\section{Genus Aulographis (Häickel 1887, zum Teil).}

Dieses von Häckel aufgestellte Genus hat in dem hier zugrunde liegenden Srstem wohl die weitgehendsten Umänlerungen erfahren, indem erstens mehrere Formen, die E. Häckel hier untergebracht hatte, num der Gattung Aulokleptes angehören; indem zweitens mehrere andere von E. Häckel und A. Borgert (in seiner Bearbeitung der nordischen Tripyleen) zin Aulographis (Häckel) gestellte, nummehr muter dem Gattungslbegriff Anlocoryne (Fowler) zusammengefaßt werden. Nach der Häckel'schen Einteilnng waren drei in ihrer Bildungsweise verschiedene Stachelformen zn einer Gruppe vereinigt worden. Das Subgemus Aulographella Häckel wurde bereits erwähnt, welches durchweg Diatomeen als Stachelgrundlage besitat. Dasselbe gilt für Aulographis pistillum Häckel, welcher Art der Antor der äußern Form wegen in dem Snbgenus Lulographantha Häckel ihren Platz gab. Für Julographis penecillata Häckel läßt sich dasselhe rermuten. Im Prinzily durchweg anders gebant, als die von mir unter dem Genus Aulographis zusammengefaßten Formen, sind anch alle dem Häckel'schen Subgenus Aulographoniun angehörenden A n la canthiden. Sie werden im folgenden als Gattung Aulocoryne (Fowler) beschrieben werden. So bleiben von den ursprünglich vier Untergattungen nur zwei ïbrig, woron eine auch nur znm Teil. In der nenen Gestalt wird die Gattung Aulographis, von deren mrspriinglicher allgemeiner Charakteristik alles erhalten bleibt, wie folgt, definiert:

Unter der Gattung Aulographis (Häckel) mihi verstehe ich Aulacanthiden mit Mantel ron dïnnen tangential gelagerten, oft gekrümmten, hohlen, an beiden Enden offenen Kieselnadeln und hohlen Radialstacheln. Letztere nehmen in zentrifugaler Richtung an Wandungsdicke zu und tragen einfache Endäste, welche sich nicht weiter in sekurdäre Äste verzweigen, und in welche sich der innere Hollraum des Stachels nicht fortsetzt. Wenigstens bei völlig ausgebildeten Stacheln ist das der Fall. (Es kann nämlich vorkommen, daß bei manchen Stacheln das Innere der Endäste nicht kompakt erscheint, sondern als unregelmäßig begrenzte Höhlung mit der Stachelröhre kommuniziert. Möglicherweise haben wir es lier mit einem unfertigen Stadinn zu tm odler wir müssen das Verlaalten als einen beginnenden Anflösungsprozeß betrachten. 
Da ich hierin keinen normalen Zustand zn erblicken vermochte (diese Stacheln kamen neben durchaus regelmäßig gebanten vor) glaube ich diesem ( mostand keine systematische Bedeutung zumessen zu können.) E. Häckel hat, wie gesagt, mehrere Untergattungen von hulographis unterschieden. von welchen zwei auch hier Verwendung finden können nnd deshalb beibehalten werden sollen, indem bei denselben das ünßerliche Merkmal glcichzeitig der Ansilruck zweier verschiedener Entstehungsrichtungen ist. In den einen Fall (Aulographantu Häckel) sehen wir nämlich, daß der Terminal-Stachel in eine einfache Spitze anslünft, im andern dagegen (Aulographonium Häckel) bildet derselbe an seinem Ende mehrere znrïckgebogene Häkchen ans, welche bei bestimmten Arten nur in geringer Zahl von zwei bis drei anftreten, bei andern einen einfachen oder gar doppelten Kranz bilclen. Wo wir ein solches Spathill finden, dïrfen wir annelmmen, daß der Stachel seine volle Ansbilung erfahren hat und etwas Fertiges darstellt. Anders verhïlt es sich mit den Formen, wo ein Spathill oder anch mur wenige Häkchen am Ende nicht vorhanden sind. Hier kömite dic Vermutumg Platz greifen, daß es sich um unfertige Billungsstadien handle. Aber die betreftenden Formen (d. h. ich fand mur eine, rechne aber verschiedene, ron li. Häckel beschriebene, hierher) sind in ihren ganzen Habitus doch so verschieden von den zuerst erwähnten. mol ich komte niemals eine weitergehende Veränderung beobachten, solaß ich glaube, annehmen zu dürfen, daß es sich hier um einen bestimmten Typus landelt, der nicht als unfertiges Stadinm anfgefaßt werden kann. Mit den andern Arten des gleichen Genus teilt er sonst alle Merkmale, wemn man von nebensächlichen Eigenschaften absieht, wie verschiedene Divergenz, Krümmnng, Lünge der Stacheln, die, natürlich innerhalb bestimmter Grenzen, bei ein und derselben Spezies variieren können. Der Stachel endet proximal dem spitzen Pole eines Eies ähnlich, mitunter etwas anfgebläht. Eine dementsprechende Gestalt hat hier anch der innere Hohlram. Am distalen Encle besitzt letzterer jedoch einen spitz-kuppelförmigen Abschlub, der sich streng in dieser Gestalt bei allen Arten erhält, überhant bei allen Anlacanthiden zn finden ist. welche solide Endäste bei vollkommen selbständiger Stachelbildung besitzen. Da gegen das distale Ende hin der Hohlraum etwas enger, die Wandung aber dicker wird, scheint es manchmal, als ol) der Stachel selbst sehr an Durchmesser zumehme. Dies ist jednch nur in äußerst geringem Maße der Fall. Der Hohlranm ist es, der von der zylindrischen form abweicht und spindelförmig wird; deshalh sehen wir auch später bei verwandten Gattungen, wo die Wandungsdicke dieselbe bleibt, sehr hänfig spindelförmige Stacheln anftreten. Es beruht also auch dieser Gestaltungswechsel allein auf der Wanrlungsdicke, d. h. auf der Substanzınnalıme durch Ablagermg von Kieselsänre:

a) Anloyruplis-Arten ohne S'pathill oder Hakenbildungen am Finde der

Terminaläste . . . . . . . . . . . . . Subgenus Aulographanta Häckel 1887.

\section{Aulographis pandora Häckel 1887.}

(Tafel T, Fig. 6.)

Bei dieser Spezies, welche in einigen Exemplaren untersucht werden komnte, findet sich stets ein dichter Mantel von dümnen, meist gekrümmten Tangentialnadeln. Die Radialstachehn zeigen eine nach dem distalen Ende zu schlanker werdende Gestalt, was jedoch hauptsächlich 
auf dem enger werdenden Hohlranm beruht; wenn auch der Stacheldurchmesser gegen das änßere Ende hin etwas abnimmt. Jeder Radialstachel spaltet sich bei rlen von mir beobachteten Exemplaren in drei konische (Ḧ̈ ckel fand anch mehrere - siehe ChaLbexcer-Report und Radiolarienwerk) nur wenig divergierende Endäste, die vielleicht doppelt so lang sinc, wie der Stachel an ihrer Ursprungsstelle breit ist. Die Stachehwandung ist am proximalen Ende sehr dïnn und nimmt in zentrifugaler Richtung an Dicke zu, während in entsprechender Weise der Hohlraum enger wird, um in der oben erwähnten Form abzuschließen, ohne anch in die Endstacheln ïberzugehen.

$$
\text { Größenverlı̈̈ltnisse: }
$$

Länge der Stacheln: 0,8—1,5 mm (E. Häckel $0,5-1,5 \mathrm{~mm}$ ).

Stacheldurchmesser: $0,024-0,033 \mathrm{~mm}$ (E. Häckel $0,01-0,03 \mathrm{~mm}$ ).

Länge der Endäste: $0,06-0,08 \mathrm{~mm}$ (E. Häckel $0,02-0,12 \mathrm{~mm}$ ).

Fundorte:

Plankton-Expedition: Nordäquatorialstrom $10.2^{\circ}$ N. B., $22.2^{\circ}$ W. L., $0-1000 \mathrm{~m}$ Tiefe, Schließnetz. Sïdäcpnatorialstrom 4.1 ${ }^{\circ}$ S. B., $14.2^{0}$ W. L., $0-400 \mathrm{~m}$ Tiefe, Vertikalnetz. Südäquatorialstrom: $6.8^{\circ}$ S. B., $14.2^{\circ}$ W. L., $600-800 \mathrm{~m}$ Tiefe, Schließnetz. Südäquatorialstrom: 1.80 S. B., 38.1 W. L., $0-600 \mathrm{~m}$ Tiefe, Vertikalnetz.

Ohallexger-Expedition: Mittelmeer, Atlantik, Indischer Ozean, Pacifik an der Oberfläche und in verschiedenen T'iefen.

In Mittelmeer wurde diese Art anßerdem von A. Borgert und K. B randt (letzterer Antor ohne nähere Beschreibung) nachgewiesen.

Anßer dieser Spezies wurden von E. Häckel noch folgende Arten des Subgenus Aulographanta beschrieben, die ich nicht bei dem Material der Plankton-Expedition fand:

Aulograpleis bovicomis Häckel 1887 aus dem Süd-Atlantik (östl. Buenos-Ayres) Oberfläche.

Aulographis taumorpha Häckel 1887 aus dem Nord-Pacifik. Station 231, ChaldexgerExpedition, innerhalb einer Tiefe von 4117 m.

Aulographistriglochin Häckel 1887 aus dem zentralen Pacifik. Station 271 - 274, ChallengerExpedition von der Oberflïche.

Aulographis cruciata Häckel 1887 ans dem Sïd-Atlantik. Station 325, ChaldengerExpedition von der Oberfläche.

Aulographis ancorata Häckel 1887 ans dem Südwesten des Atlantik. Station 318, ChallexgerExpedition, imerhalb einer Tiefe von $3733 \mathrm{~m}$.

Aulographis stellata Häckel 1887 aus dem indischen Ozean bei Madagaskar von der Oberfläche.

Ferner gehört hierher die von R. N. Wolfenden beschriebene Aulographis furcellata ans dem Faroe-Kanal, gefunden in einer Tiefe von $450 \mathrm{~m}$.

b) Aulographis-Arten, deren Endäste mit kleinen gekrümmten Endhaken

oder einem vollkommen ausgebildeten spathill, ans gekriimniten

Zühnchen gebildet, versehen sind . . . . . . . . Sulogenus Aulographonium Häekel 1887. 


\section{Aulographis tridactylus n. sp.}

(Tafel V, Fig. \%.)

Diese Spezies gelangte in einem einzigen Exemplar zur Beobachtung. Die tangentialen Nadeln sind kurz und spärlich vorhanden, die Radialstacheln dagegen ziemlich lang und zylindrisch gebant. Das scheinbare »enger werden« gegen das distale Ende hin wird wie bei der vorigen Art vorgetänscht durch die allmähliche Verdickung der Wandung in dieser Richtung, mit welcher eine Verengerung des innern Hohlraums Itand in Hand geht. Dieser endet proximal stumpf abgerundet, distal in eine spitze Kuppel. Die Endbildungen bestehen aus drei beinahe tangential ansgebreiteten massiven Endästen, welche in je drei sprossenähnliche Gebilde ausliufen. Ob dieselben den Beginn dreier Haken vorstellen, kann ich nicht sagen, da sie nur an einem Stachel und anch da nur unvollkommen erhalten waren. Jedenfalls ist die Bildung ander's wie bei einem Spathill, das nicht die vorbereitenden Einkerbungen zeigt, wie wir sie hier finden. Die aus dem südlichen stillen Ozean stammende, von E. Ḧ̈ ckel beschriebene Aulograplis trianguhum stinmt sonst in her äuBern Form mit unserer Aulographis tridactylus annähernd ïberein, doch ist bei jener, wie die Häckel"sche Zeichnung zeigt, ein deutliches Spathill mit vier rückwärts gekrümmten Haken rorhanden, welches sich mit der angedeuteten Endbildung, wie sie bei Aulographis triductylus vorkommt, in keine Übereinstimmung bringen läßt. Wenn man allerdings in Erwägung zieht, wie solche Bildungen nach der D r e y e r'schen Theorie entstanden zu denken sind, dann dürften wir auf einen solchen Unterschied, der danach ja nur auf einer geringfügigen Verlagerung von Bläschen beruht, nicht zu hoch anschlagen. Vorläufig, so lange nur dies eine Exemplar der Lntersuchung zur Verfiigung steht, lassen sich leider keine Vergleiche anstellen, und wenn wir die Häckel'sche Definition von Aulographis triangulum aufrecht erhalten wollen, dann muB Aulographis tridactylus als nene Spezies betrachtet werden. Auch dürfte die große Entfernung der Fundstellen gegen eine solche ldentität sprechen, wenn wir andererseits auch Beispiele von sehr weit verteilten Arten besitzen.

\section{Größenverhältnisse:}

Länge der Stacheln: Über 1,2 mm (nicht genau zu messen, weil alle zerbrochen). Stacheldurchmesser: $0,013-0,017 \mathrm{~mm}$.

Länge der Endäste bis zum Beginn der Kerbe: 0,13-0,14 mm.

Fundort:

Plankt on-Expedition: Südlicher $\ddot{\text { Aquatorialstron }} 1.7^{\circ} \mathrm{N} . \mathrm{Br} ., 17.3^{\circ} \mathrm{W} . \mathrm{L} ., 0-500 \mathrm{~m}$ Tiefe, Vertikalnetz.

\section{Aulographis uncinata n. sp.}

(Tafel V, Fig. 8.)

Diese nur in Bruchstiicken beobachtete Aulacanthidenspezies zeichnet sich dadurch aus, daß sie verhältnismäßig lange Radialstachehn besitz, welche im großen und ganzen zylindrisch gebant sind und nur bisweilen gegen das distale Ende hin etwas schlanker werden, während die Wandung dabei an Dicke zunimmt. Der innere Hohlranm endet, wie in den vorher beschriebenen Fällen, spitz, kuppelförmiğ und setzt sich nicht in die Endbildungen fort. Letztere 
bestelien aus vier stark divergierenden massiven Endüsten, welche etwas nach unten gebogen sind und am lunde drei oder vier (keinen Kranz bildende!) zurïckgekrümmte Häkchen tragen, so daß das Ende jedes Terminalastes einer bekrallten Tatze gleicht.

\section{Größenrerhältnisse:}

L ä n g e d e r S ta c h eln: Komte nicht festgestellt werden, da alle Nadeln zerbrochen waren. Stacheldur chmesser: $0,03 \mathrm{~mm}$.

länge der Endäste: 0,33 mm.

\section{Fundort:}

Plankton-Expedition: Südlicher Äqnatorialstrom $3.6{ }^{\circ}$ S. B., $33.2^{\circ}$ W. L., $600-700 \mathrm{~m}$ Tiefe, Schließnetz.

\section{Aulographis tetrancistra Häckel 1887.}

(Tafel T, Fig. 7.)

Borgert 1901 .

Diese anf der l'lankton-Expedition in grroßer Anzahl erbentete Spezies besitzt gerade, beinahe zylindrische Radialstacheln, neben einer großen Zahl von tangential gelagerten, dünnen, meistens gekrïmmten hohlen Kiesehnadeln. Die Wandungen der radiär gestellten Stachelu nelımen in distaler Richtung an Dicke zn, während der imere Hohlraum hier enger wird. Geschieht beides in ungleichem Verhältnis, so reigt der Stachel ein leicht spindelförmiges Aussehen, zumal er nach der proximalen Seite hin häufig etwas schlanker wird. Er trägt meist vier, schräg nach anßen divergierende massive Terminaläste, welche gewöhnlich etwas nach innen gekrümmt sind und ein Spathill von drei, vier oder fünf zurïckgebogenen Häkchen besitzen. Bisweilen kömnen anch nur drei Terminaläste auftreten oder ihre Zahl kann die von vier überschreiten (bis zu 6 Ästen). Doch kommt dies nicht häufig vor, wenigstens bei dem Material, welches mir zur Untersuchnng vorlag. Das proximale Ende des Stachels ist meist abgerundet, und ihm entspricht auch der innere Hohlraum, während derselbe nach anßen spitz-kuppelförmig ausläuft, sich also nicht in die 'Terminaläste fortsetzt.

\section{Größenverlı̈ltnisse:}

Länge des Stachel s: 0,5-0,7 mm (A. Borgert 0,5-0,6 mm, F. Häckel 0,7 mm). Stacheldurchmesser: Distal $0,005-0,006 \mathrm{~mm}$, Mitte $0,007-0,01 \mathrm{~mm}$ (A. Borgert 0,01-0,013 mm, E. Häckel 0,01 mm).

Läinge der Lindäste: sehr verschieden (A. Borgert 0,035-0,053 mm, E. Häckel $0,08-0,1 \mathrm{~mm})$.

\section{Fundorte:}

Plankton-Expedition: Irminger See $60.2^{\circ} \mathrm{N}$. Br, $22.7^{\circ} \mathrm{W}$. L. und $60.3^{\circ} \mathrm{N}$. Br., $27^{\circ}$ W. L., 900-1000 m Tiefe, Schließnetz. Labrarlorstrom 50.8 ${ }^{\circ}$ N. Br., 47.3 ${ }^{\circ}$ W. L., 0-500 m Tiefe, Vertikalnetz. Labralorstrom 50.0 N. Br., $48.1^{\circ} \mathrm{W}$. L., $0-300 \mathrm{~m}$ Tiefe, Vertikalnetz.

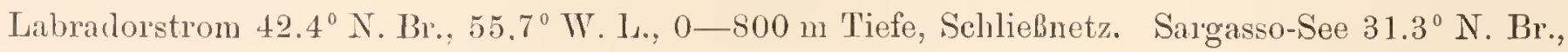


$47.7^{\circ} \mathrm{W}$. L., 0-400 m 'liefe, Vertikalnetz. Sargasso-See $30.9^{\circ} \mathrm{N}$. Br., $53.1^{\circ} \mathrm{W}$. 1., Oberfläche (unsichere Fanguummer!). Nordäquatorialstrom $10.2^{\circ} \mathrm{N}$. Br., 22.2 W. L., 0-1000 m Tiefe, SchlieBnetz. Guineastrom 3.6 N. Br., $19.1^{\circ}$ W. L., 700 -900 m 'liefe, Schließnetz. Golfstrom $41.1^{\circ} \mathrm{N}$. Br., $21.1^{\circ} \mathrm{W}^{r}$. L., 0-350 m Tiefe, Vertikahnet\%.

Chaldexger-Fxpedition: Südlicher Pacifik. Station 285, Chaldexger-Expedition, innerhalb $5346 \mathrm{~m}$ Tiefe.

Nicht vorhanden waren bei dem Material der Plankton-Expedition folgende, früher von E. Ḧ̈̈kel (siehe Chathexgen-Report) beschriebene hierher gehörende Arten:

Aulographis furcula Häckel 1887 ans dem Nord-West des Pacifik (bei Japran). Station 231, Chaldexger-Expedition, innerhalb einer 'Jiefe von $4117 \mathrm{~m}$.

Aulographis triangulum (siehe oben) Häckel 1887.

Aulographis hexancistru Häckel 1887 aus dem nördlichen Pacifik. Station 244-253, Chaldexger-Expedition, innerhalb einer 'l'iefe von $6562 \mathrm{~m}$ und $3750 \mathrm{~m}$.

Aulographis polyancistra Häckel 1887 ans dem tropischen Atlantik. Station 347, ChablexgerExpedition, imerhalb einer 'Tiefe von $4117 \mathrm{~m}$.

Aulographis asteriscus Häckel 1887 ans dem südlichen Atlantik. Station 318, ChaLlengerExpedition, innerhalb einer Tiefe vou $3733 \mathrm{~m}$.

R. N. Wolfenden erwähnt noch eine Tarietät von Alugraphis tetrancistru (Hückel), gefunden im Faroe-Kanal in einer 'Tiefe von $730 \mathrm{~m}$.

\section{Gemus Aulophyton nov. gen.}

Diese neue Gattung ist bei dem Material der Plankton-Expedition nur durch eine Speries vertreten. Sie wrude aufgestellt für Formen, welche ähnlich wie Aulographis äußerlich gebant sind, bei denen aber der innere Hohlranm nicht wie bei dulographis (Häckel) mit Beginn der Endbildungen abschliebt, sondern sich in dieselben fortsetzt. Auch ist von einer

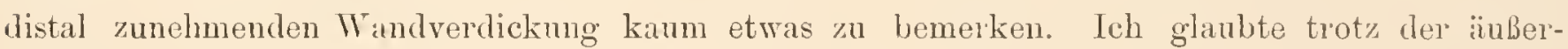
lichen Ähnlichkeit sie deswegen absondern zn müssen, weil nach meiner Ansicht gerado die Ausbildung des Hohlramms das Wesentliche bedentet, während gleiche oder ähnliche äußere Form konvergent aus verschiedenem Ursprung sich entwickeh kaun. In der Gestalt des imnern Hohlraums ist ein T'eil des Bildungsganges aber gegeben. In wenigen Exemplaren, deren Stacheln alle abgebrochen waren und in Calymma zerstreut lagen, wird diese Gattung durch folgende Sprezies repräsentiert.

\section{Aulophyton tetronyx nov. gen. nov. spec.}

(Tafel VT, Fig. 10.)

Stark gekrïmmte 'l'angentiahnadeln sincl in geringer Menge vorhanden. Die Radialstacheln, die, wie gesagt, alle zerbrochen waren bei den zur Beobachtung gelangten Exemplaren, scheinen eine bedentende Länge zu hesitzen und sind schlank gebaut. Gegen das distale Ende zn sind die Stacheln etwas dicker, ein Lmstand, der jedoch nicht so sehr auf einer Verstärkung der Wandung beruht, als vielmelı auf einer geringen Erweiterung des Hohl- 
rammes. Nan könnte hierin vielleicht einen Übergang zur nächsten Gattung erblicken, doch ist die Bildnng der Terminaläste ganz anders; dieselben haben sehr viel Ähnlichkeit mit Aulographis uncinata mihi. Auch hier können wir vier Endiste konstatieren, die kreuzweise gestellt sind. Dieselben tragen am Ende zwei krallenartige Gebilde, von welchen ein jedes aus zwei znrückgekrïmmten Häkchen besteht. Es ist also, wenn man es so anffassen will, eine mininal dichotomisehe 'T'eilnng zu beobachten. Über das proximale Ende der Stacheln kamn ich nichts änßern, da dasselbe bei keinem Stachel erhalten oder sonst aufunfinden war.

Größenverhältnisse:

Länge der Stacheln: ? (wahrscheinlich verhältnismäßig lang).

Stacheldurchmesser: $0,030-0,033 \mathrm{~mm}$.

Länge der Endäste: $0,16-0,17$ mm.

Fundort:

Plankton-Expedition: Nordäquatorialstrom $10.2^{\circ} \mathrm{N}$. Br., $22.2^{\circ} \mathrm{W}$. L., $0-1000 \mathrm{~m}$ Tiefe, Schließnetz.

VII. Genus Aulocoryne (Fowles 1898).

Anloymetplis Häckel 1887, zum T., Anlogruplis Borgert 1901. zum T.

Ein stets vorhandenes Merkmal dieser Gattung, wenn anch bisweilen nicht in demselben Maße ansgebildet, ist die kolbenförmige Aufblïhung des Stachels am distalen Ende und zwar an der Ursprungsstelle der Terminaläste, welehe stets in größerer Zahıl (wenigstens fünf) vorhanden sind. Die Radialstacheln zeichnen sich durch bedeutende Länge aus und sind schlank gebant. Mitunter nelmen sie eine etwas spindelfömige Gestalt an, welche dadurch bedingt ist, daB der Hohlraum sich anf eine gewisse Strecke hin (meist in der Mitte des Stachels oder in zweidrittel der Länge) etwas erweitert. Diese greringfügige Erweiterung ist wohl zu unterscheiden von der bereits genannten oft kugel- oder linsenförmigen Aufblähung im distalen Ende, wie wir sie bei dieser. Gattung stets finden. Ausgezeichnet sind die Stachehn ferner. dadurch, daß die Wandung äußerst gleichmäßig ist und überall, auch in den I'erminalästen, dieselbe Stïlke besitzt. Hierbei sehe ich natiirlich ab von den kleinen massiven Zähnchen, mit welchen mitunter die Endiiste ihrer ganzen Länge nach ansgestattet sind. Der innere Hohlpaum entspricht sonst ïberall der äuBern Gestalt. Die Endäste sind meist in konzentrischen Kreisen angeordnet, können jedoch auch bei einer gewissen Spezies so zahlreich werden, daß sie die Oberfliiche des Kolbens vollständig in Anspruch nehmen. Regel ist das Vorkommen emes Spathills an Ende der Terminaläste. Ls läßt sich dies auch erwarten, da der ganze Stachel das Gepuräge des Fertigen trägt und einen bestimmten Bauplan aufweist. Tangentialnadeln sind nur sehr spärlich vorhanden.

Bei den Anlacanthiden der Plankton-Expedition ist diese Gattmig durch vier Spezies vertreten:
a) mit zentral gestelltun Eudästen und einem Lireis von solchen. . Aulocoryne derututu, Aulocoryne cundelubrum.
b) mit zrei Kreisen von Endästen ohne solche im Zentrum. . . . Aulocoryne pulcinutu.
c) mit zahleeichen mregrelmäbig gestellten Endisten ....... Lulocoryne zetesios. 
1. Aulocoryne dentata (Häckel) milì.

(Tafel VT, Fig. S.)

Aulographis dentatı Häckel 1887, selır wahrscheinlich auch identisch mit Aulographis meditemenea Borgert 1901.

Un einen in dier Richtung des Stachels von einer mehr oder weniger kolbenförmigen Aufblähmng entspringenden hohlen geraden Ast stellen sich krenzweise vier fast tangential gerichtete weitere $\ddot{A} s t e$, welche ebenfalls von der wrähnten Aufblähung ansfrehen und an ihrem änßern Ende etwas nach innen gebogen sind. Dieselben, ebenso wre auch der mittlere Ast sind mit kleinen zurückgebogenen Zühnchen besetzt, welche bald in großer Zahl auftreten, bald sich nur auf einige wenige, oft kaum bemerkbare beschränken. Eine regelmäßige Anorhung derselben in heihen konnte ich ebensowenig wahrnehmen, wie ich mich ron ilren regelmäßigen Anftreten überhaupt zu überzeugen vermochte. Dies gilt sowohl für Aulocoryne dentata als anch fiir die nächst folgende Splezies Aulocoryne candelabrum. (Gerade dieser letztere Umstand, die Möglichkeit des Fehlens, bestärkt mich in der Vermutung, daß wir in der Aulographis mediterranea Borgert um eine Lokalvarietät unserel Spezies zu suchen haben. Sie besitzt nach A. Borgert keine seitlichen Zähnchen im Gegensatz zu Aulographis dentata Häckel auf den Zeichnungen in den Werken des Autors. Abel auch bei dem Material, das mir zur Verfügung stand, war die Zahl der Zälnnclıen äußelst inkonstant und bei Aulocoryne candelabrum fand ich eiu Exemplar neben anderen, das vollkommen zahnlos an vielen Stacheln war.) Ein Spathill ist stets vorhanden und zwar konnte ich auf dem mittelsten Ast in der Regrel einen doppelten Hakenkranz konstatieren, wïrend die peripheren Aste nur einen einfachen von vier bis sechs Zähnchen trngen.

Gröbenverliälto isse:

L ïnge der Stacheln: nicht meBbar, dir zerbrochen (nach E. Häckel 1,5-2,5 mm).

Stacheldurchmesser: Nitte 0,017-0,19 $\mathrm{mm}(0,03 \mathrm{~mm}$ nach E. Häckel), distales Ende $0,008-0,009 \mathrm{~mm}$.

L ̈̈nge der End ̈̈s te: Mittlerer 0,07-0,09 mm, ïußere 0,16-0,18 mm (nach E. Häckel $0,18-0,2 \mathrm{~mm})$.

Fundorte:

Plankton-Expedition: Guineastrom $3.6^{0} \mathrm{~N} . \mathrm{Bl}^{\circ}, 19.1^{0} \mathrm{~W}$. L., $450-650 \mathrm{~m}$ Tiefe, Schließnetz. Südlicher ̈̈quatorialstrom $7.3^{\circ} \mathrm{S} . \mathrm{Br} ., 21.4^{\circ} \mathrm{W}$. L., 0-400 m 'Tiefe, Vertikalnetz.

2. Aulocoryne candelabrum (Häickel) mihi.

('Tafel VI, Fig. 5, 6, 7.)

Aulographis cundelubrum Häckel 1887.

Diese Spezies ist nach dem gleichen Prinzip gebaut, wie die eben beschriebene Lulocoryne dentata (Häckel) mihi. Sie nuterscheidet sich aber von ihr dadurch, daB statt des einen mittleren Astes zwei schräg nach außen divergierende vorhanden sind. Jei den Exemplaren, die ich ans eigener Anschaumg kenne, waren dieselben immer gerade, nie gekrümmt, wie sie E. Häckel abbildet; auch die Divergenz tritt bedlentend stärker hervor. Nur die peripheren Äste zeigen 
am äußem Ende cine kleine Biegmng nach innen. Die Zahl der 'Terminaläste war bei meinen Exemplaren auch geringer, als E. Häckel sie angibt. Dessen ungeachtet glanbe ich doch, daß es sich $\mathrm{mm}$ die gleiche Art handelt, da ja das ganze Bildungsprinzip dasselbe ist. Die 'Terminaläste sind mit melır oder weniger zahlreichen gekrimmten, seitlich stehenden Zähnchen besetzt, die mitunter aber anch nur ganz schwach orler anch gar nicht ansgebildet sind. Hiertiber habe ich mich bereits ansgelassen. Wir dürfen also diesen Gebilden keinen zı großen systematischen Wert beimessen. Finden wir die lateralen Zähnchen mehr oder weniger inkonstant in ihrem Anftreten, so ist dagegen ein Ends p a th il I inmer bei jedem der Terminaläste vorhanden und besteht ans vier bis sechs nach anßen zurückgekrïmmten Zühnchen. Die Wandung des ganzen Stachels ist verhältnismäßig dünn und überall gleichmäßig, wenn wir von den Einschränkungen absehen, die bereits bei Aulocoryne dentata Erwähnung fanden. Das proximale Ende zeigt ein rundliches Aussehen.

\section{Größenverhältnisse:}

Länge der Stacheln: etwa $1,8 \mathrm{~mm}$ (E. Häckel 1,6-2,4 mm).

Stacheldurchmesser: 0,03-0,036 mm (E. Häckel 0,03-0,05 mm).

Länge deํ. Endäste: 0,15-0,25 mm (E. Häckel 0,2-0,3 mm).

Fundorte:

Plankton-Expedition: Nordäquatorialstrom $10.2^{\circ} \mathrm{N} . \mathrm{Br}, 22.2^{\circ} \mathrm{W} . \mathrm{L}, 0-1000 \mathrm{~m}$ Tiefe, Schließnet\%. Guineastrom 5.90 N. Br., 20.3 W. L., 1000-1200 m Tiefe, Schließnetz.

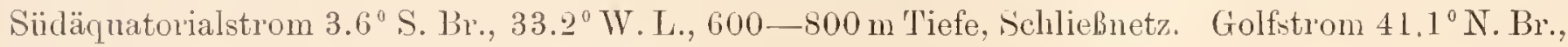
$21.1^{\circ} \mathrm{W}$. I., $0-350 \mathrm{~m}$ Tiefe, Vertikalnetz.

Chathenger-Expedition: Süd-Pacifik bei Juan Fernandez.

\section{Aulocoryne pulvinata (Häckel) mihi.}

(Tafel KI, Fig. 9.)

Aulographis mulrinata Häckel 1887, Aulograpleis moorensis Fowler 1898, Auloaraphis pulvinata Borgert 1901.

Anf dem mehr oder weniger kolben- bis linsenartig anfgeblähten distalen Ende der meist spindelförmig grestalteten Radialstacheln entspringen randständig zwei konzentrische Reihen nach außen divergierender T'erminaläste, deren Stellung in den beiden Kreisen abwechselt. An den einander zugekehrten Seiten sind die Äste mit je einer Reihe nach Art einer Säge aufeinander folgender; zurïckgebogener Zähnchen besetzt und tragen am äußern Ende ein Spathill von sechs oder mehr radial gestellten, etwas abwärts gebogenen Häkchen. Die 'T'erminaläste selbst können etwas nach innen gekrümmt sein. Die Wandıng der Stachehn war bei den von mir beobachteten Exemplaren äußerst düm und aus diesem Grunde sind sie durch Druck wohl meist abgebrochen, wenn ich das 'T'ier behufs genauer Untersuchung trotz aller Vorsichtsmaßregeh unter ein Deckglas brachte. Resistenter dagegen verhielten sich die 'T'erminaläste, die kaum einmal rerletzt wurden. Die Bruchstelle entstand, was merkwürdig 
erscheint, da der geringste Durchmesser am distalen Ende sich befindet, fast immer in proximalen Drittel. Es möchte dies wohl mit Unstïnden zusammenhüngen, die ich bei den Betrachtungen iiber die Stachelentstehung näher erörtert habe.

Größenverhältuisse:

Läng e der Stacheln: 1,4-1,6 mun ungenan (A. Borgert 1,8-2,4 nm, Fi. Häckel 2—2,4 mm). Stacheldnrehmesser: Distal 0,01 mm, Nitte 0,02-0,03 mm (A. Borgert 0,025 bis

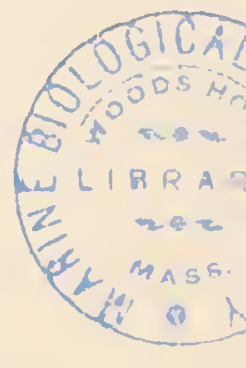
$0,07 \mathrm{~mm}$, E. Häckel $0,03-0,07 \mathrm{~mm}$ ).

Länge der Endäste: 0,044 mm (E. Häckel nnd A. Borgert 0,05-—0,08 mm).

Fundorte:

Plankton-Expedition: Irminger See $60.3^{\circ} \mathrm{N}$. Br., $27.0^{\circ} \mathrm{W}$. L., 0-600 m 'l'iefe, Vertikalnetz. Sïdlicher Ärnatorialstrom $1.7^{\circ} \mathrm{N}$. Br.. $17.3^{\circ} \mathrm{W}$. L., 0 - $00 \mathrm{~m}$ 'liefe, Vertikalnet\%.

Chablexger-Expedition: Süd-ost-Pacifik bei Valparaiso innerhalb $4000 \mathrm{~m}$ 'liefe.

Nach Fowler: Nördlicher Ast des Golfstroms $59^{\circ}$ N. Br., $7^{\circ}$ W. L., $640-880 \mathrm{~m}$ Tiefe, Schließnetz.

4. Aulocoryne zetesios Fowler 1898.

('Tafel VII, Fig. 1.)

Aulogruphis zitesios Borgert 1901.

Diese Art ist ansgezeichnet durch änßerst zerbrechliche Rarlialstacheh von bedentender Länge. Trotz der relativ zahlreichen Exemplare gelang es mir nie, anch nur einen vollständig erhaltenen Stachel $z$ beobachten. In clen weitans meisten Fällen war der birnförmig anfgeblähte Endknopf abgebrochen und man sah dliese Gebilde mit den Endfürten ïberall nmherliegen. Tangentialnadeln fehlen scheinbar, wenigstens konnte ich dieselben nicht in der Weise feststellen, wie dies bei andern Gattungen und Arten der Fall war. Gelegentlich ließen sich Frendkörper beobachten, welche wohl mehr zufïllig an ihren Plat\% geraten waren. Statt dessen sind aber eine sehr große Anzahl von Radialstacheln vorhanden, welche einen dichten Wald bilden. Sie haben eine nahezn zylinclrische Form, die manchmal die Gestalt einer schr gestrecliten Spindel annimmt. Das proximale Encle ist eiförmig zugespitzt, das clistale trägt eine kolbenförmige Aufblälung des innern Hohlraums nnd diese ist äber und über besetzt mit langen, radiür ausstrahlenden, faclenförmigen lindästen, welche korkzieherartig gewurden sind und ein Spathill von mehreren (sechs bis zelın) zurückgebogenen Zähnchen am Ende tragen. Anf ihrer ganzen Länge sind sie anßen bedeckt mit einer spiraligen, den Lanfe der Windungen folgenden lieihe von kleinen zuriickgekrümmten Zähnchen. Der innere Hohlıam entspricht der äußern Form und setat sich, trotz deren Feinheit, in die Endïste, wie es den Anschein hat, fort.

\section{Gröbenverhältnisse:}

Länge der Stachelu: Aus angegebenen Grïnden nicht genan meßbar, jedenfalls aber über 1,7 mm lang (uach A. Borgert bis zu $3 \mathrm{~mm}$ ).

Staclield nrchmesser: $0,014-0,022 \mathrm{~mm}$.

Länge der Endäste: 0,15-0,2 mm. 
Fundorte:

Plankton-Expedition: Irminger See $60.3^{\circ}$ N. Br., $27.0^{\circ}$ W. L., 0-600 m Tiefe, Vertikalnetz.

Nach Fow ler: Nördlicher Ast des Golfstroms (Faroe-Kanal) $60^{\circ} \mathrm{N}$. Br., $5^{0} \mathrm{~W}$. L., $335-465 \mathrm{~m}$ 'Tiefe, Schließnetzfang.

Zur Gattung Lulocoryne dürften ferner folgende nicht auf der Plankton-Expedition erbeutete, von H. Hä ckel unter dem Subgenus Aulographonium mit dem Gattungsnamen Aulographis beschriebene Formen gehören (siehe ChaLLexare-Report und Radiolarienwerk):

Aulographis tripentas Häckel 1887 aus dem Sïd-Ost-Pacifik (bei Juan Fermandez) immerhalb $3930 \mathrm{~m}$ 'Tiefe.

Iulographis verticillata Häckel 1887 ans dem Süd-Pacifik. Station 293, ChablengerExpedition, immerhalb $3780 \mathrm{~m}$ Tiefe.

Aulographis sermelata Häckel 1887 ans dem Nord-Pacifik. Station 253 und 254, ChallexgerExpedition, imnerhalb einer Tiefe von $5535 \mathrm{~m}$ und $5718 \mathrm{~m}$.

\section{Genus Aulospathis Häckel 1887.}

Die hierber gehörenden Aulacanthiden sind mit einem Mantel von zahlreichen Tangentialnadeln versehen. Die relativ langen, spindelförmigen Radialstacheln tragen außer Endbildungen noch im distalen Drittel der Stachellänge sich seitlich abzweigende Äste, welche im allgemeinen quirffömig angeordnet sind, jedoch sonst in der Stellung meist keine Regelmäßigkeit zeigen und anch häufig nicht alle auf derselben Höhe ihren Ursprung nehmen. Immerhin ist diese laterale Abzweignng nur auf eine kurze Strecke des Stachels beschränkt, welche ungefïh an der Grenze zwischen mittlerem und äßerem Drittel der Stachellänge liegt. Die Wandungen der Stacheln sind dünn, im allgemeinen regelmäßig und überall gleichartig. Der Hohlramm setat sich sowohl in die Endbildungen, wie in die Lateraläste fort. Erstere können bei manchen Arten ihren Ursprung aus einer eifö'mig aufgeblähten Stachelerweiterung nehmen, welche bei andern Formen nicht zur Ausbildung kommt. Regel scheint das Vorkommen eines Endspathills zu sein, mit welchem nicht nur die Terminaläste, sondern auch die lateralen Answüchse versehen sind. Es besteht meistens ans einem einfachen oder doppelten Kranz von je vier bis sechs gekrïmmten Zähnchen. Nach E. Häckels Vorgang können wir zwei Untergattungen unterscheiden:

a) mit aufgeblähten Endeu . . . . . . . . . Subgenus Lulospathessa Häckel 1887.

\section{Aulospathis bifurca Häckel 1887.}

Borgert 1901 .

(Tafel VII, Fig. 2 a und b.)

Die Tangentialnadeln bilden einen dichten Mantel. Die Radialstachehn an sich sind spindelförmig, sehr dünn werdend gegen das proximale Ende, welches sich wieder leicht erweitert. Distal ist eine eiförmige Aufblähung des innern Hohlraums vorhanden. Ans ilır entspringen zwei, bisweilen auch drei divergierende, jedoch im Verlanf sich leicht nach innen krümmende hohle Endäste. Die Lateraläste nehmen etwa an der Grenze des mittleren und 
äußeren Drittels der 'Tube ihren Ursprung. Ihre Anzahl und Richtung ist lreine regelmäßige, bisweilen zwei, manchmal auch vier bis sechs. Wenn anch im großen und ganzen quirlförmig gestellt, entspringen sie meist doch nicht alle in derselben llöhe. Krïmmungen sinł an ilnen anch zu beobachten. Das $\mathrm{Spathill} \mathrm{ist} \mathrm{ans} \mathrm{einem} \mathrm{Kranz} \mathrm{von} \mathrm{vier} \mathrm{bis} \mathrm{sechs} \mathrm{gekrümnten} \mathrm{Zühnchen}$ gebildet. Mitunter steht noch ein Zähnchen in Zentrum. 1)er innere Hohlraum entspricht, natïrlich bis auf das Spathill, der änßern Gestalt vollkommen. Trotz der ziemlich dünnen Wandungen zeigten die Stacheh sich sehr resistent.

Gröbenverhältnisse:

Läinge der Stacheln: 2,28-2,52 mm (A. Borgert 1,5-2,5 mm).

Stacheldurchmesser: Distal 0,042-0,048 mm, Nitte 0,06-0,066 mm, Proximal $0,02-0,025$ (A. Borgert 0,04-0,07 mm).

Länge der Endäste: 0,13-0,18 mm (A. Borgert 0,1—0,16 mm).

Fundorte:

Plankton-Expedition: Irminger See $60.3^{\circ} \mathrm{N}$. Br., $27.0^{\circ} \mathrm{W}$. L., $0-600$ m 'liefe, Vertikalnetr.

CHallexger-Expedition: Sïd-Pacifik. Station 293-295, Challexger-Experlition imnerhalb einer 'Tiefe von $2700-4150 \mathrm{~m}$.

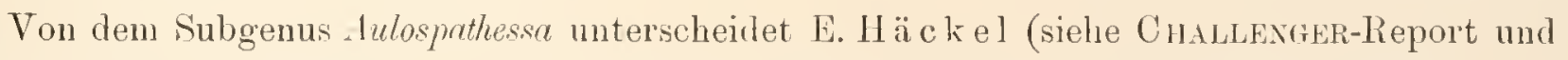
Radiolarienwerk) noch folgende nicht anf der Plankton-kxpedition beobachtete Spezies:

Aulospathis trifurca Häckel 1887 (Station 289-300, Challexger-Lxpedition).

Aulospathis quadrifuren Häckel 1887 (Station 291, CHALLExaER-Expedition).

Aulospathis polymorpha Häckel 1887 (Station 289, Challexger-Expedition).

Sämtlich aus dem südlichen stillen Ozean innerhalb Tiefen bis etwa $5000 \mathrm{~m}$.

b) die Radialstacheln olne Aufblähungen an distalen Ende. Die

Terminaläste entspringen direkt an der Tubse . . . . . Subgenus fulospathilla Hïelsel 1887.

\section{Aulospathis monodon nov. sp.}

(Tafel TII, Fig. 3 a und b.)

Tangentialnadeln sint in geringer Menge vorhanden. Die zahlreichen Radialstachelı sind relaliv lang und melır oder weniger spindelförmig gebaut. Das proximale Ende länft bisweilen etwas spitz zn, doch scheint das nicht liegel zu sein, da es auch in beinahe ebensoviel Fïllen ein alggerundetes Anssehen zeigt. Das distale Hude hat große Ähnlichkeit mit dem einer Pipette, indem es sich ziemlich unvernittelt verjüngt. Es besteht fast regelmäBig ans einem einzigen schlank gebanten Ast. Nur sehr selten konnte ich deren zwei beobachten. Daß ein Spathill hier vorhanden ist, kam ich nicht bchanpten, denn säntliche Spitzen waren nach außen geöffnet, so daß es den Anschein hatte, als ob das eigentliche Ende felılte, d. h. abgebrochen sei. Da die Lateraläste, welche, was Stellung anbelangt dasselbe Verhalten zeigen, wie bei der vorher beschriebenen Art und in ihrer Anzahl zwischen drei und sechs schlanken, stets ein Spathill tragen, so dürfte die Annahme einer Verstümmelung der Terminal- 
spitzen wohl richtig sein; das heißt, daß anch diese normalerweise mit einem $\mathrm{Spathill}$ versehen sind. Dasjenige der Seitenïste besteht aus einem Dolpelkranz von vier bis sechs gekrïmmten Vähnchen. Die Stachelwandungen sind selır gleichmäbig und der innere Hohlranm entspricht der äußern Gestalt.

Größenverhältnisse:

Länge der Stacheln (bis zur Bruchstelle): 0,9-1,0 mm.

Stacheldurchmesser: Mitte 0,04-0,06 mm, Proximal 0,018 mm, Distal (Durchmesser des Astes) 0,02—0,024 mm.

Lïnge des Endastes: schätzungsweise $0,25 \mathrm{~mm}$.

$$
\text { Fundort: }
$$

Plankton-Expedition: Südlicher Äquatorialstrom $7.8^{\circ} \mathrm{S} . \mathrm{Br} \cdot, 17.3^{\circ} \mathrm{W} . \mathrm{L}, 0-400 \mathrm{~m}$ Tiefe, Vertikalnetr.

\section{Aulospathis triodon Häckel 1887.}

(Tafel VII, Fig. 4 a und b.)

Tangentialnadeln sind vorhanden. Die Radialstacheln zeigen gewöhnlich ein etwas spindelförmiges Ausselıen und werden nach dem stumpf auslaufenden Proximalende zu dünner. Das distale endet in drei (vereinzelte Stacheln auch vier) nach außen divergierende, mehr oder weniger nach imnen gekrümmte Äste, welche an ilnrer Spitze einen doppelten Kranz von vier bis sechs gekrünmten Zähnchen tragen. Gerade so verhalten sich in dieser Beziehung die Lateraläste, welche teils quirlförmig eng zusammenstehen, teils vollkommen unregelmäßig auf eine kurze Strecke verteilt, gerade oder grekrümmt nach den verschiedensten Seiten hin divergieren. Thre Anzahl schwankt zwischen vier bis sechs. Die Stachelwandung ist sehr dünn. Der innere Hohlraum setzt sich in Lateral- und T'erminalbildungen der äußern Gestalt entsprechend fort.

$$
\text { Größenverhältuisse: }
$$

Länge der Stacheln: 1,8-2,1 mm (E. Häckel 2-3 mm).

Stacheldurchmesser; Mitte 0,04-0,048 mm, Distal 0,02-0,03 mm, Proximal $0,009-0.01 \mathrm{~mm}$ (E. Häckel $0,03-0,05 \mathrm{~mm}$ ).

L äng e der Endäiste: 0,16-0,19 mm (E. Häckel 0,2—0,3 mm).

$$
\text { Fundorte: }
$$

Plankton-Expedition: Sargasso-See $31.5^{\circ}$ N. Br., 59.0 W. L., zwischen 900 und $1100 \mathrm{~m}$ 'Tiefe, Schließnetz. Sargasso-See $31.5^{\circ} \mathrm{N}$. Br., $40.7^{\circ} \mathrm{W}$. L., zwischen 1300 und $1500 \mathrm{~m}$ Tiefe, Schließnet\%.

Chaldexger-Expedition: Nord-P'acifik. Station 250-253, Challexger-Expedition, zwischen 4300 und $5000 \mathrm{~m}$ Tiefe.

N ich t vertreten waren bei dem Material der Plankton-Expedition folgende von E. Häckel (ChAlLex(ier-Report und Radiolarienwerk) beschriebene Arten des Subgenus Aulospathilla Häckel: 
Aulosputhis diodon Häckel 1887 aus dem Nord-1'acifik. Station 231, CHALLExGEr-Expredition, innerhalbs einer 'l'iefe von $4117 \mathrm{~m}$.

Aulospathis tetrodon Häckel 1887 ans dem Nord-Pacifik. Station 244 zu 245, ChaldexakriExpedition, zwischen 5060 und $5500 \mathrm{~m}$ T'iefe.

Aulospathis hexodon Häckel 1887 ans dem westlichen tropischen Pacifil. Station 224, Chaldexger-Experlition, innerhalb $3385 \mathrm{~m}$ Tiefe.

Aulospathis furcata Häickel 1887 ans dem Pacifik (süd-östlich der Sandwichs-Inseln). Zwischen 5000 und $5500 \mathrm{~m}$ Tiefe.

Aulospathis variabilis Häckel 1887 ans dem Kentralen Gebiet des Pacifik. Station 271 bis 274, Chaldextier-Expedition, zwischen 4300 und $5000 \mathrm{~m}$ 'T'iefe.

\section{Genus Aulodendron Häckel 1887}

(wurde auf der Plankton-Expedition nicht erbeutet; Beschreihnng der einzelnen Arten siehe E. Hä ckel im CHALLENGERReport, ferner bei Cleve siehe Verzeichnis und Borgert, nordische Tripyleeu).

Wir haben num alle auf der Plankton-Experition erbenteten A ulacanthiden-Formen kennen gelernt. Im Anschluß an ihre Beschreibung wurden auch diejenigen Arten angeführt, die außerdem auf frihthen Experlitionen und Fahrten gefunden worden sind. Das hierbei angewandte System hat auch, so gnt es ging, der mutmaßlichen Verwandtschaft Rechnmig getragen. Wir gingen dabei von einer Art aus, welche Fremclkörper benutzt, um dieselben ihren Bedürfnissen anzupassen. Die anfänglich durch Zusammenwirken äußerer und inmerer Umstände geschaffenen physiologischen Verhältnisse wurden durch Weitervererbung immer fester gelegt und dadurch zu einer Fähigkeit, an bestimmten Körperstellen auch ohne Einwirkung von Fremdbestandteilen Kieselsäure abscheiden zu können. Die ungeführten Gattungen entsprechen nach meiner Annahme den einzelnen Bildungsrichtungen oder manchmal auch Stadien, welche die Stachelentwicklnng einnahm. Wie die Spezialisierung weiterging, können wir bei einzelnen Gattungen noch sehr schön verfolgen. So zeigt zum Beispiel die Gattming Aulocoryne zunächst eine Form in der Spezies Aulocoryne dentata (resp. mediterranea), wo um einen zentralen Ast sich ein Kranz von andern bildet, zmü̈chst vier (vielleicht anch drei), dann mehr. Nun verdoppelt sich der mittlere Ast: Wir gelangen zu der Art Aulocoryne candelubrum. Dieselbe Spezies zeigt Formen mit drei und vier mittleren Ästen am gleichen Tier. Wir sehen also, daß die T'endenz herrscht, die Endäste zu vermehren. Zunächst wird dies da geschehen, wo am meisten Raum ist, also in der Mitte. Wenn die Neubildngen hier zu zahlreich werden, müssen sie sich anf einen zweiten Ḱreis verteilen und zwar wird der Ramm am wenigsten beengt zwischen je zwei Ästen des ̈̈ußern Kreises, dessen Äste sich auch vermehrt laben. Wir erhalten so eine Form, wie sie durch Aulocoryne pulvinata repräsentiert wird. Die Äste vermehren sich immer mehr (oder was dasselbe ist, die Psendopodienbüschel werden immer feiner), werden dünner und suchen durch schraubenartige Drehung zu ersetzen, was ihnen an Festigkeit verloren gegangen ist. Anf diese Weise mag Aulororyme zetesios schließlich entstanden sein. Wo wir uns umsehen, bemerken wir eine Tendenz, die Zahl der Endäste zu vermehren, 
indem gleichzeitig die äußere Form eine weniger veränderliche Gestalt gewinnt, dadurch daß ein weiteres Wachstum durch Snbstanzvermehrung des einzelnen Stachels immer mehr verschwindet. Dies kommt durch die Ưbereinstimmung des imnern Hohlraums mit dem äußern Habitus zum Anstruck. $\mathrm{Ob}$ alle diese Gattungen. sich getrennt aus einer Anlokleptesform entwickelt laben, oder welche davon nur wieder Vorstufen für spezialisiertere Arten sein mögen, darüber glaube ich mich noch nicht näher mit Gewißheit änßern zu dürfen. Jedenfalls bilden die Aulacanthiden eine fest umgrenzte Gruppe unter den Radiolarien, die aus skeletlosen $\mathrm{Phaeodarien} \mathrm{hervorgegangen} \mathrm{ist.}$ 


\section{Faunistischer Teil.}

Ans Grïnden, die in der Einleitung bereits Erwähnung fanden, wird in diesem Abschnitt des Öfteren auf Angaben der Protokolle hingewiesen werten müssen, die mir zu überlassen Herr Professor K. Brandt die große Liebenswürdigkeit hatte. Manches Ergänzende für die Schließnetzfänge und die gesanten Angaben über die Ergebnisse der Züge mit dem Hensen’schen Planktonnetz sind ihnen entnommen. Gerade letztere haben, wie wir im kommenden noch sehen werden, durch ihr großenteils negatives Fangresultat hervorragende Bedeutung für unser Wissen über die vertikale Verbreitung der Aulacanthiden gewomnen.

In den Aufzeichnnngen waren begreiflicherweise die Arten nicht näher bestimmt, und man hatte sich nur mit der Angabe des Genus begnïgt. Dazu kommt, daß diese Gennsnamen sich natürlich auf das bisher gebränchliche System beziehen, sich also nicht so ohne weiteres fïr die vorliegende Abhandlung verwenden lassen. Wie wir wissen, beherbergt beispielsweise die neue Gattung Lulokleptes Formen, die nach dem frïheren System bei schneller Orientierung ganz gut als zu Aulographis Häckel oder Auloceros Häckel gehörend bezeichnet werden konnten. In demselben Sinne sind möglicherweise auch Arten von Aulographis mihi und Aulocoryne (Fowler) mihi unterschiedslos mit dem Namen Aulographis angefülnt worden. In solchen Fällen war alsn nicht zu entscheiden, welche Forn ursprünglich beobachtet worden war. Allerdings lassen ja benachbarte Fänge, welche en materie vorhanden waren und zur Untersuchung gelangten, Schlüsse zu. Aber diese bleiben eben doch immer nur Vermutungen, die sich allerdings mit Vorbehalt benutzen lassen. Um jederzeit eine Nachpüifung möglich zn machen, habe ich in den folgenden Tabellen die in den Protokollen vermerkten Anlacanthiden, die ich wegen Fehlens der betreffenden Fangnummer nicht untersuchen konnte, mit der nrsprüngliclien Bezeichmung unter dem Gattungsnamen angeführt. War mur das Vorhandensein der Gattung als solche vermerkt, so ist dies in den T'abellen durch ein Kreuz bezeichnet; war eine bestimmte Anzahl angegeben, so gibt die in den 'Tabellen vorhandene Ziffer darüber Aufschluß. Diese Bezeichmungen verlaufen vollkommen unabhüngig von denjenigen, welche bei den Speziesnamen eingetragen sind. Es ist also z. B. ganz gut möglich, daß eine Art bereits unter einem anderen Gattungsnamen bei derselben Fangnummer figuriert, wie es unter anderem auch vorkommen kann, daß laut Protokoll Auloceros Häckel als vorhanden angefïhrt und auch in meinen Tabellen durch ein Kreuz, beziehungsweise eine Zahl bei dem Gattungsbegriff Auloceros vermerkt ist, während die Untersuchung eimen Aulokleptes ergab, der unter seiner Speziesbezeichnung in der ihm 
zugehörenden Tabellenreihe auftritt. Maßgebend können natürlich nur die letzteren sein. Die vorhin genannten weiteren Angaben dienen $m$ r dazu, einen möglichst vollständigen Überblick über das zn gewähren, was die frühleren vorlänfigen Untersuchungen (zum Teil schon an Bord ansgeführt) ergaben. Ich habe mich dabei genau an das schriftlich Überlieferte gehalten. Hiervon gesondert läßt sich also das Material überblicken, welches mir tatsächlich in konservierten Präparaten vorlag. Während wir also für die Angabe der Verbreitung der einzelnen Gattungen etwils kritisch mit den Tabellenresultaten zn Werke gehen müssen, dürfen wir für die Ansbreitung der Anlacanthiden ïberhanpt ruhig anch das mit verwenden, was nur durch Protokollbericht vorläufig festgestellt wurde. Nach diesen Toransschickungen seien die nächsten Abschnitte der Verbreitnng der Aulacanthiden im nördlichen und tropischen Atlantischen Ozean gewidmet.

Als Tripyleen werden die Anlacanthiden im allgemeinen als Tiefenbewohner betrachtet. Dieser Umstand, ron welchem wir im kommenden noch sehen werden, ob er volle Berechtigung hat, veranlaßt uns, die Verbreitung von zwei Gesichtspunkten aus zu betrachten und in zweiter Linie die dabei getrennt erhaltenen Ergebnisse mit einander in Beziehung zu setzen. Der Versnch einer ursächlichen Begrïndung des örtlichen Vorkommens wird sodamn den Abschnß bilden. Znnächst wenden wir uns der Betrachtung der horizontalen Verbreitung zu, um dann diejenige in vertikaler Richtung anzuschließen. Was die Reihenfolge im einzelnen anbelangt, so wird im allgemeinen die Route des NATIOxג maßgebend sein, jedoch in der Weise, daß die berïhrten Meeresgebiete geschlossen fïr sich betrachtet werden, auch wenn sie während der Fahrt in zwei getrennten Zeitabschnitten durchfischt wurden.

\section{Horizontale Verbreitung.}

Die Plankton-Expedition hatte Gelegenheit, folgende Meeresströmungen und ozeanische Gebiete zu nntersuchen :

1. Östliche Region und nördlichen Ast des Golfstroms.

2. Irminger-See.

3. Ostgrönlandstrom.

4. Westgrönlandstrom.

5. Labradorstrom an seiner Grenze mit dem Golf-resp. Floridastrom.

6. Floridastrom in seinem nordöstlichen 'leil.

7. Sargasso-See, welche von West nach Ost durchfahren wnrde.

8. Nordäquatorialstrom, welchen der NATIONAL einmal in westlichen Regionen durchschnitt und einmal in östlichen bei seinem Ursprung aus dem Kanarienstrom.

9. Guineastrom, der in entsprechender Weise zweimal dnichquert wurde.

10. Südäquatorialstrom, wohl am ansgiebigsten erforscht, indem er von Norden her bis Ascension durchschnitten, sodann in seiner Länge bis zur Mündung des Amazonenstroms verfolgt und schließlich noch einmal in dieser westlichen Gegend gekrenzt wurde.

Nicht in Betracht kommen für die Verbreitung der Aulacanthiden der Ost- und der Westgrönlandstrom; welche keinerlei Arten lieferten. Wir können ferner übergehen den 
westlichen Qnerschnitt des Sïdïquatorjalstroms, welcher anf allerdings mu wenigen Stationen ohme ein für uns branchbares liesultat mutersucht wurde. Die ïbrigen obengenamnten Meeresgebiete beherkergten sämtlich Aulacanthiden, wenn anch in verschiedener Artverteihng und Anzahl.

\section{Golfstrom.}

Wie schon oben ingedentet, können wir hier zwei Gebiete unterscheiden, die anch in faunistischer Beziehung getrennt sind. Während wir im nördlichen Ast nur drei Arten von

Tabelle I. ${ }^{1}$ )

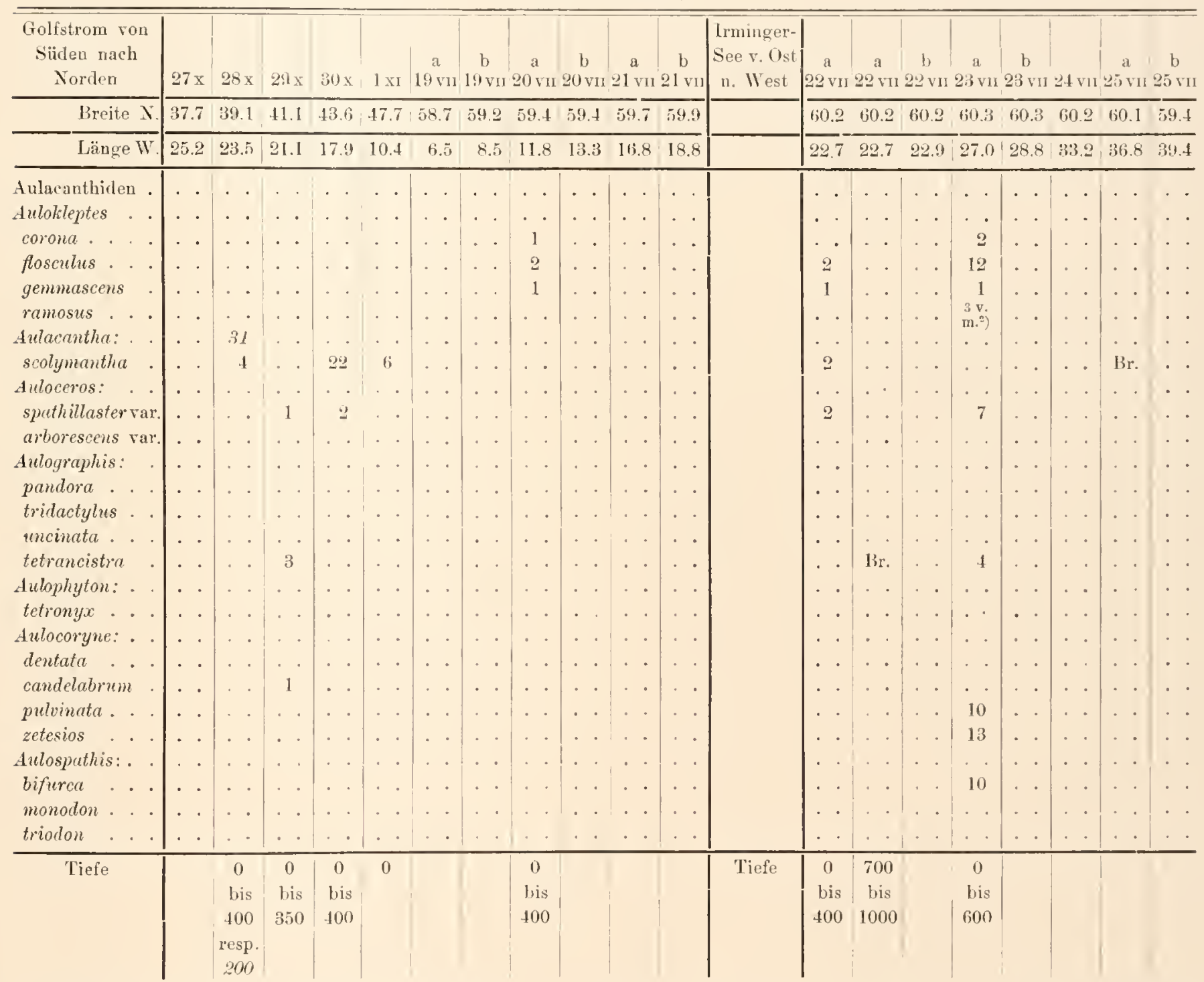

Aulokleptes finden, zeigen die niedrigeren Breiten eine große Zahl von Aulacantha scolymantha Häckel, ferner sind vertreten Auloceros spathillaster (Hïckel) var. Aulographis tetranciste Häckel

1) Hier und in den folgenden Tabellen bedeuten die Ziffern in liegender Schrift Fangergebnisse mit dem Planktonnetz. Dasselbe gilt für die Tiefenangabo.

2) จ. $\mathrm{m}=$ var. multituberculatus. 
und Aulocoryne candelabmom (Häckel); letztere drei Arten nur in geringerer Menge. Von Fowler wurde im nördlichen Ast der Strömung beim Faroe-Kanal noch Aulacantha scolymantha Häckel, ferner Aulographis pulvinata Häckel und Aulocoryne zetesios Fowler anfgefunden. Von Aulacantha scolymantha wissen wir schon durch die CHALLExGER-Expedition, daß sie kosmopolitisch ist, und wie sich im folgenden noch zeigen wird, begegnen wir dieser Spezies auch fast allenthalben anf der Route des Natroxal. Was die Gattung Aulokleptes mihi anbelangt, so werden wir sehen, daß sie nit Ansnahme einer Spezies nur in löheren Breiten vertreten ist. Anch die von Fow lerim Faroe-Kanal gefundenen Formen sind typisch für höhere Breiten, namentlich Aulocoryne zetesios Fowler. Der nördliche Ast des Golfstroms hat also schon teilweise Bewohner kalter Meere in sein horizontales Gebiet aufgenommen. Verschieden hiervon verhält sich die andere untersuchte Region der gleichen Meeresströmung. Hier finden wir ein Gemisch von Vertretern ans verschiedenen Gebieten. Hervorzuheben ist namentlich das Vorkommen von Auloceros spathillaster (Häckel) var., welcher Unterart wir noch mehrere Male unter merkwürdigen Unständen begegnen werden.

\section{Irminger See.}

(Siehe auch Tabelle I.)

Eine ganz charakteristische Fauna zeigt dieses Mischgebiet von kalten und warmen Strömungen in Bezug auf Aulacanthiden. Anch hier finden wir, wie nach den obigen Angaben zn vermuten war, die Gattung Aulokleptes mihi und zwar in vier Arten, wobei die Spezies Aulokleptes ramosus mili durch eine Varietät vertreten ist, die nur in diesen hohen Breiten erbentet wurde: Aulokleptes ramosus var. multituberculatus. Anßer dieser Art sind also vorhanden: Aulokleptes corona mihi, Aulokleptes flosculus (Häckel), Aulokleptes gemmascens (Häckel), welche drei Arten bereits ihre Torposten in den nördlichen Ast des Golfstromes gesandt hatten. Wenn Fundortsangaben für verwandte Formen in tropischen Gebieten seitens der CHALlifger-Expedition vorliegen, so haben wir den zweiten Faktor, die Fundtiefe, mit in Betracht zn ziehen, wozu jetzt noch nicht die passende Gelegenheit geboten ist. Charakteristisch für die Irminger See ist anch die schon erwähnte, hier in größeren Mengen auftretende Aulocoryne zetesios Fowler. Ebenso können wir Aulocoryne pulvinata (Hïckel) als eine Form der kalten Regionen ansprechen, wenn wir sie anch späterhin weiter sïdlich unter besonderen Verhältnissen antreffen. Von der Gattung Auloceros ist die hier erscheinende Varietät von Auloceros spathillaster Häckel mit Vorliebe in kälteren Strömungen heimisch, wie wir noch sehen werden. Außer der überall vorkonmenden Aulacantha scolymantha Häckel, die in reichlicher Zahl auftritt, finden wir noclı Aulographis tetrancistra Häckel, welche Spezies eine ansgedehntere Verbreitung besitzt. Je weiter wir gegen Westen kommen, nm so ärmer wird das Meer an Aulacanthiden. Ost- und Westgrönlandstrom enthalten keine einzige Art. Allerdings muß hierbei in Betracht grezogen werden, daß der Ostgrönlandstrom nur eben auf der Fahrt berïhrt wurde. Aber die sich schon vorher geltend machende Abnahme spricht sehr für eine da herrschende Armut. Der Westgrönlandstrom wurde in seiner ganzen Breite von der lixpeditonsroute durchschnitten, ohne ein für uns positives Resultat zu bringen. 


\section{Labradorstrom.}

Hier bildet sich an der Grenze zwischen dieser kalten und der Golfströmung wieder eine kleine Ansammlung von Aulacanthiden. Reichlich namentlich vertreten ist Aulographis tetrancistra Häckel, welche Art wohl hier in größter. Menge gefungen worden ist. Etwas weniger zahlreich findet sich wieder Aulacantha scolymantha Häckel. Sie bilket mit der vorhergehenden Sprezies die oben genannte

'T'abelle II.

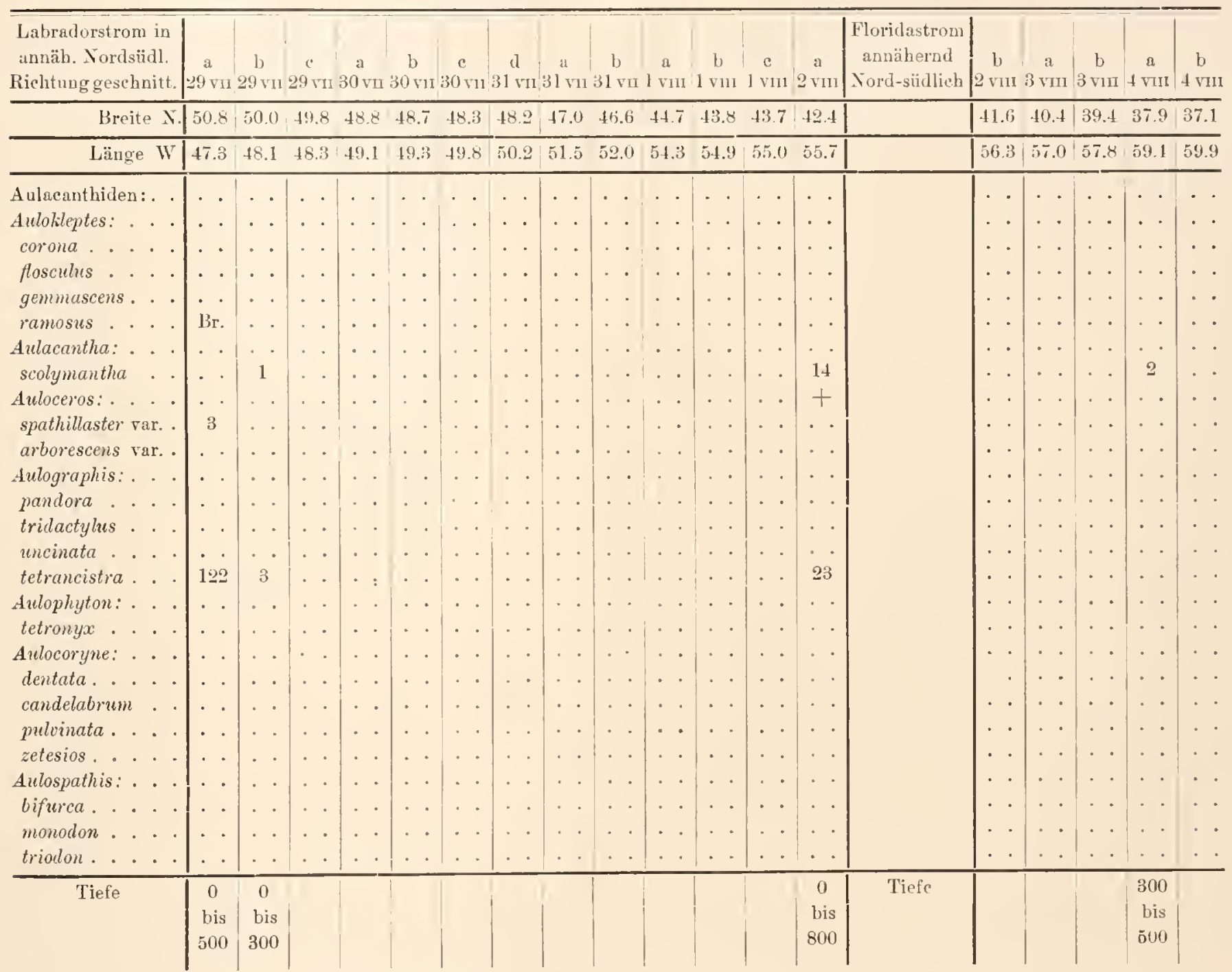

Massenansammlung an der Grenze des Floridastromes, während Auloceros arborescens (Häckel) var. und Aulokleptes ramosus - diesmal nicht die Varietät multituberculatus, sondern longispina — an der Stelle erbeutet wurden, wo der Labradorstrom um die Ecke von Nen-Fundland herumbiegt.

\section{Floridastrom.}

(Siehe auch Tabelle II.)

Die geringe Strecke dieser Strömung, welche zur Erforschnng gelangte, ist sehr arm an Aulacanthiden. An einer einzigen Stelle wurde Aulacantha scolymantha Häckel durch das Schließnetz heraufgebracht. 


\section{Sargasso-See.}

In diesem Gebiet vorherrschend sind die Formen Aulacantha scolymantha Häckel und Aulographis tetrancistra Häckel. Im Protokoll ist allerdings an melneren Punkten das Vorkommen der Gattung Auloceros (Häckel) vermerkt. Bei einer solchen Nummer fand ich einen Aulokleptes ramosus von der Form, wie wir sie im Labradorstrom kennen lernten, der wohl identisch Tabelle III.

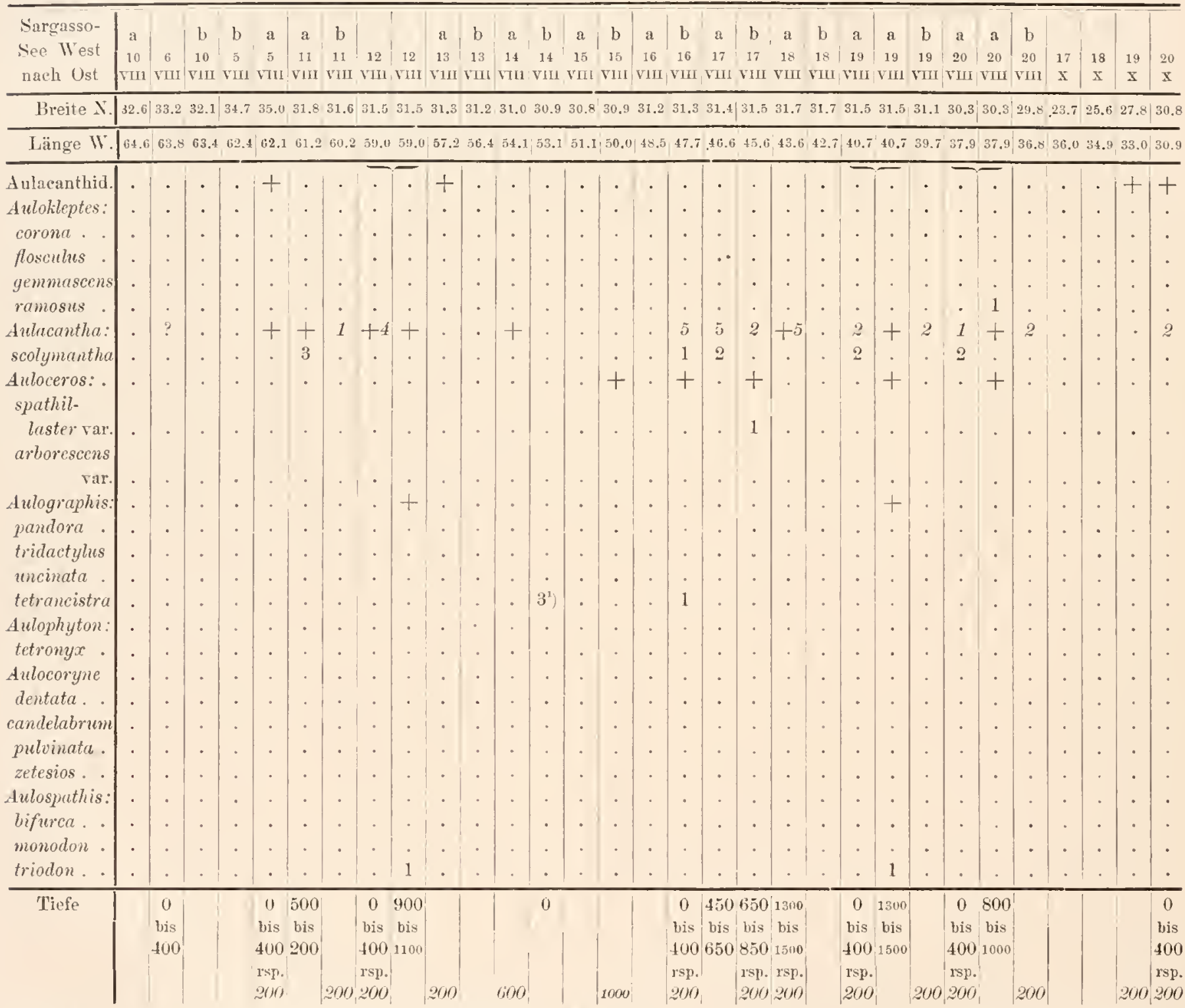

sein wird mit der im Protokoll verzeichneten Auloceros, da diese Gattungen äußerlich ja sehr viel Ähnlichkeit haben. Ein weiteres Präparat von einer Auloceros angebenden Protokoll-Nummer zeigte mil Auloceros spathillaster (Häckel) var', während mir bei den übrigen Fïngen eine Artbestimmung aus erwähnten Gründen versagt blieb. Aulographis pandora Häckel wurde in wenigen Resten anfgefunden und zwar im mittleren Gebiet der Sargasso-See. In gleicher Weise vereinzelt brachte das Schließnetz nicht weit von der eben erwähnten Fundstelle eine Aulospathis triodon Häckel herauf.

1) Unsichere Angabe. 


\section{(i. Nordäquatorialstrom mit Kanarienstrom.}

Ton einem westlichen Gebiet, für welches der Nordïquatorialstrom allein in Betracht kommt, haben wir hier ein östliches zu unterscheiden, wo derselbe nit dem Kanarienstrom in Verbindung steht. Beide Regionen wrden vom Natioxal in nach Norden zu konvergierenden Linien durchschnitten. Zwischen beiden besteht ein gewaltiger famistischer Tabelle IV.

\begin{tabular}{|c|c|c|c|c|c|c|c|c|c|c|c|c|c|c|c|c|c|c|c|c|c|c|c|}
\hline Fordäquatorial- & & & & & & & & & 7. & The & & & & ser & irno & ram & ch & h & igt. & & & & \\
\hline $\begin{array}{l}\text { u. Kanarienstrom } \\
2 \mathrm{mal} \text { ron Sïd naeh } \\
\text { Nord durehschnitt. }\end{array}$ & $\begin{array}{l}13 \\
x\end{array}$ & $\begin{array}{c}14 \\
x\end{array}$ & $\begin{array}{c}15 \\
x\end{array}$ & $\begin{array}{l}16 \\
x\end{array}$ & $\begin{array}{c}2 \\
1 \mathrm{x}\end{array}$ & $\begin{array}{l}2 \\
\mathrm{x}\end{array}$ & $\begin{array}{l}\mathrm{b} \\
1 \\
1 \mathrm{x}\end{array}$ & $\begin{array}{l}\mathrm{a} \\
1 \\
\mathrm{Ix}\end{array}$ & \begin{tabular}{|c|}
$\mathrm{b}$ \\
30 \\
$\mathrm{v} m$ \\
\end{tabular} & $\begin{array}{c}\mathrm{a} \\
30 \\
\text { vill }\end{array}$ & $\left|\begin{array}{c}29 \\
\text { rinl }\end{array}\right|$ & \begin{tabular}{|c|}
$b$ \\
$26 i$ \\
rIII
\end{tabular} & $\begin{array}{c}a \\
26 \\
\text { vШI }\end{array}$ & \begin{tabular}{|c|}
$b$ \\
25 \\
vIII
\end{tabular} & $\begin{array}{c}a \\
25 \\
\text { vili } \\
\end{array}$ & $\begin{array}{c}24 \\
\text { viII }\end{array}$ & \begin{tabular}{|c|}
$\mathrm{b}$ \\
23 \\
vтII
\end{tabular} & $\mid$\begin{tabular}{c|}
$a$ \\
23 \\
viti \\
\end{tabular} & \begin{tabular}{|c|}
$\mathrm{b}$ \\
22 \\
$\mathrm{v}$ \\
\end{tabular} & $\begin{array}{c}\mathrm{b} \\
22 \\
\mathrm{viI}\end{array}$ & $\mid \begin{array}{c}a \\
22 \\
\sin \end{array}$ & \begin{tabular}{|c|}
$b$ \\
21 \\
vIII
\end{tabular} & $\begin{array}{c}\mathrm{a} \\
21 \\
\mathrm{vHr} \\
\end{array}$ \\
\hline Breite $\mathrm{X}$. & 12.0 & 14.1 & 18.5 & 20.1 & 10.2 & 10.2 & 12.3 & 13.3 & 1.381 & 16.1 & 16.8 & 18.6 & 18.9 & 19.9 & 20.7 & 20.5 & 24.6 & 25.1 & 26.3 & 26.3 & 27.1 & 28.3 & 20.8 \\
\hline Länge WT & 40.3 & 39.1 & 36.1 & 37.8 & 20.2 & 20.2 & 22.3 & 22.7 & $23.0=$ & 23.1 & 25.1 & 26.0 & 213.4 & 27.2 & 28.1 & 29.4 & 31.0 & 31.5 & 32.5 & 32.5 & 33.3 & 34.3 & 35.8 \\
\hline 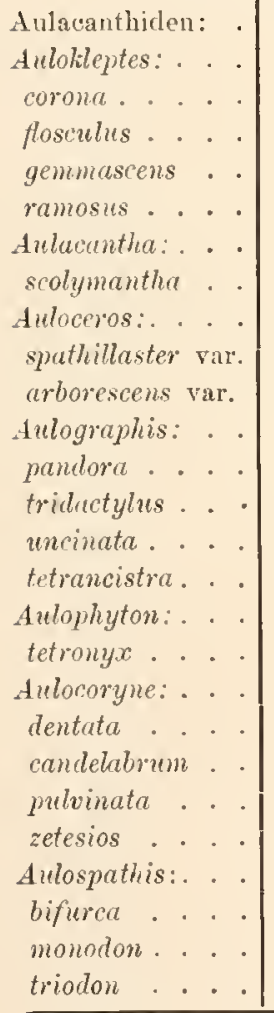 & 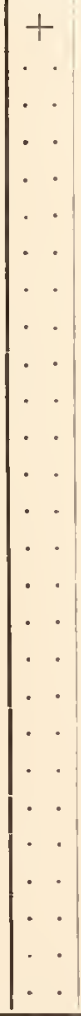 & $\begin{array}{c}\cdot \\
\cdot \\
\cdot \\
\cdot \\
\cdot \\
\cdot \\
\cdot \\
\cdot \\
\cdot \\
\cdot \\
\cdots \\
\cdots \\
\cdots \\
\cdots \\
\cdots \\
\cdots \\
\cdots \\
.\end{array}$ & $\begin{array}{l}. \\
. \\
. \\
. \\
\cdots \\
.\end{array}$ & $\begin{array}{l}. \\
. \\
. \\
. \\
. \\
.\end{array}$ & $\begin{array}{c}0 \\
0 \\
\cdot \\
2 \\
0 \\
29 \\
1 \\
1 \\
2 \\
0 \\
1 \\
1\end{array}$ & 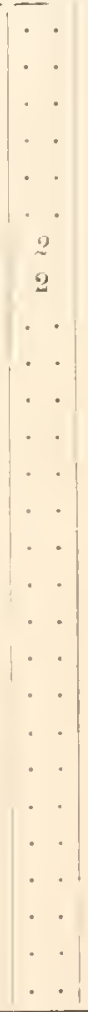 & $\begin{array}{c}\cdot \\
. \\
\cdots \\
\cdots \\
\cdots \\
2 \\
\cdots \\
\cdots \\
\cdots \\
\cdots\end{array}$ & 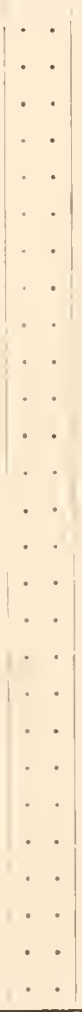 & 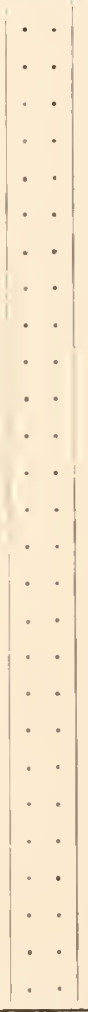 & 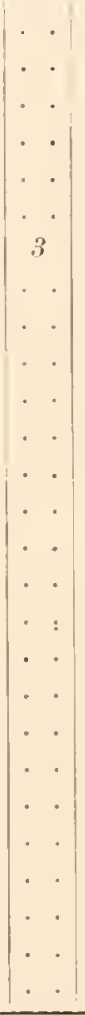 & 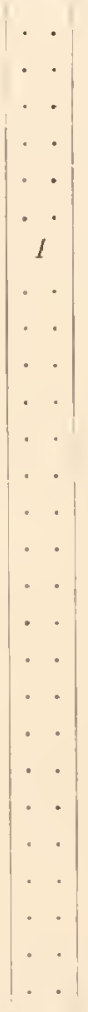 & 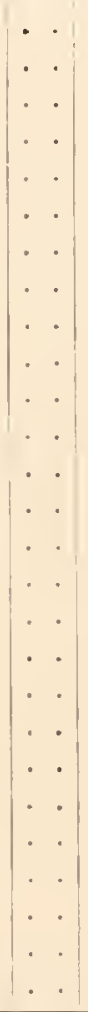 & 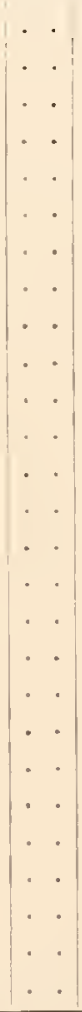 & 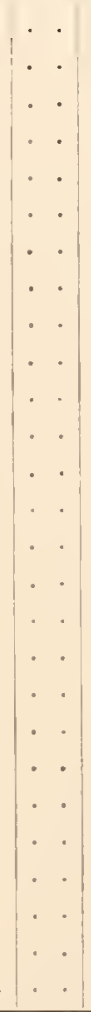 & 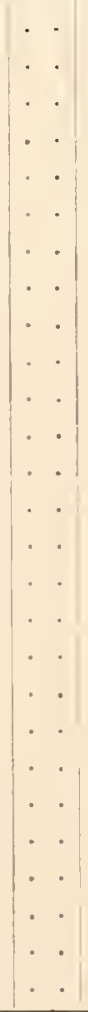 & $\begin{array}{l}\cdot \\
\cdot \\
\cdots \\
. \\
\cdots \\
\cdots \\
\cdots \\
\cdots \\
\cdots \\
\cdots \\
\cdots \\
\cdots \\
\cdots \\
\cdots \\
\cdots \\
\cdots \\
\cdots \\
\cdots \\
\end{array}$ & 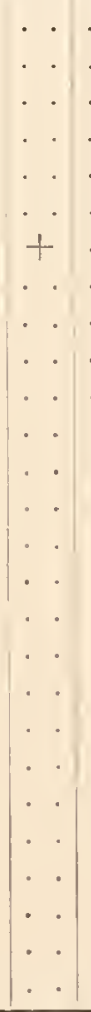 & $\begin{array}{c}\cdot \\
\cdots \\
+ \\
\cdots \\
\cdots \\
\cdots \\
\cdots \\
\cdots \\
\cdots \\
\cdots \\
+ \\
\cdots \\
\cdots \\
\cdots\end{array}$ & $\begin{array}{c}\cdot \\
\cdot \\
\cdot \\
\cdot \\
\cdot \\
\vdots \\
\cdot \\
+ \\
\cdots \\
+ \\
\cdots \\
\cdots \\
\cdots \\
\cdots \\
\cdots \\
\cdots \\
\cdots \\
\cdots \\
\cdots \\
\end{array}$ & 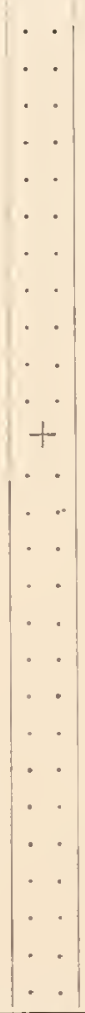 & 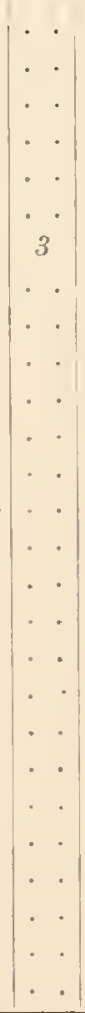 & 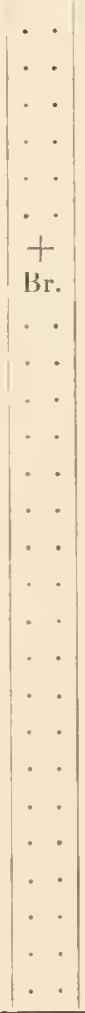 & 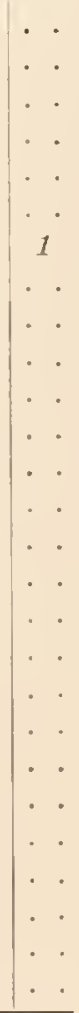 \\
\hline Tief & \begin{tabular}{|c|}
0 \\
bis \\
500
\end{tabular} & & & & $\begin{array}{c}0 \\
\text { bis } \\
1000\end{array}$ & \begin{tabular}{|c|}
0 \\
bis \\
400 \\
resp. \\
?ai)
\end{tabular} & $\begin{array}{c}0 \\
\text { bis } \\
400\end{array}$ & & & 200 & $20(9)$ & & & & & & $\begin{array}{l}400: \\
\text { bis } \\
600\end{array}$ & \begin{tabular}{|}
2800 \\
bis \\
3000
\end{tabular} \mid & 2000 & $\left|\begin{array}{c}1500 \\
\text { bis } \\
1700\end{array}\right|$ & & $\left|\begin{array}{c}0 \\
\text { bis } \\
400 \\
\text { resp. } \\
2(10)\end{array}\right|$ & \\
\hline
\end{tabular}

Unterschied, wenigstens in Bezug auf die Formen, welche hier zur Erörterung gelangen. Im Westen große Armut, sowohl an Arten, wie an Zahl. Mau könute einwenden, daß hier weniger gefischt worden wäre, aber eine der Stationen liegt fast genau in derselben Breite, unter welcher im östlichen Gebiet sich wohl die größte Nlannigfaltigkeit an Formen zeigt, nie sie sich nur in Vergleich stellen läßt zu jener Ansammlung in der Irminger See. Während im Westen nur Spuren von A ulacanthiden im Protokoll vermerkt sind, gelangten ans hem 
östlichen Gebiet (und zwar in der Nïhe der Stelle, wo eine Rïickstannng des Guineastroms beim Übergang der Nordafrikanischen oder Kanarieuströmung in den Nordäquatorialstrom stattfindet) nicht weniger wie acht Arten zur Beobachtung, von welchen allerdings Aulacantha scolymanthu Härkel sich durch die größte Individnenzahl anszeichnet. Wir finden hier Aulokleptes ramosus milii (Form longispina), Anloceros spathillaster (Häckel) var. und arborescens (Häckel) var.. ferıer Aulographis pandora Häckel und tetrancistra Häckel; außerdem eine nene nur durch eine Art vertretene Gattung: Aulophyton tetronyx mihi. Von dem Genus Aulocoryne (Fowler) gesellen sich mehrere Exemplare der Aulocoryne candelabrum (Häckel) hinzu. Etwas weiter nördlich nimmt die Mamnigfaltigkeit und Häufigkeit rasch ab. Wir finden da nur noch die kaum irgendwo fehlende Aulacantha scolymantha Häckel. Außerdem werden im Protokoll noch die Genera Aulographis Häckel mehreremals, das Genus Auloceros Häckel und Aulo-

Tabelle V.

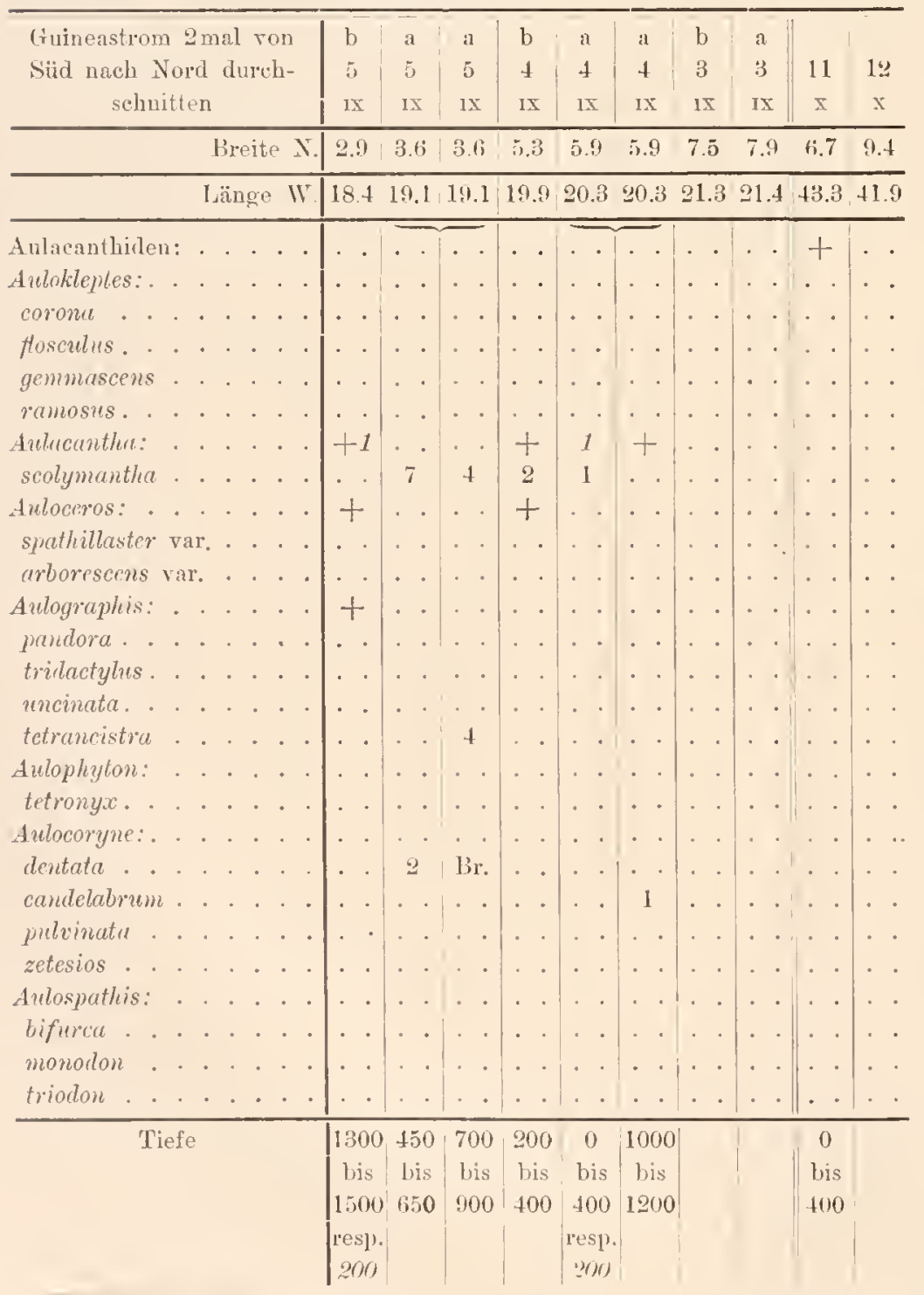
spathis Häckel je eimmal erwähnt. Um welche Arten es sich dabei handelte, und wie groß die Anzahl war, geht ans den Anfreichnungen nicht hervor. ") Merkwïrdig ist der Umstand, daß zwischen der Massenansammlung am südlichen Rande und den eben erwälnten Fundorten eine lïngere Strecke vollkommen leer bleibt. Diesmal füllt der Einwand einer geringeren Anzahl von Untersuchungsstationen hinweg, wie wir ihn als möglichen, jedoch wahrscheinlich nicht alleinigen Grund für die Armut im Westen angegeben haben.

\section{Guineastrom.}

Für dieses Meeresgebiet gilt in Bezug anf das Erforschungsfeld das Gleiche, wie für das Vorangehende. Anch hier durchschneidet der Schiffskurs zweimal die Strömung: Eimmal westlich in der ungefähren geographischen Länge der A mazonas - M östlich etwa in der Mitte zwischen den KapVerden und Ascension. Was oben über das Fangergebnis im Nordäquatorialstromgebiet gesagt wurde, kann hier wiederholt werden. Das gleiche

1) Nach einer mündlichen Mitteilnng von Her'n Professor B randt ist jo ein Exemplar anzunehmen. 
Bild: Armut in Westen und Anläufung im Osten, jedoch hier nicht so auf eine Stelle beschränkt, sondern etwas mehr verteilt und nicht in solchem Artenreichtum. Wir vermissen die Gattungen Aulokleptes mihi, Aulophyton mihi und Aulospathis Häckel. Hauptsächlich vorhanden ist neben Aulacantha scolymantlia Häckel, Aulographis tetrancistra Häckel. Zu Aulocoryne candelabram (Häckel) ist Aulocoryne dentata (Hückel) hinzugetreten. Taut Protokoll wïre noch das Vorkommen von Auloceros zu konstatieren, doch habe ich für eine Speziesangabe keinerlei Anhaltspunkte. Anch Aulographis soll in weiteren Exemplaren vorhanden gewesen sein. Möglicherweise sind nuter fuloceros zwei verschiedene Genera zusammengefalit, wie bereits vermutet wurde; denn sowohl Aulokleptes ramosus mihi, wie Auloceros arborescens (Häckel) var. und spathilluster (Häckel) var. kommen in den angrenzenden Gebieten vor.

\section{Südäquatorialstrom.}

Hier können win drei verschiedene Untersuchungsgebiete unterscheiden. Zweimal durchschneidet, wie in den beiden vorhergehenden fällen, der Kurs die Strömung und drittens folgt er derselben von Ascension bis zm Mündung des lio 'Tokantins. Analog den vorhergehenden Ergebnissen sehen wir auch hier eine relative Artenmenge im Osten. Sie nimmt allmählich ab hinter Ascension, um wieder anzusteigen hinter Fernando Noronha. Über die Verhältnisse in dem Querschnitt nördlich von Pà à läßt sich nichts äulieru, da es an Untersnchungen gebricht, die hier nur vereinzelt ausgefuhrt wurden. In Osten finden wir anßer Aulacantha scolymantha Häckel namentlich die Gattung Aulokleptes, vertreten durch Aulokleptes. ramosus var. longispina mihi. Die Fundstellen befinden sich meist nördlich von Ascension und nur einmal tritt diese Form zrischen Fernando Noronha mo Ascension auf. Ebenso ist in dem östlichen Querschnitt relativ häutig vorhanden Aulographis pundora. Auch das einzige Exemplar von Aulographis tridactylus wurde hier gefangen. Vereinzelt tritt anch Aulocoryne pulvinata (Häckel) auf. Westlich von Ascension finden wir Aulospathis monoclon nov. sp. und einmal Auloryne dentata (Häckel) neben Aulacentha scolymantha Häckel, welche anch weiterhin die Fahrt begleitet. '/n ihr gesellen sich hinter Fernando Noron ha vereinzelte Exemplare von Aulographis uncinata nov. sp. und Aulocryne candelabrum (Häckel), ferner von Auloceros arborescens (Häckel) var. Einen ähnlichen Sammelpunkt bildet auch die Station in der Mitte zwischen dieser. Insel und dem Golf von Parà. Wieder erscheint hier Auloceros arborescens (Häckel) var., aber die obige Aulographis-Art wird durch Aulograplis pmendora Häckel und Reste von Aulogruplics tetrancistra ersetzt. Ton da ab ist die A ulacanthidenfauna auf Aulacantha scolymantha Häckel beschüinkt.

Der Golf von Parà hat keinen Beitrag geliefert.

Ehe wir daran gehen die einzelnen Verbreitungsbezirke zu einander in Beziehung zu bringen, wird es nötig sein, dieselben auch von dem zweiten Gesichtspunkt aus zn betrachten. Die Phäodarien resp. Tripyleen werden als Tiefseebewohner angesehen. Wir haben also auch die Familie der Aulacanthiden darauflin zim nutersnchen, ob ihr Vorkommen auf eine bestimmte Tiefenzone beschränkt und, wenn das der Fall sein sollte, welche das ist, ferner wie sich Gattungen und Arten je nach der Örtlichkeit ihres Vorkommens zu bestimmten 


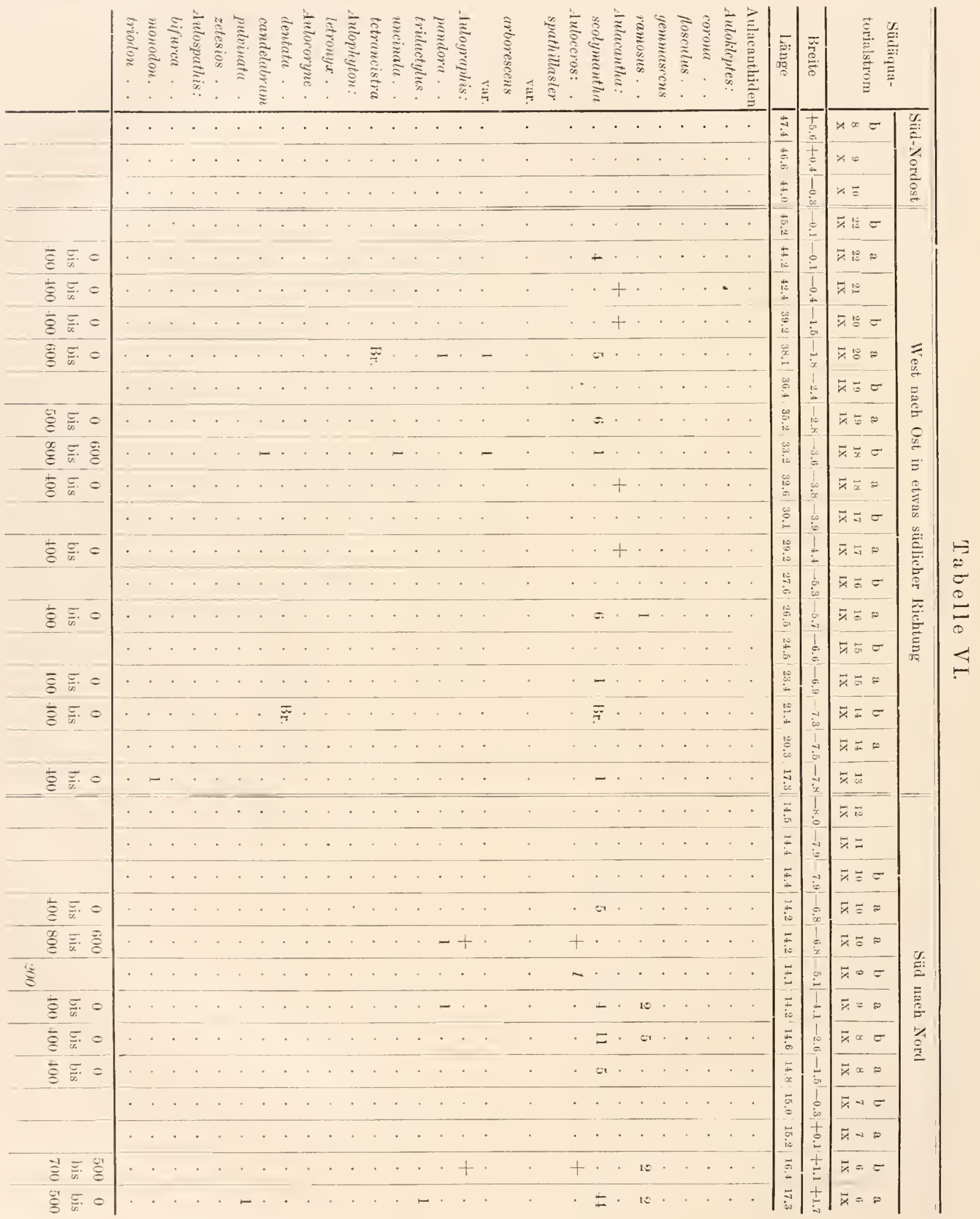


Thefen verhalten. Wir haben also anch ein Bild von der vertikalen Verbreitung der A ulacanthiden zn entwerfen. Es wird dies mm so einfacher sein, als uns die Übersicht iiber die horizontale Verbreitung bereits wichtige Anhaltspunkte gegeben hat, so z. B. ïber Massenanhäufungen an bestimmten Stellen.

\section{Vertikale Verbreitung.}

Die Wichtigkeit der Fanglrotokolle wurde bereits gewürdigt. Ebenso ist auf die Mängel in denselben, die sich durch die etwas weit ungrenzenden Benennungen bei der vorlänfigen Bestimmnng der gefangenen Aulacanthidenformen geltend machen, aufmerksam gemacht worden. Ich werde deshalb öfters auf Kombination angewiesen sein und mub auf eine absolute Richtigkeit einzelner Angaben verzichten. lumerhin glaube ich doch manches vertreten zu kömnen. Wichtig sind hierbei die Planktonnetzä̈ge dnrch ihr rein negatives Lrgebnis anf gewissen Strecken geworden. Planktonnetz und Schließnetz lissen sich ja direkt anf einander beziehen. Aber anch das Vertikalnet\%, in Tergleich gebracht mit den Resultaten der beiden genannten Apparate, erlanbt Schlïsse auf die Art der Terbreitung der Anlacanthiclen in vertikaler Richtung.

Wenn wir also an ein nud derselben Stelle einen Zug mit dem Schließnetz in größerer Tiefe machen, welcher Anlacanthiden mit heraufbringt, wïlırend das Planktonnetz leer davon bleibt, dann sagt uns das Ergebnis ohne weiteres, daß n ur die mnteren Regionen der durchfischten Wassersäule Anlacanthiden bergen. Der Schliebnetzfang allein verrät nur das Vorkommen in der geralle Inrchfischten Schicht, gibt uns aber wenigstens genan die Tiefe an, wo der Fang stattfindet. Anclers verhält es sich mit dem Vertikalnet\%. Wenn wir eiu solches 2. B. $700 \mathrm{~m}$ tief herablassen und finclen beim Heraufziehen Anlacanthiden darin, dann können wir nur sagen, daß an der betreffenden Stelle solche Lebewesen rorkommen, aber nicht in welcher Tiefe sie gefangen wurden; denn dieselben köunen ebensognt aus höhern, wie aus tiefern Schichten, welche das Netz durchfiltierte stammen. Etwas klarer wird das Bild, wenn an derselben Stelle noch ein Zug mit dem Planktometz gemacht wurde. Nehmen wir an, derselbe sei resultatlos verlanfen und habe die Tiefe von $200 \mathrm{~m}$ erreicht. Es bedentet dies soviel für uns, als daß wir nun wissen, daß Anlacanthiclen an der betreffenden Stelle erst unterhalb $200 \mathrm{~m}$ Tiefe vorkommen. Wab sie überhanpt vorhanden sind, sagt uns das Vertikalnetz, während das Planktomnetz in diesem speziellen fall uns dariiber im Unklaren lassen wiirde. Durch Vergleich mit benachbarten Füngen, die in verschiedener Tiefe gemacht wurden, wird es bisweilen möglich sein die wahrscheimliche vertikale Verbreitungszone festznstellen.

MIan könnte nun einwenden, daß Vertikal- und P'lanktonnetz etwas zu verschiedene Ergebuisse zu Tage förderten, als daß man so ohne Weiteres von einem auf das andere schlieben dürfe. In einer Beziehung ist das anch richtig: Gewiß, cler Apparat, mit dem kegelförmigen, die Mü̈ndung verengernden Anfsatz, wie ihn das Planktonnetz besitat, wird eine Wassersïule von geringerem Durchmesser abfiltieren, als das Tertikalnetz mit seiner großen uneingeschrïnkten Öffnnug, aber was in seiner Zngrichtung liegt wird er doch fingen. Es wäre nun merkwïrdig; weun auf der langen Strecke im Norden nur zufällig keine Aulacanthiden mit dem Hensen'schen Planktomnetz erbeutet worden wären bei sechsundzwanzig Zügen, während doch 
weiter im Süden das gleiche Netz streckenweise beinahe bei jedem Zug solche Organismen mit heraufbrachte, wie dies zum Beispiel in der Sargasso-See und dem Nordäquatorialstromgebiet der Fall ist. Wenn wir aus dem Fehlen der Anlacanthiden in Planktonzügen innerhalb zweihundert Meter streng genommen auch noch nicht auf ein Fehlen derselben überhaupt schließen dürfen, so können wir doch gewiß amnehmen, daß ihr Vorkommen in dieser Zone nur ein sehr zerstreutes und spärliches sein kann. Bringt uns also das Vertikalnetz aus größerer 'Tiefe eine erhebliche Anzahl von Formen mit herauf, während das Planktonnetz an gleicher Stelle in geringerer Tiefe leer davon bleibt, so spricht das für die Tatsache, daß an den betreffenden Orten in tiefern Schichten diese Lebewesen anch dichter verbreitet sind. Wiederholt sich diese Erscheinung anf ganze Strecken hin, welche annähernd diesełben änßern Bedingungen bieten, so gewinnt die Richtigkeit unserer Annahme an Sicherheit. Wir dürfen also mit gewisser Einschränkung die Vertikal- nnd Planktonzüge als sogenannte Stufenfünge ansehen, und sie als Ergänzung der Schließnetzänge betrachten. Nit wenigen Ausnahmen erreichten alle Planktonzïge die 'Tiefe von zweihundert Metern. In den beigegebenen Tabellen sind die Angaben über diese Füngre der Unterscheidnng wegen in liegender Schrift ansgeführt. Nachdem dies zn Rechtfertignng späterer Folgrerungen voransgeschickt, wenden wir uns in bereits gegebener Reilıenfolge der Betrachtung der einzehnen Stromgebiete zu. Dabei ist jedoch natïrlich der Begriff Stromgebiet nur ein aus der Hydrographie der Oberfläche übernommener, denn manche der einzelnen genannten Strömungen machen sich nur bis in relativ geringe Tiefen geltend.

\section{Golfstrom.}

Konnten wir bereits bei der horizontalen Verbreitung einen Unterschied konstatieren zwischen höheren und mittleren Breiten, so ist dies jetzt wieder der Fall. In den nördlicheren Gebieten sehen wir die obersten Wasserschichten so ziemlich frei. Erst unterhalb $200 \mathrm{~m}$ beginnt das Auftreten von Aulokleptes. Fowler, der in der gleichen Gegend Untersuchungen anstellte, gelangte zu clem gleichen Ergebnis, inclem er sogar erst unterhalb $600 \mathrm{~m}$ auf Aulacanthiden traf. Etwas anders verhalten sich die Gebiete nordöstlich von den Azoren. Hier scheint eine Bevölkerung der oberen Schichten vorzuher'schen. Wenigstens gilt dies für Aulacantha scolymantha Häckel; Auloceros spathillaster (Häckel) var. scheint erst in etwas tieferen Regionen sich zu finden. Aulographis tetrancistra Häckel und Aulocoryne candelabrum (Häckel) wurden imnerhalb $350 \mathrm{~m}$ gefangen. Da das Planktonnetz keine von diesen letztgenamnten Gattnngen zu 'Tage förderte, ist es nöglich, claß dieselben erst unterhalb $200 \mathrm{~m}$ auftreten. Schließnetzfïnge wurden in diesem Gebiete keine gemacht.

\section{Irminger See.}

(Siehe auch Tabelle VII.)

Hier scheinen die obersten Schichten vollständig frei von Anlacanthiden zu sein. In einer Tiefe von $400 \mathrm{~m}$ treffen wir bereits anf einige Aulokleptes- und Auloceros-Formen. Artenund Individnenzahl nehnen bei einem 'Tiefergehen bis $600 \mathrm{~m}$ zu. Hier stoßen wir dann des weiteren anf Aulographis tetrancistra Häekel, sowie Aulocoryme pulvinata (Häckel) mnd zetesios 
Fowler in relativ großen Mfengen. Anch lulospathis bifurca IIückel gresellt sich hinzm. Reste von Aulographis tetrancistra Häckel in einem Schliebnetyfang ans $800-1000 \mathrm{~m}$ 'T'iefe beweisen das Vorhandensein dieser Art auch in der genannten 'Tiefe. Das Protokoll fühlut ferner aus der gleichen Stufe fragliche Reste von Aulacanthiclen an. Es wäre also möglich, daß auch noch andere Genera, wie Aulocerox (Häckel) und dulospathis Häckel soweit herunterreichen, 'I'abelle VII. 'I'a belle VIII.

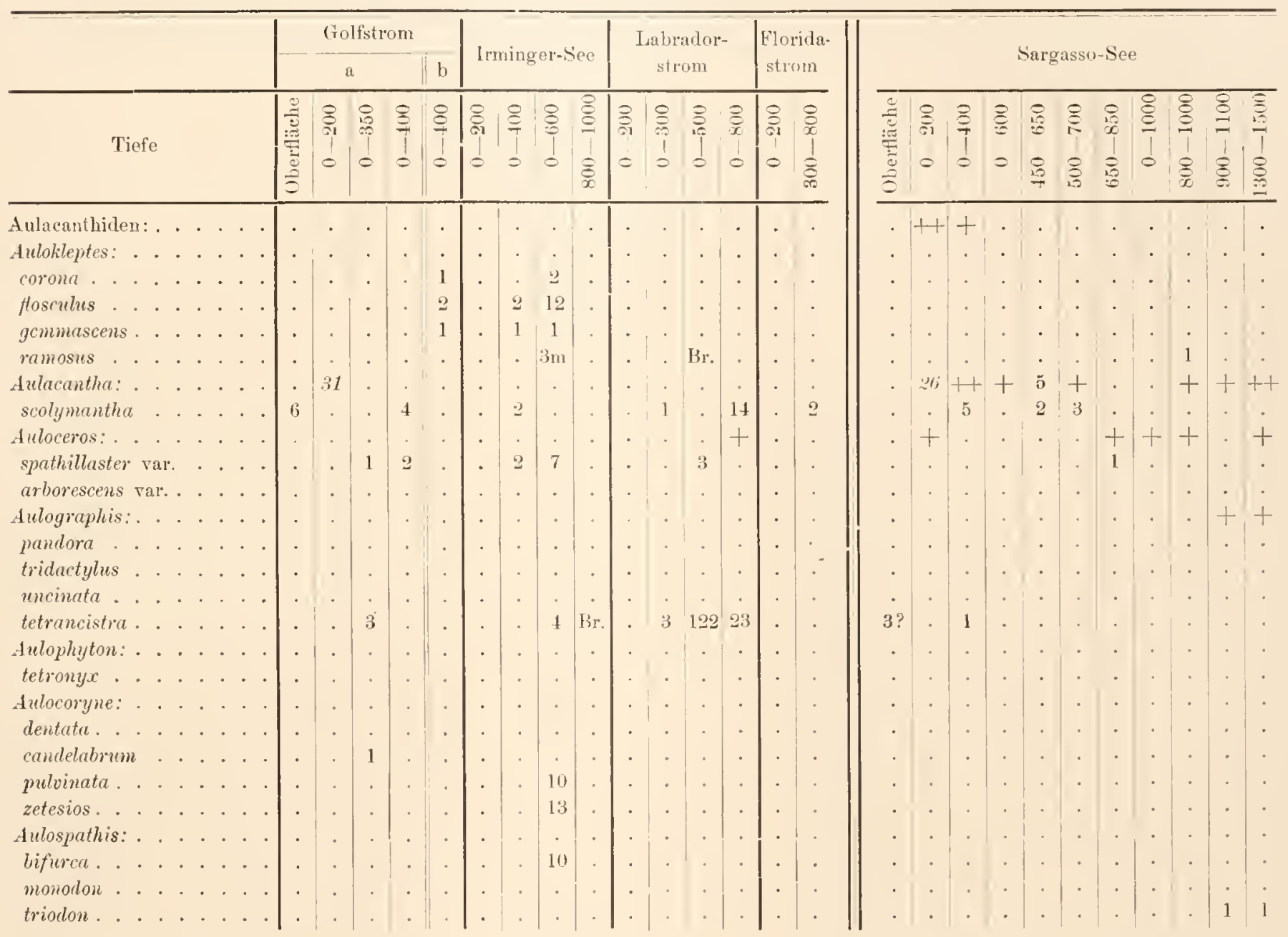

namentlich da wir an später zu erwähnenden Stellen Lulospathis Häckel in noch bedentenderen Tiefen finden. Wir können also hier im Norden eine Zunahne in Arten- mn Individnenzahl in einer Tiefe von 400-600 m konstatieren, worauf wieder eine Abnahme folgt.

\section{Labradorstrom.}

(Niehe auch Tabelle VII.)

Anch hier bleiben, so weit die Züge mit dem Planktomnet\% eine Annalme erlauben, die oberen Schichten leer. Wie sich ans beigefügter Tabelle ergibt, läßt sich ebenfalls, wie in der Irminger' See ein Maximum zwischen 400 mo $500 \mathrm{~m}$ nachweisen; dem wenn auch bis 7. $800 \mathrm{~m}$ Tiefe noch Aulacantha scolymantha Häckel mnd Aulographis tetrancistra Häckel nach- 
zuweisen ist - und letztere Art sogar in ziemlicher Menge, - so können diese Exemplare ebensogut ans etwas höheren Regionen stammen. während das negative Resultat oberhalb $200 \mathrm{~m}$, das Verbreitungsgebiet in tiefere Schichten als $200 \mathrm{~m}$ verlegt. Auloceros spathillaster (Häckel) var. scheint erst in einer 'J'iefe von etwa $500 \mathrm{~m}$ vorzukommen, da Fänge in höheren Schichten diese For'n vermissen lassen.

\section{Floridastrom.}

(Siehe auch Tabelle VII.)

Der einzige Fang, der unter etwa dreizehn Zügen, die sich auf fünf Stationen verteilen, ein positives Resultat lieferte, brachte wenige Exemplare von Iulacantha scolymantha Häckel aus einer Tiefenzone von $300-500 \mathrm{~m}$.

\section{Sargasso-See.}

Es ist schwer oder eigentlich kanm möglich, hier in Bezng anf die vertikale Verbreitung irgend welche Schichten als besonders bevorzugt oder vermieden zu kennzeichnen. Von der Oberflïche bis in 'liefen von $1500 \mathrm{~m}$ sind Anlacanthiden nachgewiesen. In dieser Meeresgegend macht sich der wenigstens zm Zeit bestehende Ansfall von Anlacanthiden mancher Schließnetzfünge besonders geltend. Gerade in Bezug auf die tieferen Regionen sah ich mich nm auf die allgemeinen Angaben der Protokolle angewiesen, aus welchen hervorgeht, daß sowohl das Genus Aulacontha Häckel, wie Aulographis Häckel und Auloceros Häckel sicher bis in die genannten Tiefen herabreichen. Außerdem konnte ich das Vorkommen von Aulospathis triodon Häckel in einem Schlielnetzfang ants einer 'Tiefe zwischen 1300 und $1500 \mathrm{~m}$ feststellen. Während wir Aulacantha und anch Aulographis Häckel (wenigstens Aulographis tetrancistra Hïckel) bis in die obersten Regionen verfolgen können, scheint Auloceros (Hiickel) erst unterhalb $600 \mathrm{~m}$ sein Verbreitungsgebiet zu haben: Auloceros spathillaster (Häckel) var. fand sich in einem Schließnetzfang aus einer Schicht zwischen 650 und $850 \mathrm{~m}$. Ob che Angabe in der 'Jabelle, welche Aulographis tetruncistra Häckel auch an der Oberfläche erscheinen läBt, richtig ist, bleibe dahingestellt. Es handelt sich in diesen Fall um eine sehr undentliche Etiquettierung des I'räparates. Im Protokoll konnte ich hierfür keinen Aufschluß finden.

\section{Nordäquatorialstrom und Kanarienstrom.}

Auf der westlichen Durchquerung dieses Strongebiets ist nur die Protokollangabe zn registrieren, welche das Vorkommen von Aulacanthiden imnerhalb einer Tiefe von $0-500 \mathrm{~m}$ meldet. Interessanter gestaltet sich das Verbreitungsgebiet an östlichen Anfang der Strömung, wo einerseits die Nordafrikanische Trift in dieselbe ïbergeht, andererseits der Guineastrom an dieselbe angrenzt. Für die liöheren Regionen ist nur Aulacantha scolymantha Häckel festzustellen. Unterhalb $600 \mathrm{~m}$ begimnt aber ein größerer Formenreichtum, der sieben Gattungen in sich schließt. Davon scheinen alle, mit Ausnahme von Aulacantha, erst in einer Region unterhalb $600 \mathrm{~m}$ sich aufzuhalten, Auloceros spathillaster (Häckcl) var. und Auloceros arborescens (Hïckel) var., dann Aulographis pandora Hïickel und Aulograplis tetrancistra Hïckel, ferner Auloplyton tetronyx nov. gen. nov. spec., schlieblich Aulocoryne candelabrum (Häckel) konnte ich aus Tiefen bis zu $1000 \mathrm{~m}$ beobachten. Im Protokoll sind noch Schliehnetzfänge bis zu $3000 \mathrm{~m}$ angegeben, 

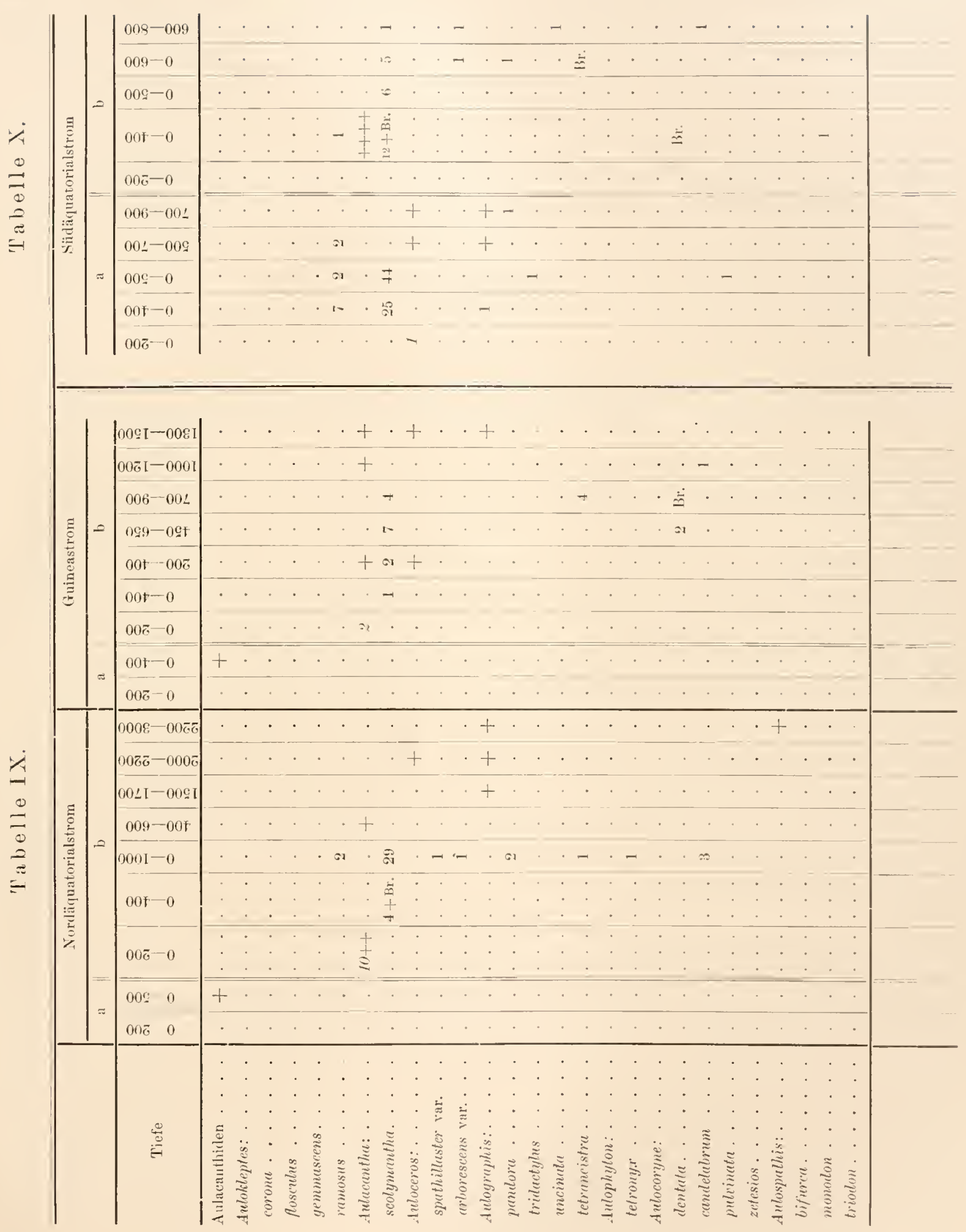

Im nermann. Die Tripyleen-Familie der Aulacauthiden. I. l. 
welche alle die Gattung Aulographis enthalten zu haben seheinen. Es ist aber sehr wahrscheinlich, dab unter diesen Begriff auch Arten fallen, welche ich nummehr zur Gattung Aulocinyne, vielleicht auch Aulophyton rechne. Aulospathis Hïckel wird sogar bis mnter $2800 \mathrm{~m}$ Tiefe verfolgt. Der Umstand, daß 'Züge bis $100 \mathrm{~m}$ nur Aulacantlue scolymantha Häickel mit heranf beförderten, während ein Tertikalang in nächster Nähe bis 1000 m anßer dieser Gattung noch sechs andere enthielt, lälit zunächst eimmal als obere Grenze fïr diese die $400 \mathrm{~m}$-Linie annehmen. Ein allerdings weiter im Torden erfolgter Schliebutzfang zwischen 400 mo 600 m brachte wieder nur Aulacantha, während tiefer gehende an Nachbarstationen nach clem Protokoll Aulographis und Aulosputhis mitbrachten. Vergleichen wir die beiden Resnltate zusammen, dann ist man wohl geneigt, wie bereits weiter oben auch geschehen, die obere Grenze noch etwas tiefer als $400 \mathrm{~m}$ zu legen sowohl für Alulographis, als auch fïr Aulophyton und Aulocoryme; wenigstens in diesem Gebiete.

\section{Guineastrom.}

(Niehe auch Tabelle TX.)

Zn ganz :̈lnnlichen Resultaten. wie im vorigen Abschnitt, gelangen wir auch hier: Im westlichen Querschnitt spärliche Anlacanthiden von einer Station, an welcher las Netz bis zu $400 \mathrm{~m}$ herabgelissen wmrle. Im Osten dagegen größere Mannigfaltigkeit. Auch hier, wie im Grebiet des Nordärquatorialstroms verbreitet ich Aulucantha sculymantha Häckel bis in die ober'n Regionen, wobei die Spezies allerdings anch bis nachweislich $900 \mathrm{~m}$ hinabsteigt. Nach einer Anmerkung im l'rotokoll soll sie sogar noch unterhalb $1300 \mathrm{~m}$ gefunden worden sein. Für Auloceros, wobei ich nm die im Protokoll mit solchem Namen bezeichneten Formen im Ange habe, wurde das Torkommen unterhalb $200 \mathrm{~m}$ bemerkt mol anch noch in einem Schlielinetzfang aus einer Tiefe zwischen 1300 und $1500 \mathrm{~m}$ protokollarisch aufgeführt. AuBerdem komte ich Aulographis tetrancistra Häckel noch unterhalb $700 \mathrm{~m}$ konstatieren und Aulocoryne dentata (Häckel) unterhalb $450 \mathrm{~m}$. Letztere erschien in Resten wieder zwischen 700 ind $900 \mathrm{~m}$. Aulocoryne candelabrum (Häckel) trat erst tiefer als $1000 \mathrm{~m}$ auf. Toch tiefere Fünge kenne ich mur aus dem Protokoll $(1300-1500 \mathrm{~m})$. Bereits genannt wurden Sulacantha und Auloceres. Hinznznfiigen ist noch -lulographis. Auch in diesem Mleeresgebiete können wir also konstatieren, daß der Artemreichtum mit der Tiefe zunimmt.

\section{Südäquatorialstrom.}

Über den westlichen Querschnitt ist keine weitere Bemerkung zu machen. Der östliche ist besonders ansgezeichnet iurch das Auftreten von Aulokleptes ramosus mihi in der Varietät Aulokleptes ramosus longispina. Die Terbreitungsiegion derselben scheint nnter $200 \mathrm{~m} 7, \mathrm{n}$ beginnen und bis 700 m zи reichen, doch können wir eine Abnahme nach unten bemerken. Das Gileiche gilt von Aulacantha scolymantha Häckel, die jedoch nnr vereinzelt bis in größere Tiefen herabsteigt. 1)as Maximm scheint rwischen 200 und $500 \mathrm{~m}$ zu liegen. Aulocoryne pulvinata (Häckel) erscheint spärlich auch hier; außerlem Aulographistridactylus nov. spec. Beide stammen ans einem Vertikalzug ans 500 m Thiefe. Verfolgen wir den Schiffskur's längs der Richtung der Strömung, so können wir bemerken, wie das Mamnigfaltigkeitsmaximnm wierler etwas in tiefere Regionen sinkt. Für 
Aulactutha scolymantha bleiben allerdings die bisherigen Terhälnisse bestehen. Luloceros urborescens (Häckel) val'. Aulographis pantoru und tetruncistru Häckel, ferner Aulogruphis uncintn nov. spec., Aulocoryne dentalu (Häckel) treten erst unterhalb 500 m Thefe anf. Merkw ürdigerweise erscheint aber Aulospathis monodon nor. spee. hereits oberhalb $400 \mathrm{~m}$. Merkwïrlig deshalb, weil die Gattung Aulosprthis sonst nur in den tiefsten Schichten sich aufhält. Ebenfalls aus der Region oberhalb $400 \mathrm{~m}$ stanmt ein kxemplar vom Aulokleptes romosus nov. gen. nov. spec. und Reste von Aulneoryne dentatı (Häckel), welche ich beobachten konnte.

\section{Gesamtübersicht über die horizontale und vertikale Verbreitung der Aulacanthiden im nördlichen und tropischen atlantischen 0zean.}

Im Vorangehenden wurle vorsucht, ein Bild der horizontalen, wie der vertikalen Verbreitung cler Aulacanthiden anf dem von der Plankton-Expedition herïhten Gebiet zn geben. T'abelle XI.

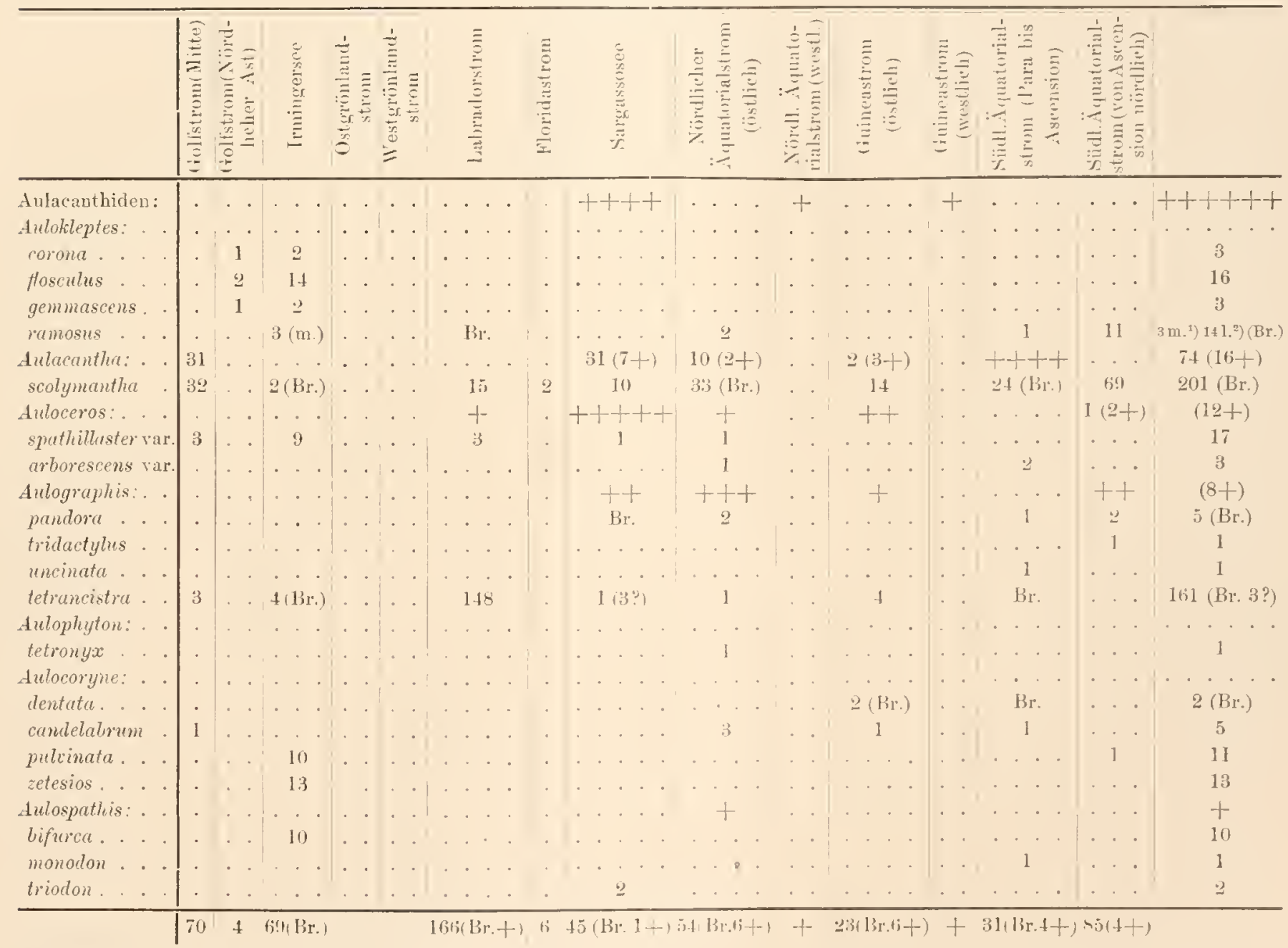

Nachdem wir nun einen Überblick erhalten haben, wirl es leichter sein, dic einzelnen Fundorte in Betreff' des Torhandenseins der verschiedenen Arten miteinander in Beziehung zu bringen 1) $m=$ var. multituberculatus. $\stackrel{\Rightarrow}{l}=$ var. longispina. 
und wo es angeht, einige Schlubfolgerangen zu ziehen. Hauptsächlich an drei Stellen haben wir Ansammlungen einer größeren Anzahl von Arten und Gattungen sowie auch an Einzelwesen. Die eine befindet sich hoch im Norden in dem Gebiet der Trminger-See, die zweite (nnbeileutender, was Artenzahl anbelangt) beim Anstritt des Labradorstroms aus der Davisstrabe, die dritte enßlich nmschliebt ein Gebiet, welches etwas suidlich der Kap Verden beginnt und bis Ascension reicht. Es liegt nahe, ans der gleichartigen Tatsache, dal, wir hier Sammelplätze vorfinden, anch nach der Ursache zu suchen und darnach zu fragen, ob wir hier an diesen Stellen Bedingungen rorfinden, die, mnter sich amnähernd gleich, nun auch dieselben Folgeerscheinungen veranlassen. Was haben diese drei Gebiete gemeinam? Wie wir T'abelle XIT.

\begin{tabular}{|c|c|c|c|c|c|c|c|c|c|c|c|c|c|c|c|c|c|c|c|c|c|c|c|c|}
\hline & 竎 & $\begin{array}{l}0 \\
0 \\
0\end{array}$ & . & $\frac{1}{1}$ & 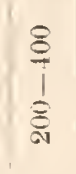 & $\begin{array}{c}9 \\
\vdots \\
1 \\
0\end{array}$ & 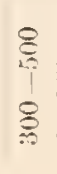 & $\begin{array}{l}9 \\
0 \\
0 \\
0 \\
0\end{array}$ & $\begin{array}{l}9 \\
1 \\
0 \\
0\end{array}$ & 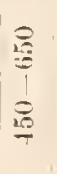 & $\stackrel{g}{1}$ & $\begin{array}{l}8 \\
8 \\
8\end{array}$ & $\begin{array}{l}\overline{\bar{a}} \\
\underline{a} \\
=\end{array}$ & 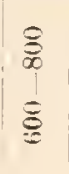 & $\begin{array}{l}0 \\
0 \\
0 \\
1 \\
0 \\
0 \\
0\end{array}$ & $\begin{array}{c}8 \\
\stackrel{8}{1} \\
\vdots\end{array}$ & $\frac{\bar{\Xi}}{\underline{\Xi}}$ & $\frac{\S}{\stackrel{1}{1}}$ & $\begin{array}{l}\stackrel{\Xi}{\Xi} \\
\Xi\end{array}$ & $\begin{array}{l}\frac{9}{3} \\
\frac{1}{1} \\
\frac{8}{3} \\
9\end{array}$ & $\begin{array}{l}0 \\
0 \\
1 \\
0 \\
0 \\
0 \\
0\end{array}$ & 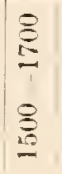 & 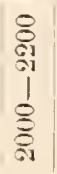 & 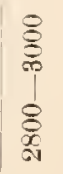 \\
\hline 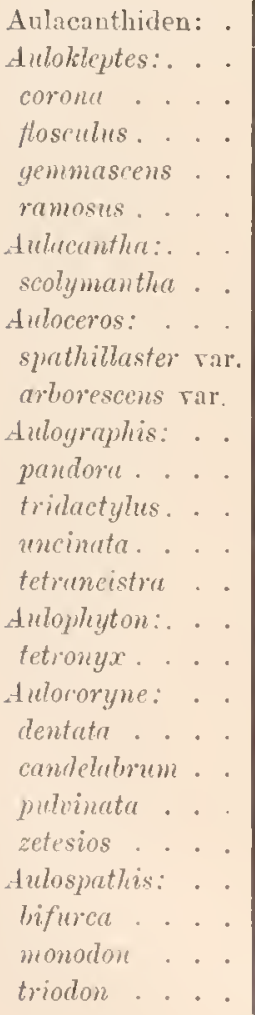 & 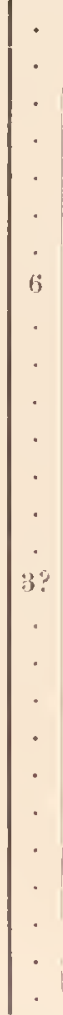 & 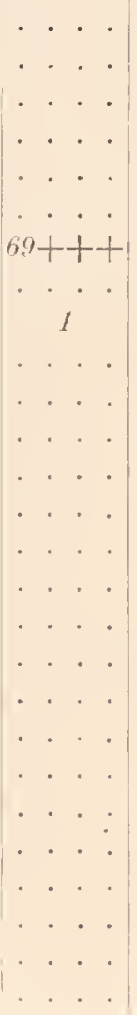 & $\begin{array}{l}. \\
. \\
i \\
. \\
. \\
. \\
. \\
. \\
. \\
. \\
.\end{array}$ & 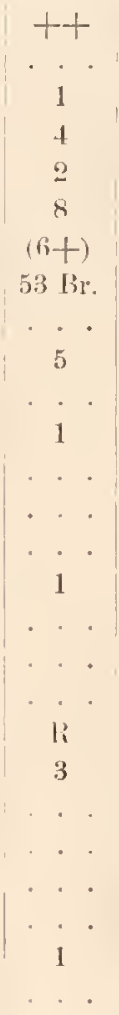 & $\begin{array}{l}\cdots \\
+ \\
+ \\
2 \\
+ \\
+\end{array}$ & 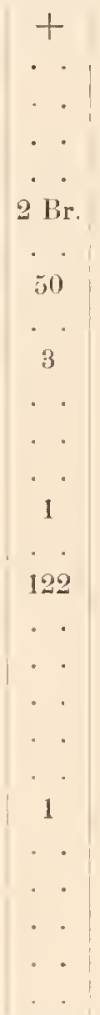 & $\begin{array}{l}\cdot \\
\cdot \\
\cdot \\
\cdot \\
2 \\
\cdot \\
\cdot \\
\cdot \\
\cdot \\
\cdot \\
\cdot \\
\cdot \\
\cdot \\
\cdot \\
\cdot \\
\cdot \\
\cdot\end{array}$ & 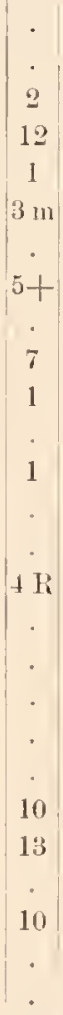 & 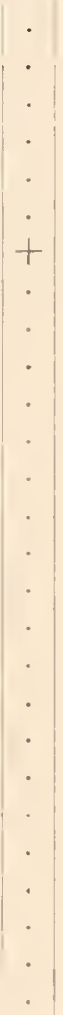 & $\begin{array}{l}5 \\
5 \\
2 \\
. \\
. \\
. \\
. \\
. \\
2 \\
. \\
. \\
.\end{array}$ & $\begin{array}{l}. \\
. \\
.\end{array}$ & 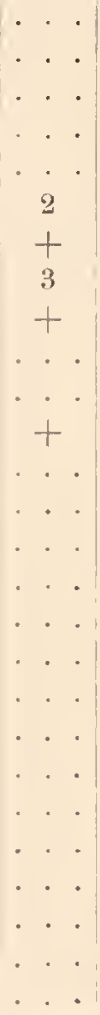 & 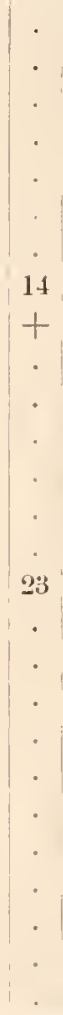 & $\begin{array}{l} \\
. \\
1 \\
+ \\
1 \\
+ \\
1 \\
1 \\
\cdots\end{array}$ & $\begin{array}{l}. \\
. \\
. \\
. \\
. \\
. \\
. \\
.\end{array}$ & 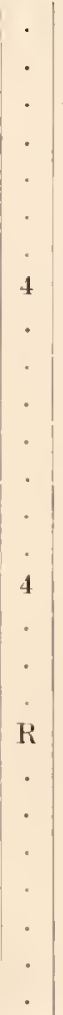 & $\begin{array}{c}0 \\
2 \\
. \\
29 \\
+1 \\
1 \\
1 \\
0 \\
2 \\
. \\
1 \\
0 \\
1 \\
. \\
3 \\
0\end{array}$ & $\begin{array}{c}\cdot \\
\dot{t} \\
\dot{b} \\
\cdot \\
\cdot \\
\cdot \\
\cdot \\
\cdot \\
\cdot \\
\dot{\mathrm{R}} \\
\cdot \\
\cdot \\
\cdot \\
\cdot \\
\cdot \\
\cdot \\
\cdot \\
\cdot \\
\cdot \\
\cdot\end{array}$ & 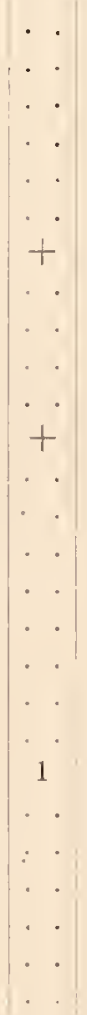 & $\begin{array}{c}\cdot \\
\cdot \\
\cdot \\
\dot{x} \\
+ \\
\cdot \\
\cdot \\
\cdot \\
\cdot\end{array}$ & 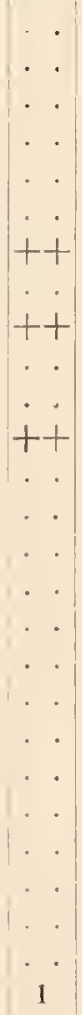 & 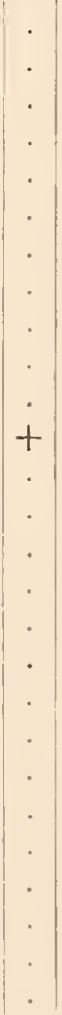 & 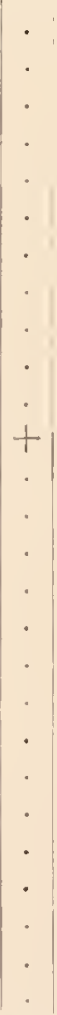 & 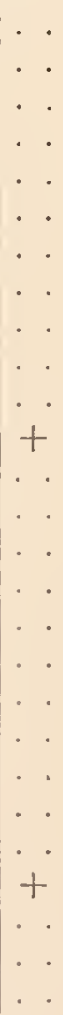 \\
\hline & $6 i 9$ & $\begin{array}{c}31 \\
+++\end{array}$ & 7 & $\begin{array}{l}79 \\
+ \text { B.R }\end{array}$ & ${ }^{2}+$ & 179 & 2 & $\begin{array}{c}69 \\
\text { li } \\
+\end{array}$ & + & 9 & & $\begin{array}{r}5 \\
++\end{array}$ & 37 & 5 & & 8 & $\left|\begin{array}{c}40 \\
13 r \\
+\end{array}\right|$ & $\left|\begin{array}{l}+ \\
\mathrm{R}\end{array}\right|$ & $\begin{array}{c}1 \\
++\end{array}$ & 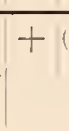 & $16+$ & + & + & ++ \\
\hline
\end{tabular}

seben, befindet sich keines derselben inmitten eines Stromgebietes, sondern es gehen an den betreffenden Orten stets zwei oder melurere Stromgebiete ineinander über. In der Irminger See treffen kalte arktische Strömungen nit wärmeren der Auslänfer des Golfstroms zusammen. Ganz ähnliche Terhältnisse finden wir beim Labradorstrom, welcher bei Nen-Fundland auf den Floridastrom stößt. Anch in dem an dritter Stelle genannten Gebiet finden wir einen Übergang von kalten zn warmen Strönmngen. Die westafrikanische kalte Strömung macht 
sich in tieferen Regionen geltend bis in die Nähe der Kal, Verden. Wenn wir die Temperaturen fïr die einzelnen 'Tiefen von Westen nach Osten verfolgen, dann bemerken wir im Nordäquatorial-, Guinea- und Sïdäquatorialstrom, ja schon in der Sargasso-See einen plötzlichen Temperaturabfall, sowie wir in das östliche (iebiet kommen, und zwar wird er um so stärker, je mehr wir nach Südosten vorrücken. Auch die Tabellen, welche O. Krïnmel in dem hydrographischen Teil der Ergebnisse der l'lankton-Expedition veröffentlicht hat, lassen diese Erscheinung deutlich hervortreten. Nan verfolge nur die 'Temperaturangaben der $200 \mathrm{~m}$ und 400 m-Linie. Im östlichen 'T'eil des Guinea- nnd Siidäquatorial-Stroms steigt die $10^{\circ}$ Kurve bis in Regionen von $300 \mathrm{~m}$ 'Tiefe, während wir in diesen Schichten im Westen noch $20^{\circ}$ oder $15^{\circ}$ haben. Gerarle dieses kältere W'asser ist es aber, welches die meisten Formen beherbergt. Hier finden wir ähnhiche Terhältnisse wieder wie in der Irminger See. Verwandte Formen, wie Aulokleptes und Aulocoryne, treten wieder in grölserer Zahl anf, diesmal wahrscheinlich aus antarktischen Gegenden stammend und vou der Südwestafrikanischen 'I'rift hierher verschleppt. Ob der scheinbare Einfluß, welchen dieselbe auf das ganze Gebiet der Tiefen unter dem Südäquatorialstrom ausübt, wirklich allein von dieser Strömung herrïhrt, vermag ich nicht zu entscheiden. Wir beobachten allerdings lïngs der ganzen Sïdäquatorialtrift in nach Westen zn allmählich tiefer werdenden Regionen einen ziemlich einheitlichen Charakter der Anlacantlidenfauna, die ganz entsprechend einem etwaigen Einfluß von Südosten etwas spärlicher wird, je weiter wir nach Westen vorrücken. Nur an einer ganz bestimmten Stelle hinter Fernando-Noronla sehen wir wieder einen kleinen Sammelplatz in T'iefen von etwa $600 \mathrm{~m}$. Möglicherweise sind dies noch Nachwirkungen der vertikalen Strömungen, wie sie längs der brasilianischen Küste vorherrschen sollen. Als Arten, die für kältere Strömungen charakteristisch sind, nenne ich Aulokleptes corona milii, Aulokleptes tlosculus (Häckel). Aulokleptes gemmorsens (Häckel), Aulokleptes ramosus mihi, Aulocoryme zetesios Fowler, Aulocoryne mulvinata (Häckel), . Iulocoryne candelabrum (Häckel) und anch teilweise Aulororyne dentata (Häckel), ferner Aulospathis bifurca Häckel, Aulospathis triodon Häckel. Anch Aulographis pandora Häckel kann hierher gerechnet werden, ebenso, wie die Gattung Auloceros (Häckel) mili. Merkwürdig verhält sich Aulacantha scolymantha Fäckel und Aulographis tetrancistra Häckel. Für letztere Art können wir noch eher eine wem auch nicht ansschließliche Bevorzngung der kälteren Schichten behaupten, als für erstere. Diese überall verbreitete Art kommt nicht nur an der Obertläche in großen Mengen bisweilen ror, sondern wir finden sie anch bis in die tiefsten Regionen. In $1500 \mathrm{~m}$ Tiefe wurde noch Aulacantha scolymantla Häckel nachgewiesen auf der PlanktonExpedition. Es ist also nicht richtig, von Aulacanthiden schlechthin zu sagen, sie seien Tiefenbewohner, denn gewisse Arten steigen bis zur Oberfläche empor. Mit Sicherheit kann ich dies allerdings nur für Aulacantha scolymantha Häckel behaupten. Selır tief gehen die Gattmgen Auloceros (Häckel) und Aulospathis Häckel herah. Im Protokoll wirl anch bei Zïgen ams 2800-3000 m noch Aulograplis genannt, doch ist aus bereits erwähnten Grïnden schwer zu sagen, was unter diesem Begriff verstanden ist. Der Aufenthalt im Wasser bietet je nach Wärme, Druck, Dichtigkeit, Salzgehalt ganz verschierlene Existenzbedingungen, auf welche gerarle die einzelligen Lebewesen sehr genau zu reagieren scheinen. Lis lag num nahe anzunehnen, 
daß die jeweiligen Existenzbedingungen sich in der Organisation sichtlich bemerkbar machten. Da die Aulacanthiden sich eigentlich mu durch die Art und Weise der Ansbillung des Kieselskelets voneinander unterscheiden, so dürfte sich wohl die Einwirkung von außen zunichst mit Veränderungen dieser Körperbestandteile in Terbindung bringen lassen. Es gelang mir jerloch nicht, hier zu eimem definitiven Resnltat zn kommen. Wohl darf man ammehmen, laß kalte, dichte Wasserschichten einen schweren Skeletbau ohne bedentende Oberfächenvergrößerung durch Nadelvemehrung gestatten, wie wir solche Bikdungen bei Aulokleptes finden, aber gerade die Gattung, welche wohl die tiefsten Schichten $7 u m$ Aufenthaltspllatz gewïhlt hat (Aulospathis) zeichnet sich durch äuBerst dünne, zahlreiche und durch Seitenäste spezifisch noch leichter gemachte Stacheln aus. Vielleicht hängt die Artansammhnng an den gemannten Stellen mit der hier stattfindenden Vermischung der verschiedenen Wasserschichten zusammen. Das einzige Anzeichen, daß das Skelet mit den Aufenthaltshedinginngen sich ändern kann, gibt Aulacantha scolymantha Häckel. Sie, die ïberall zu existieren vermag, ist anch die einzige Form, welche die Schwere und den Reibungswiderstand ihres Körpers durch zweierlei Skeletumformung verändern kann. Bei ilı ist die Möglichkeit einer fortdaucrnden Ablagerung auf ler einzelnen Nadel unl eine Vermehrung der Stachelzahl ïberhaupt gegeben. Sie wird sich also am vielseitigsten ampassen können, daher auch ihre allgemeine Terbreitung. Je einseitiger die Ausbildung des Skelets. desto geringer anch die Anpassnngsfähigkeit. (Hierbei darf natiirlich anch die nungekehrte Möglichkeit, daß das Medium erst die Skeletbildung in ibrer speziellen Form zur Folge haben kann, nicht außer Acht gelassen werden.) Von diesem Gesichtspunkt ans läßt sich auch die Verbreitnng von Aulospathis verstehen, ebenso von Aulocoryme, wo eine Veränderung der Schwere des einzelnen Starchels durch Auflagerung ansgeschlossen ist. Warum wir diese Gattungen allerdings grerade auf kaltes und dichtes 'Tiefenwasser beschränkt sehen, dafür fehlt mir bis jetıt eine Wrklärung. Für die Richtung der Ausbreitung kömnen die Strömungen der Oberfläche natürlich nn in beschränktem IIaße in Betracht kommen, da das Hauptanfenthaltsuebiet der Aulacanthiden meist erst jenseits ihrer nnteren Mächtigkeitsgrenze beginnt. Wohl aber dürfen wir mit Strönungen rechnen, die durch andere sprezitisch leichtere in die 'Tiefe gedrückt werden. 'T'eilweise wird es natürlich hierbei zur Vermischung kommen, andererseits werden aber anch wohl Wassermassen einen Rest ihrer fritheren Geschwindigkeit beibehalten und in der alten oder einer von dieser ahgelenkten Richtnng in unteren Regionen weiterströmen, bis auch dieser Rest an lebendiger Kraft aufgezehrt ist. Anf diese Weise können wir mus das vereinzelte Vorkommen mancher A ulacanthidenarten zn erklären suchen. Mtitten in der Sargasso-See in bedeutender Tiefe finclen wir an einer Stelle, welche in gerader Fortsetzung des Labradorstroms liegt, eine Luloceros-form, welche genau derjenigen entspricht, welche wir im Labradorstrom selbst beobachten. Dies Tier, das für sich keine Bewegmng von größerer Bedeutnng macht, kann nur passiv an seinen Aufenthaltsort gelangt sein. Der Labradol'strom trifft, wie wir wissen, in der Nähe von Nen-Fundland auf den Floridastrom. Ein Teil der Labradortrift spaltet sich ab und gleitet dem amerikanischen I'fer entlang. Ton dem indern 'T'eil nehmen wir an, daß er untertancht. Durch diese untermeerische Strömumg mag anch das Auloceros-Exemplar von seiner ursprünglichen Heimat in 
die Tiefen der Sargasso-See geführt worden sein. So ist es auch nicht unmöglich, daß die untermeerische Trift der westafrikanischen strömung noch weit nach Norden sich geltend macht. Wir finden nördlich der Azoren vereinzelte Exemplare von Aulocoryne candelabrum (Häckel), welche sonst nur im tropischen Tiefengebiet auftritt und zwar wahrscheinlich dort eingeführt durch von Süclen kommende kalte Strömungen. Eine nahe verwandte Form fand A. Borgert im Mittelmeer. Auch sie findet sich erst in größerer Menge in den 'Tropen, wiederum in kaltem 'Jiefenwasser. Von diesen Strömungen weiter nach Norden verschleppt, mögen diese Formen allmällich durch aufsteigende Wassermengen in die Trift des Golfstroms gelangt sein (etwa $200 \mathrm{~m}$ tief), welcher sie weiter verfrachtete. Auf diese Weise erhält wahrscheinlich auch des Mittelmeer einen Zuwachs an nenen Formen. Wichtig für diese Fragen wird namentlich eine genane Untersuchung der Organismen der südwestafrikanischen Strömung und des antarktischen Meeres werden. Śchon die Befunde der Chaldexger-Expedition deuten anf eine Einwanderung von Süden in die Tropen, während die nordischen Formen melı auf ihr Gebiet beschränkt zn sein scheinen. Die Ergebnisse der deutschen Tiefsee- und Südpolar-Expedition, welche beide ja gerade dies Gebiet genaner untersuchten, vermögen höchst wahrscheinlich hieranf eine Antwort zu geben. 


\section{Literatur-Verzeichnis.}

1. 1862 E. Häckel: Die Radiolarien (Rihizopode radiarice), Berlin 1862.

2. 1879 E. Häckel: Über die Phaeodarien, eine neue Gruppe kieselschaliger mariner Rlizopoden. Sitzb. Ges. Med. 1. Naturw., Jena 1879.

3. - R. Hertwig: Organismus der Radiolarien, Jena 1879.

4. 1880 D. Pantanelli u. de Stefani: Radiolaria di Santa Barbara in Calabria. Atti Soc. Tosc. Sc. nat. Proc. rerl, T. 2, 1880.

5. 1881 E. Häckel: Entwurf eines Radiolariensystems auf Grund von Studien der Chaldenger-Radiolarien. Jena, 7. Nat., V. 15, 1881.

(i. 1882 O. Bütschly: Beiträge zur Kenntnis der Radiolarienskelette, insbesondere der der Cyrtida. Z. wiss. Zool., Bd. 36, Leipzig 1882.

7. 1886 Castracane: degli Antehminelli; Report on the Diatomaceae collected by H. M. S. Chaldenger. Botany, Vol. II, Lundon 1886.

8. 18st K. Braudt: Mitteilung in C. Chuns Werk: Die pelagische Tierwelt in größeren Meerestiefen und ihre Beziehungen zur Uinerfächenfuna. Bibl. Zuol., Bd. I, Heft 1.

9. - E. Häckel: Report on the Radiolaria collected by H. II. S. Challenger 1873-1876, Rep. sc. Res. Challenger, Zool. V, 18.

11. - T. Hensen: Über die Bestimmung des Planktons oder des im Meere treibenden Materials an Pflanzen und Tieren. V. Ber. komm. deutscb. Meere, Bertin 1887.

11. - K. Möbius: Systematische Darstellung der Tiere des Planktons, gewonnen in der westlichen Ostsee auf einer Fahrt ron Kiel in den atlantischen Ozean. T. Ber. Komm. dentsch. Meere, Berlin 1887.

12. 1888 E. Häckel: Die Radiolarien, eine Honographie. 1V. Teil: die Phaeodarien oder Cannopyleen Radiolarien, Berlin 1888.

13. 1889 K. Brandt: Über die biologischen Untersuchungen der Plankton-Expedition. Verh. der Gesell. f. Erdkunde, Berlin 1889, Dez.

14. 1891 A. Borgert: Über Dietyochiden, insbesondere über Mistephomus sperulum, sowie Studien an Radiolarien. Z. wiss. Zool., Bd. 51, Leipzig 1891.

15. 1892 A. Borgert: Torbericht ïber einige Phacodarien (Tripyleen)-Familieu der Plankton-Expedition. Ergebnisse d. Planktun-Expedition, V. 1, A, Kriel n. Leipzig 1892.

16. - K. Brandt: Über Anpassungserscheinungen und Art der Verhureitung von Hochseetieren. Ergebnisse d. Plankton-Expedition, V. 1, A, kiel u. Leipzig 1892.

17. - F. Dreyer: Ziele und Wege biologischer Forschung, beleuchtet an der Hand einer Gerïstbildungsmechanik. Jena, Zeitsclır., 13d. 26, N. F. 19.

18. 1893 O. K r ̈̈̈m mel: Geophysikalische Beobachtungen. Ergebnisse d. Planliton-Expedition, Bd. I, C, Kiel n. Leipzig 1893.

19. 1895 W. Karawaiew: Beolsachtungen über Struktur und Vermehrung von Aulacautha scolymatha Häckel. Zool. Anz., Jahrg. 18, Teipzig 1895.

20. 1895 K. Brandt, Die SchlieGnetzfänge der Plankton-Expedition. Verh. der Gesell. deutsch. Naturf. und Ärzte, Jübeck 1895. 
21. 1896 A. Borgert: Zur Fortpflanzung der tripyleen Radiolarien (Phacodarien). \%ool. Anz., Jahrg. 19. Leipzig 1896.

22. - A. Borgert: Fortptlanzungsverhältnisse der tripgleen Radiolarien (Fhacodarien). Verh. dentseh. Zool. Ges.. 6. Vers., Jeipzig 1896.

23. - W. Karawaiew: Beobachtungen ïber Radiolarien. Sichiften naturf. Gesell., Kiew T, 14, 2.

24. - H. Lohmann: Die Appendicularien der Plankton-Expedition. Ergehisse der Plankton-Experlition, Bd. IL. E. c., Kriel u. Teipzig 1896.

25. 1897 E. Vauhöffen: Das Plankton des Karajak-Fjordes. Frönland-Wxp. M. Ges. f. Errknnde zu Berlin 1891-1893 Bd. II, I Cap. II.

26. 1898 G. H. Fowler: Cuntributions to our knowledge of the plankton of the Faroe Channel, No VTI. Proceed. of the Zool. Soc. of London for $18: 8$.

27. - P. T. Clere: 1'ankton collected by the Swedish-Experition to Kuitzhergen in $1898 . \quad$ Kongl. Srensk. Tetensk. Akad. Handl., Bd. 32, No. 8.

28. 1899 H. Lobmann: Untersuchungen ïler den Auftrieh der Strafe von IIessina nit besonderer Berüeksichtignng der Appendicularien und Challengerien. S'B. Ak., Berlin 1899.

๒9. 1900 A. Borgert: Tntersuchnngen äber die Fortplanzung der tripyleen Radiolarien, speziell ron tulacuntha scolymantha Häckel. 1. T'eil, Zool. .lahrb. Anat., Bd. 14. 2, lena 1900.

30. - C. Chun: Aus den Tiefen des Weltueeres, Schilderungen rer dentschen Tiefsee-Expedition, Tena 1900.

31. - E. Jörgensen: Protophyten und Protozoen der norwegischen Westküste. Iergens Museums Aarbog 1899, No TI, 1900.

3.. 1901 A. Borgert: Die Tripyleen in: Nordisches Plankton, heransg. ฬ. K. Brandt, Kiel n. Leipzig 1901.

33. - A. Borgert: Die tripyleen Radiolarien des Mittelmeeres. Mt. Stat. Neapel, Bd. $14,2,1901$.

34. 1902 R. Norris Wolfenden: The Plankton of the Faroe Channel and Shetlands. Prelininary Notes on some Radiolaria and Copepoda. Iournal of the Marine Biol. Association. Tol. vi, No. 3. 1902.

35. I903 F. Inmermann: T̈ber Fremdkörperskelette bei Anlacanthiden. Zoul. Anz., 27. Iahro., Leipzig 1903.

36. - A. Borgert: Mitteilnngen über die Tripyleen-Ausbeute der Mlankton-Expeditiun. II. Die 'Tripyleen-Arten aus den Schliebnetzfängen. Zool. Jahrb., Abt. f. Syst., Bd. 19. Heft 1i, Jena 1903. 


\section{Figuren-Erklärung.}

\section{'Tafel I.}

Fig. 1. Vollständiges Exemplar einer Lulacanth scolymantha. Eine greringfügige V'erschiebung der Zentralkapsel hat stattgefuuden. Vergrößerung 11 i: 1 .

Fig. 2. Ton K. Brandt als Polyzoënstadium bezeichnet. Tach einem Präparat einer Aulacantha scolymmetha aus dem Golf ron Neapel. Vergröbernug $300: 1$.

Fig. 3a, b. Zwwei distale Stachelendeu einer Aulucantha scolymantha bei stärkerer Vergrößerung t50:1.

\section{'T a f el II.}

Fig. 1. Distales Ende eines Stachels von Aulokleptes flosculus (unansgebildetes Stadimm) mit einer Rhizosolenie als Grundlage. Spiralen und sichalenzeichnung der letzteren deutlich sichtbar.

Fig. 2. Aulohleptes-Stachel mit Rhizosolmiu styliformis Brightwell als Grmudlage. Letztere in Teilnng. Das distale Encle der Diatomee ist abgebrochen und leeinthBt die dariiber lagernden Schichten und damit auch die Form der Endbildung. Auclı die Teilungsstelle macht sich in der äubern Gestalt des Stachels geltend.

Fig. 3. Anlokleptes-Stachel mit einer algebrochenen Rhizosolenie als Grundlage. Beginuende Zackenbildung am distalen Ende.

Fig. 4. Distales Ende eines Stachels von Anlohleptes floschlus var. inermis mit einer Thulassothrix als Grundlage.

Fig. 5. Distales Ende eines Stachels vou Aulokl'ptes rumosus mit einer Rhizosoleniu uluta Brightwell mit stark lierrortretender Teilungsnarbe. VergröBerung.

Fig. 6. Teil eines lulokleptes-Stachels mit wenig ausgebildetem sekundären Kieselïberzng anf einem Kettenstadium einer Rhi=osoleniu styliformis Brightwell. Das eine Diatomeengehänse war mit Luft gefüllt, wodurch die Schuppenbildung deutlich hervortrat. Bei dem zweiten war nur eine Spirale schwach zu erkennen. Vergrößerung 800:1.

\section{'Tafel III.}

Fig. 1. Distales Stachelende einer ausgeprägten Form ron Aulokleptes flosculus var. inernis mit einer Rlizosolenia (spec.?) als Grundlage.

Fig. 2a-d. Terschieden ausgebildete Anfangsstadien von Aulokleptes ramosus bei dem gleichen Tier beobachtet. Vergrößermug 115:1.

Fig. 3. Distales Stachelende ron Aulvileptes ramosus var. multituberculutus mit einer 'Thalassothrir (spec.?) als Grundlage. V'ergrößerung $300: 1$.

Fig. 4a, 1). Twei distale Stachelenden des gleichen Lndividunms von der Varietät Aulokleptes ramosus longispina. Bei a bildet eine wenig dentliche Rhizosolenie die trundlage der Nadel, bei b eine 7hulussothrix. VergröBerung $115: 1$.

Fig. 5a, b. Zwei sehr mregelmäßig gebildete Stachelenden vom gleichen Individum eines Anlokleptes rumosus var. longinjina. Zwei Rhizosolenien bilden die Grundlage. Vergröbermng 115:1. 


\section{Tafel IV.}

Fig. 1a, b. Zwei Stachehn des gleichen Tieves, eines fulolileptes munnsus rar. Lompispina mit Rhizosolenien als Grundlage. Der rerschiedene Ausbildnngsgrad der Zacken tritt in Zahl und Länge dentlich herror. Tergrößerung $115: 1$.

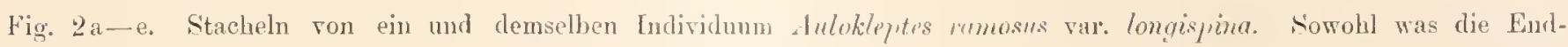
bildungen anbelangt, berrscht grofe Terschiedenheit, als anch in Bezug aut die Grundlage, die, wie hier ersichtlich, aus verschiedenen Diatomeen bestehen kann. Tergröberung 115:1.

Fig. 3a-d. Stachelenden ron ein und denselben Ther, huloktpptes rmmosus var. longispim in verschiedenen Ansbildungstadien, aler in Ganzen von ziemlich regelmäbiger tiestalt. Als (irundlage dient zum 'Teil hlizosulenia (bei einem Stachel die spezios alatı deutlich exkennbar), zun Teil Thulussothrix. Tergrölerung 115:1.

\section{'T'a fel V.}

Fig. 1. Distales Stachelende von Aulohleph's Hosulus var. pistillum nit einer Rhizosoleniu alutu Brightwell als Gruntlage. Vergrößerung $450: 1$.

Fig 2. Distales Stachelende von Aulokloptes tosculns typirus nit einer Rlizosolenia (spec.?) als Grundlage. Sehr deutlich hervortretende Schichten nnd Faltenbildungen. Tergröberung :30):1.

Fig. 3. Distales Stachelende von Aulokleyles gemmuscens var. bipurlitus mit einer Symedra (spece?) als Grundlage. Tergrößerung 115:1.

Fig. 4. Distales Stachelende von Aulokleptes ypmmasrons typicus mit einer Thalussothrix (spec.?) als Grondlage. Vergröberung 115:1.

Fig. 5a. Distales, b. Proximales Stachelende von Anlokleqtes gemmusrezs var. sceptrmm mit einer Rhizosolenia atlantrica? Peragallo als Grundage. Vergrölerung $115: 1$.

Fig: 6. Distales Stachelende einer Aulogruplis pumlom. Vergrößernng 115:1.

Fig. 7. Distales Stachelende einer Aulormplis tetruncistra. Teroröberung :301):1.

Fig. 8. Distales Stachelende einer Lulouruplizs uncinatu. Vergröberung :300:1.

Fig. 9. Distales Stachelende einer Inloyraphis tridactylus; die änBersten Terminalspitzen sind ahgebrochen. doch läBt sich eine Teilung in drei Fortsätze vermuten. Vergrölierung 300:1.

Fig. 10. Distales Stachelende von Aulnceros sputhillaster var. Tergröberung 30():1.

Fig. 11, 12. Zwei verschieden ansgelildete Stachelenden von Anloepros arlorescens var. (nicht vom gleichen T'ier). Beide Formen können auch zusammen vorkommen in entsprechender Größe. TergröBerung Fig. 11, $115: 1$. Fig. $12,300: 1$.

\section{Tafel T I.}

Fig. Ia. Distales Ende eines Stachels von Anlokleptes coronu. Eine Thulassothrie bildet die Grnndlage.

Fig. 1b. Proximales Ende des gleichen Ntachels.

Fig. 2. Drei distale nud ein proximales Stachelende des gleichen Individumms, Aulokleptes flosculus.

Fig. 2a. Wohl ausgebildete Flosculus-Form mit einer Thalassothrix als Grundlage und anderweitigem Fremdkörpereinschluf, welcher auf der Diatomee an einer Stelle lagert.

b. Inermis-Form mit Rlizosolenin alut Brightwell als Grundlage.

c. Merkwürdiges Proximal-Fnde, wahrscheinlich mit einer Symelra als Frundlage.

d. Inermis-Form mit Kettenfragnent ron likizosoleniu semispinu Hensen als Grundlage.

Fig. 3. Distales Stachelende von . luloklpptes flosenhes var. tridentatus mit nicht deutlich erkennbarer Khizosoleniu als Gimudlage.

Fig. 4. Distales Stachelende von dulokleptes joscuhs var. confluens mit Kettenfragment von Rlizosolenia semispiua Hensen als Grundlage.

Fig. 5. Ganz unbezahntes, distales Stachelencle einer sonst bezahnten Aidocoryur cumlulalmun. Vergrößerung $115: 1$.

Fig. 6, 7. Etwas rerschieden ausgelildete Stachelenden von Aulororme candelulmm. Bei Fig. 7 sind die Zähnchen besonders zahlreich. Vergröberung 115:1. 
Fig. 8. Distales Stachelende einer Aulocoryue dentata. Tergrößernng 300:1.

Fig. 9. Distales Stachelende einer Aulororyue muluinuta. Tergröberung 300:1.

Fig. 10. Distales Stachelende ron Aulophyton tetronyx mit hohlen Terminalästen. Vergrößerung 300:1.

\section{Tafel VII.}

Fig. 1. Distales ergänztes Stachelende (die Röhre des Stachels ist rekonstruiert) einer Aulocoryure zetesins. Verorößerung $115:$ I.

Fig. 2a u. b. Die distalen Enden zweier Stacheln vom gleiehen Tier, Aulosputhis lifiura. Tergröberung $115: 1$.

Fig. 3а и. b. Zwei Stacheln des gleichen Exemplares von Aulospathis monodon. Die äuBersten Enden sind vermutlich abgebrochen.

Fig. ta u. b. Zwei rerschieclen ansgebildete Stacheln eines und desselben Exemplares von Aulosyathis triodon. Tergröberung $115: 1$.

\section{Tafel VIII.}

Karte der horizontalen Verbreitnng der auf der Plankton-Expedition erbeuteten Aulacantliden. 
Planktir sapelitu n L h

Taf 1.

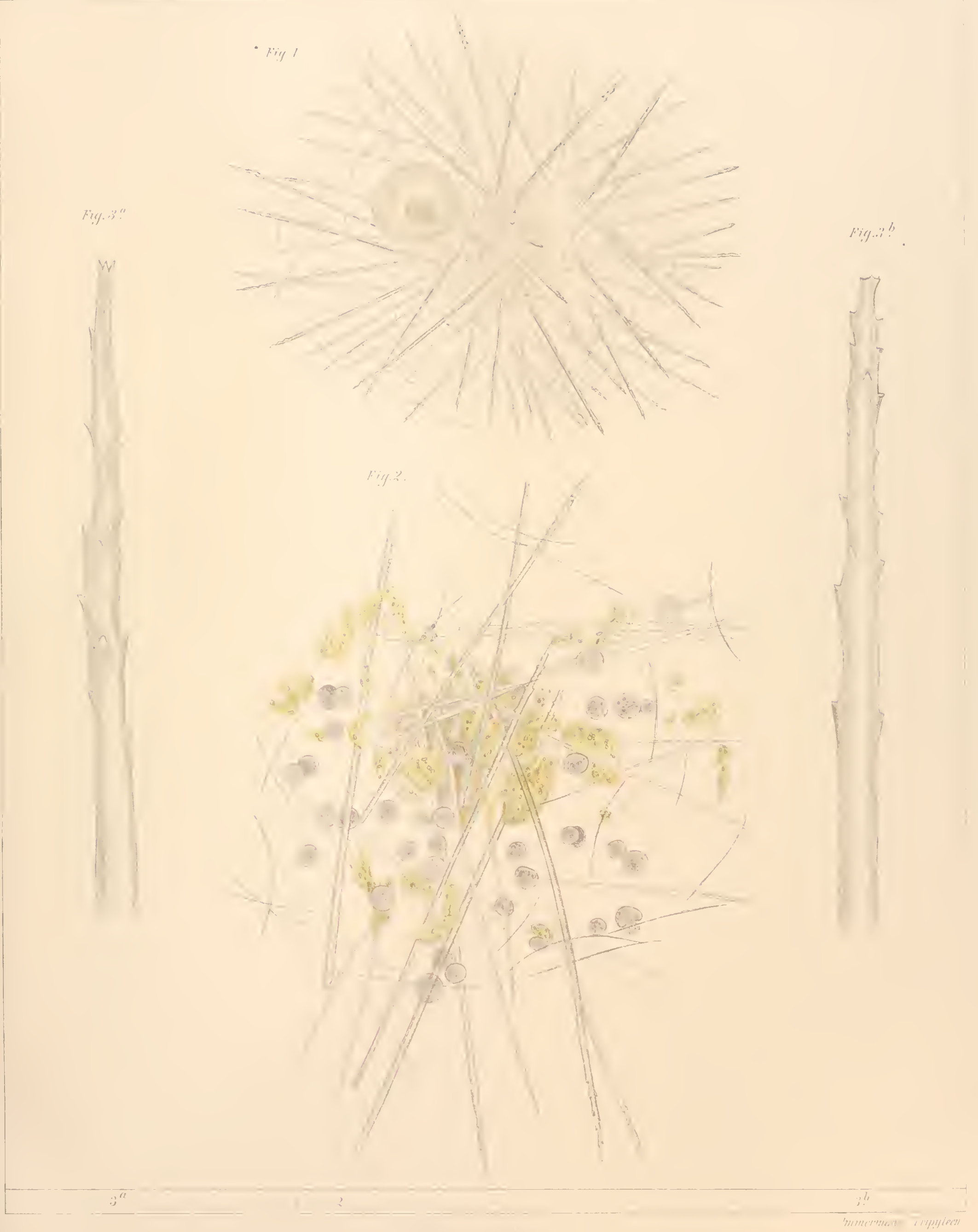






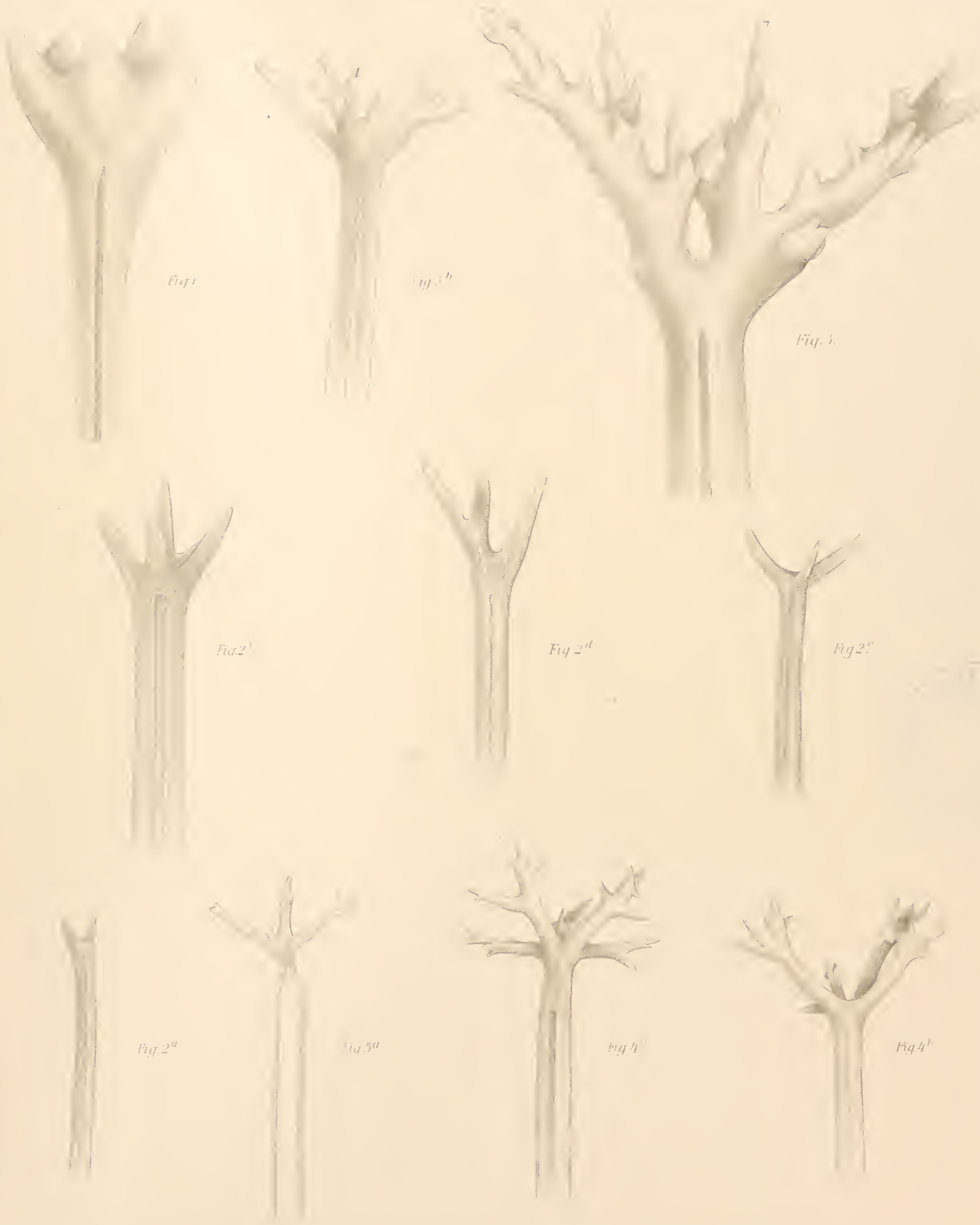
$+12^{b} \quad, 5^{0}$ $2^{d} \quad 4^{a}$

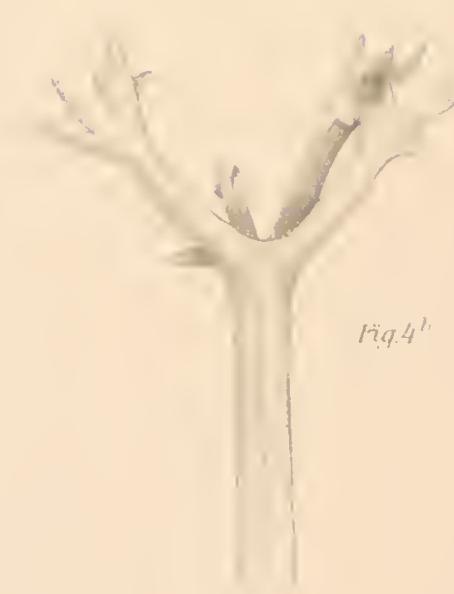



Fig. I"
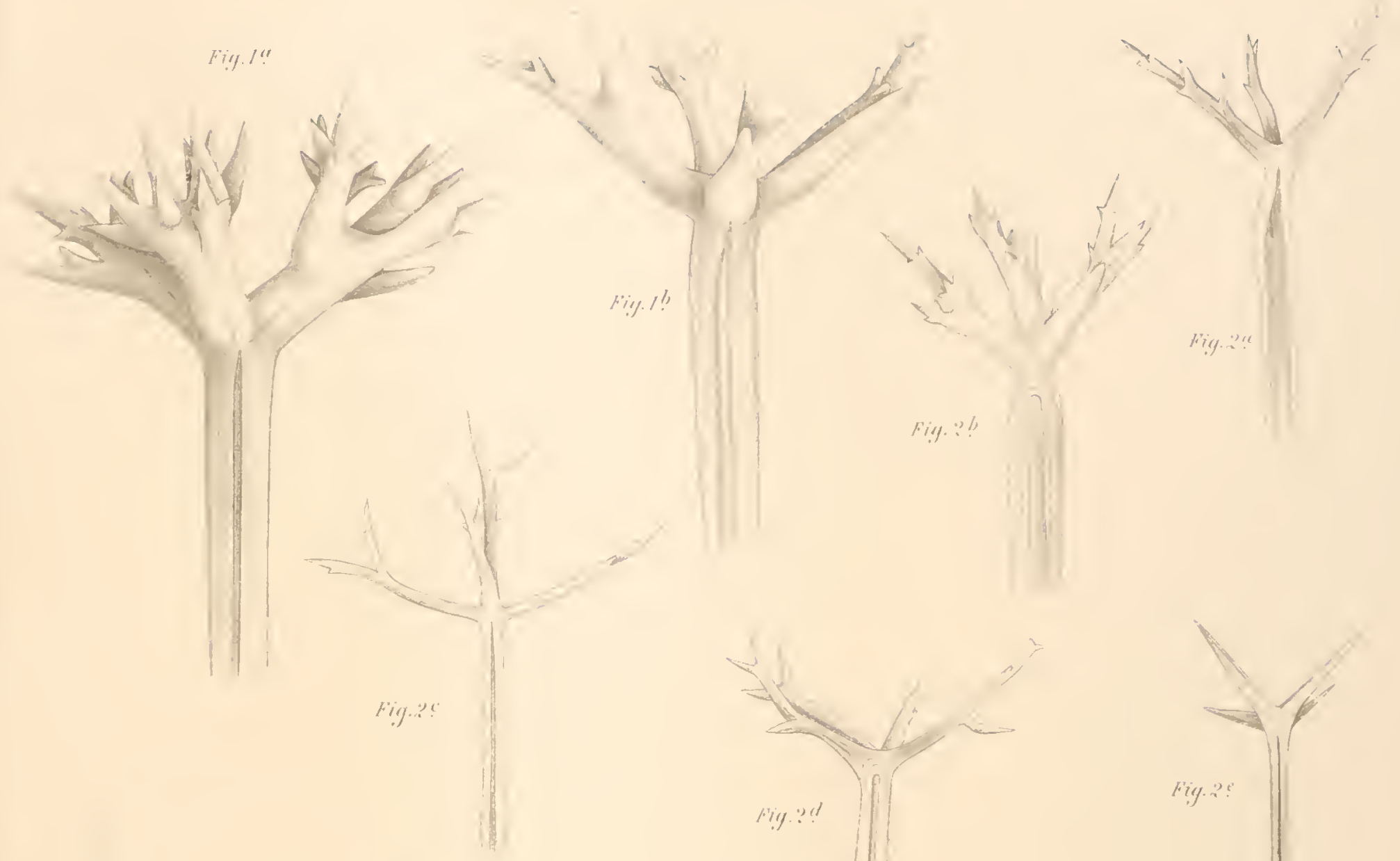

whe
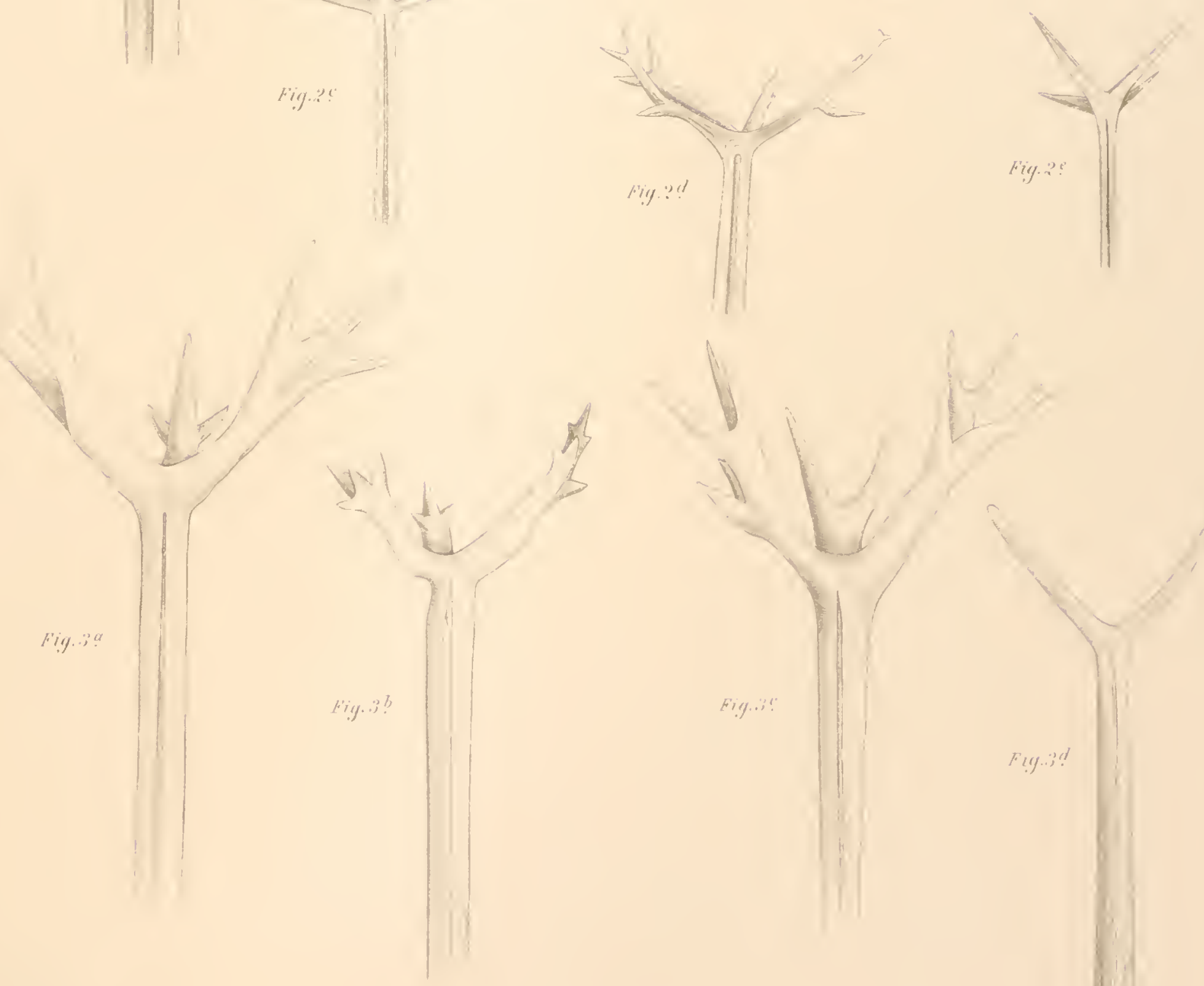

Fig. :?

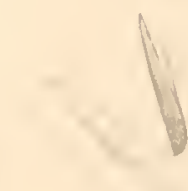

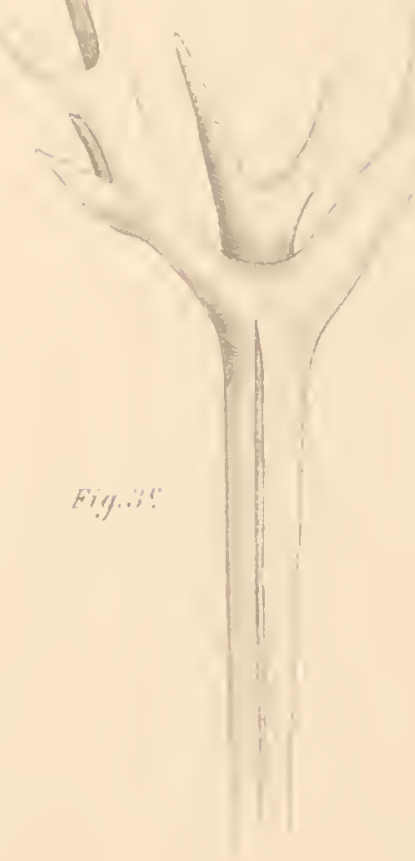

$\because ! 3$

$\overline{7.3}$

$20 \quad \because 9 \quad ?^{b}$

$\because " ?$ 

Plankion Expedith th L /
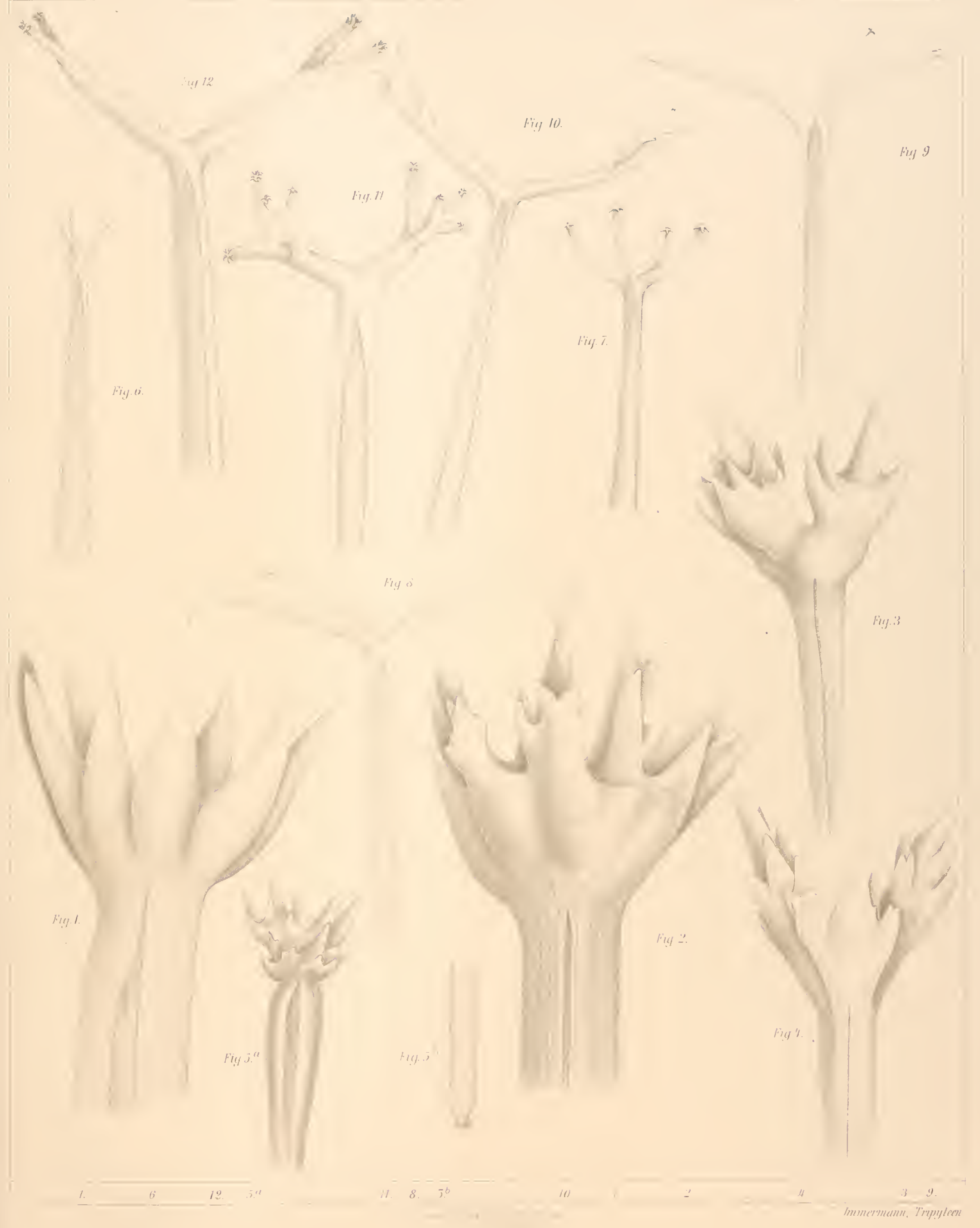


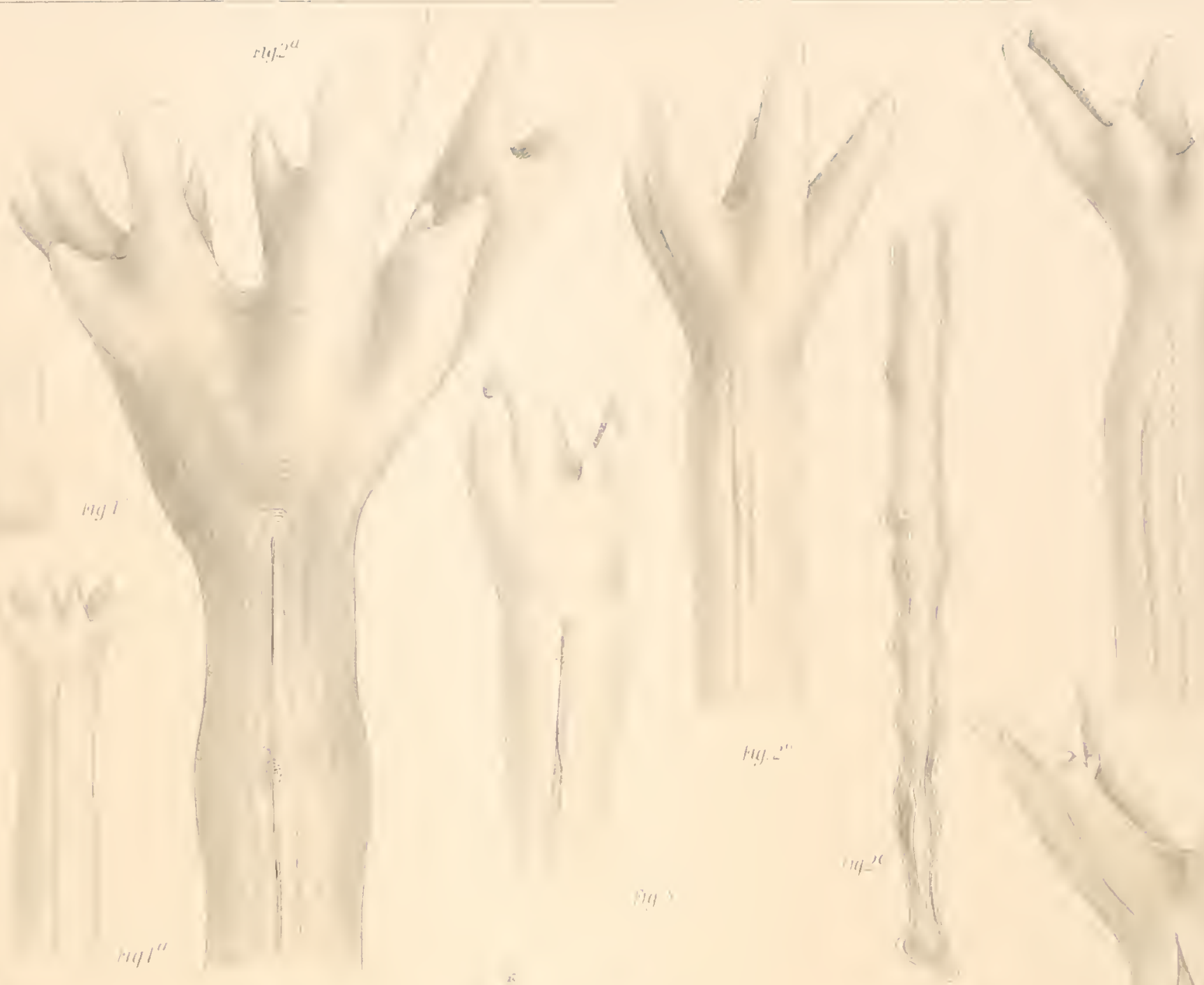

is
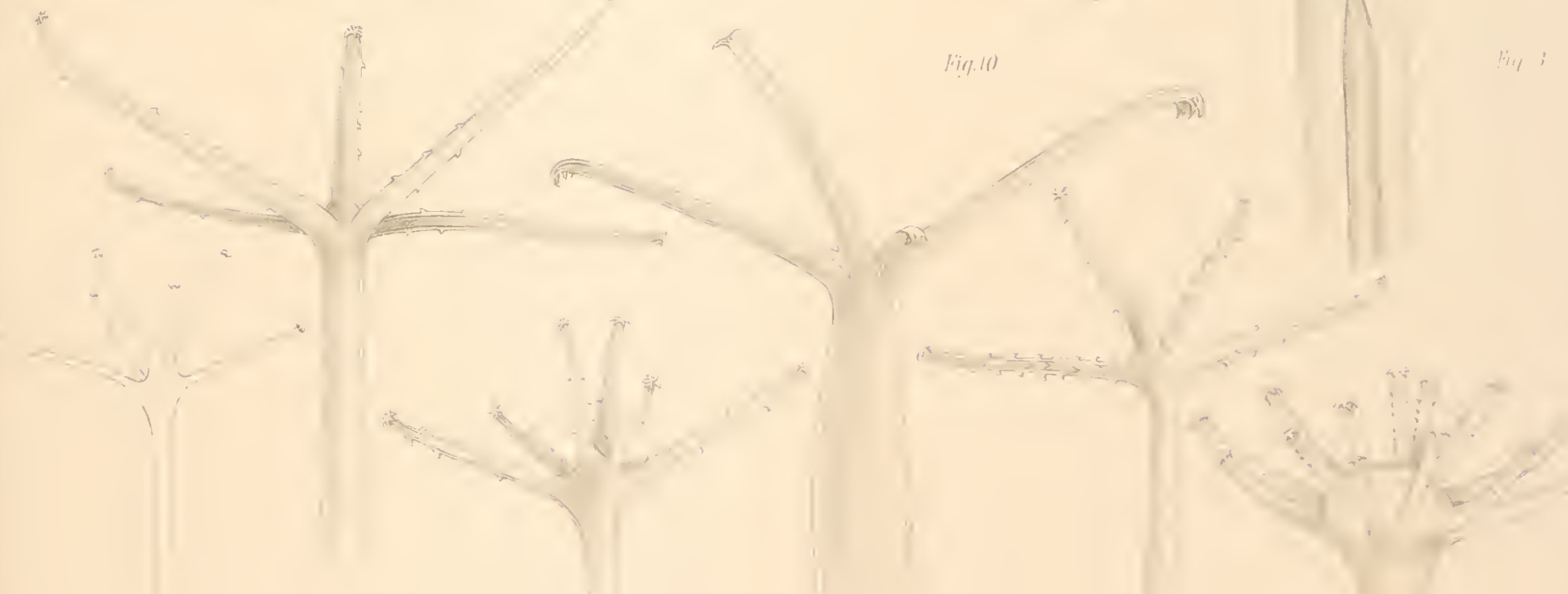

Fin.s
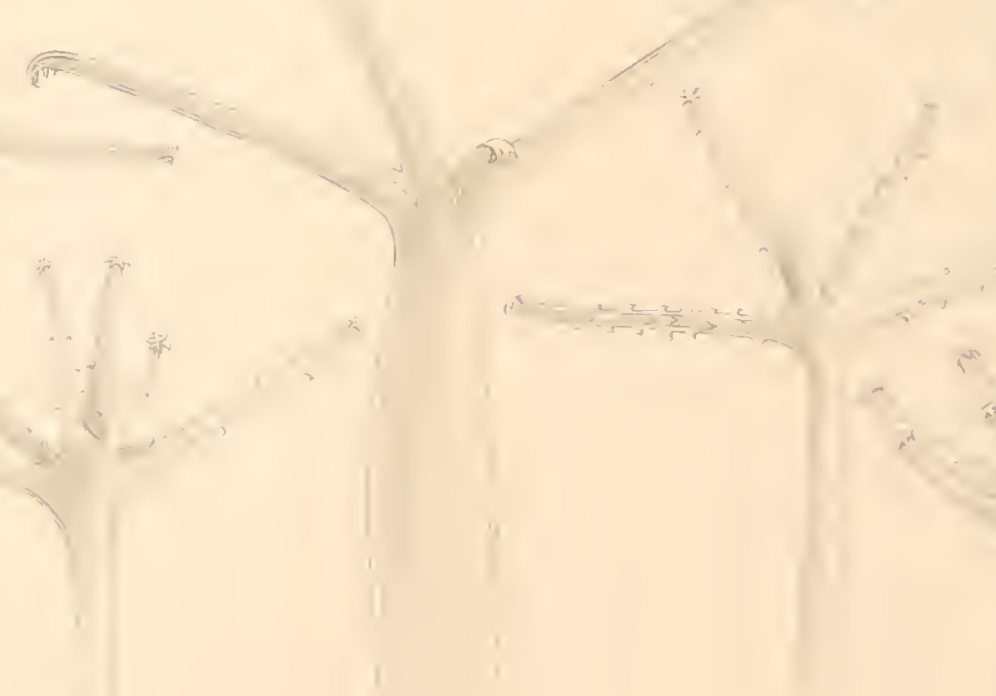

lig.

Firj.

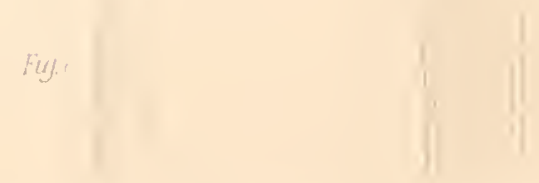





$$
\begin{aligned}
& y-4 \\
& F+F y
\end{aligned}
$$




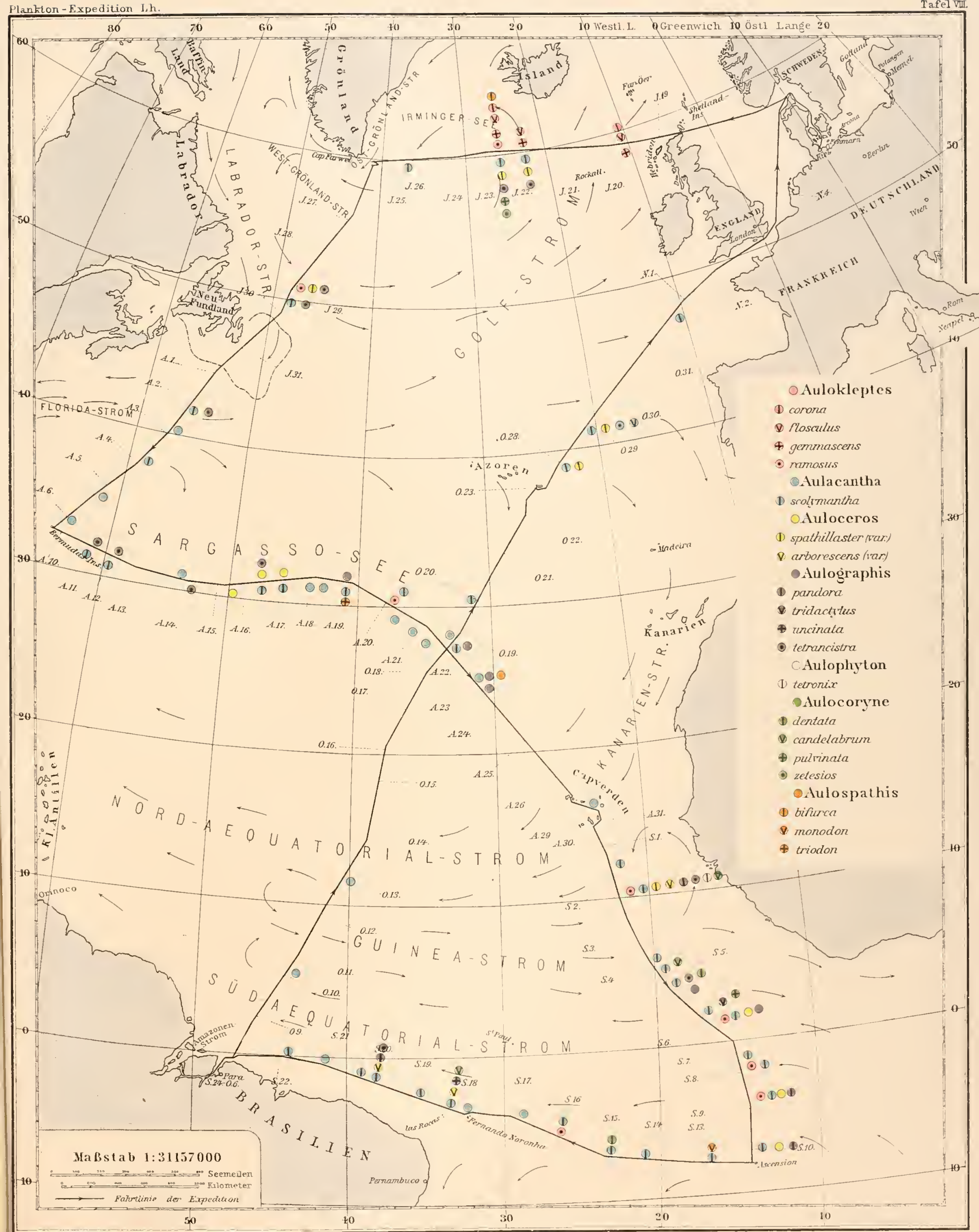





\title{
Wandtafeln
}

fïr den Unterricht in der

\section{Geologie und physischen Geographie}

lierausgegeben ron

\author{
Dr. Hippolyt Haas \\ l'rofessor a. d. Lniv. kiel \\ gezeichnet rom Maler Julius Fürst in Kriel.
}

Gröbe des einfachen Blattes $45 \times 61$ am. Vollstïndig in 50 Blatt mit farloigen Profiltafelu.

Preis 40 Mark.

Die Sammlung umfaßt:

12 'Tafehn, welche die Tulkane und die v'nlkanischen Erscheinungen zur Anschaumug lringen.

3 'Tafeln zur Erläutermog des Vorganges der Gebirgsbildung.

7 'Tafeln zur Demonstration der' Verwitter'ungs- und Erosionstätigkeit.

3 'Tafeln zur Darstellung der äolischen Wirkungen.

7 'Tafeln zur Darstellung der Taitigkeit des flüssigen unl festen Wasser's.

18 Tafelu Profile.

Ausführliche Prospekte mit Abbildungen stehen auf Wunsch kostenfrei zu Diensten.

\section{Anschauungsbilder}

fiir den Unterricht in der

\section{Geologie und physischen Geographie.}

$$
\text { Von }
$$

Dr. Hippolyt Haas

Professor a. d. Unir. livel

gezeichnet vom Maler Julius Fürst in Kiel.

20 'afelu in Bildgröße ron $45 \times 61$ cm.

Preis komplett in Umschlag 16 Mark: einzedue Tafelu je I Marli.

Illustrierter Prospekt steht kostenfrei zu Diensten.

In vielen Schulen und Instituten werden diese Anschaumgsmittel bereits mit bestem Erfolge benutat. 
Verlag von Lipsius \& Tischer in Kiel und Leipzig.

Eine

nene Berechnming der mittleren Tiefen der Ozeane

nebst einer vergleichenden Kritik der verschiedenen Berechnungsmethoden.

Ton

Dr. Karl Karstens.

1894. 32 Seiten gr. $8^{0}$ und 27 Tabelleu.

Preis 2 Mark.

Von der philosophischen Fakultät der Christian-Albrecht-Universität in Kiel mit dem neuschassischen Preise gekrönt!

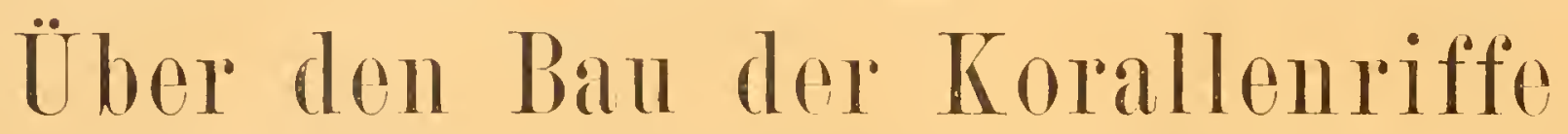

und die Plankton-Verteilung an den Samoanischen Küsten nehst vergleichenden Bemerlanngen und einem Anlang:

Ůber den Palolowurm von Dr. A. Collin.

Von

Dr. Augustin Krämer, Marinestabsar»t.

1897. X1, 17t Seiten gr. 8". Nit 34 Albildungen unul Karten.

Preis 6 Mark.

Das Süsswasserplankton.

Methode und Resultate der anantitativen I'ntersuchmon

ron

Dr. Karl Apstein.

VI. 201 Seiten gr. 80. Nit 113 Abbildungen und vielen Tabellen.

Preis Mark 7,20.

Lime nene Bestimmmung des Pols der Lamdlatblingel. ron

Dr. Hermann Beythien.

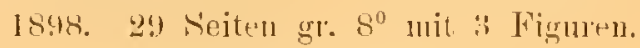

Preis Mark 1,20.

Von der philosophischen Fakultät der Christian-Albrecht-Universität iı Kiel mit dem neuschassischen Preise gekrönt!

Über die Weltkinte des Kosmographen von Ravennia. Versuch einer Rekonstruktion der Karte von E. Schweder. 



